\title{
Phytosomes as Innovative Delivery Systems for Phytochemicals: A Comprehensive Review of Literature
}

\author{
Mahmood Barani (iD) \\ Enrico Sangiovanni ${ }^{2}$ \\ Marco Angarano (iD) ${ }^{2}$ \\ Mohammad Amin Rajizadeh ${ }^{3}$ \\ Mehrnaz Mehrabani ${ }^{4}$ \\ Stefano Piazza ${ }^{2}$ \\ Hosahalli Veerabhadrappa \\ Gangadharappa ${ }^{5}$ \\ Abbas Pardakhty (iD) ${ }^{6}$ \\ Mehrzad Mehrbani ${ }^{7}$ \\ Mario Dell'Agli (iD ${ }^{2}$ \\ Mohammad Hadi \\ Nematollahi iD ${ }^{8}$
}

'Medical Mycology and Bacteriology Research Center, Kerman University of Medical Sciences, Kerman, 76169-13555, Iran; ${ }^{2}$ Department of Pharmacological and Biomolecular Sciences, Università degli Studi di Milano, Milan, 20133 Italy; ${ }^{3}$ Student Research Committee, Kerman University of Medical Sciences, Kerman, Iran; ${ }^{4}$ Physiology Research Center, Kerman University of Medical Sciences, Kerman, Iran; ${ }^{5}$ Department of Pharmaceutics, JSS College of Pharmacy, JSS Academy of Higher Education and Research, Mysuru, India; ${ }^{6}$ Pharmaceutics Research Center, Institute of

Neuropharmacology, Kerman University of Medical Sciences, Kerman, Iran; ${ }^{7}$ Department of Traditional Medicine, Faculty of Traditional Medicine, Kerman University of Medical Sciences, Kerman, Iran; ${ }^{8} \mathrm{Herbal}$ and Traditional Medicines Research Center, Kerman University of Medical Sciences, Kerman, Iran

Correspondence: Mario Dell'Agli Department of Pharmacological and Biomolecular Sciences, Università degli Studi di Milano, Via Balzaretti 9, Milan, 20133, Italy

Email mario.dellagli@unimi.it

Mohammad Hadi Nematollahi

Department of Clinical Biochemistry,

Kerman University of Medical Sciences,

Kerman, Iran

Email mh.nematollahi@yahoo.com

\begin{abstract}
Nowadays, medicinal herbs and their phytochemicals have emerged as a great therapeutic option for many disorders. However, poor bioavailability and selectivity might limit their clinical application. Therefore, bioavailability is considered a notable challenge to improve bio-efficacy in transporting dietary phytochemicals. Different methods have been proposed for generating effective carrier systems to enhance the bioavailability of phytochemicals. Among them, nano-vesicles have been introduced as promising candidates for the delivery of insoluble phytochemicals. Due to the easy preparation of the bilayer vesicles and their adaptability, they have been widely used and approved by the scientific literature. The first part of the review is focused on introducing phytosome technology as well as its applications, with emphasis on principles of formulations and characterization. The second part provides a wide overview of biological activities of commercial and non-commercial phytosomes, divided by systems and related pathologies. These results confirm the greater effectiveness of phytosomes, both in terms of biological activity or reduced dosage, highlighting curcumin and silymarin as the most formulated compounds. Finally, we describe the promising clinical and experimental findings regarding the applications of phytosomes. The conclusion of this study encourages the researchers to transfer their knowledge from laboratories to market, for a further development of these products.
\end{abstract}

Keywords: phytochemical, nanomedicine, phytosome, delivery, vesicle, disease

\section{Introduction}

For several decades, medicinal herbs and their active constituents have been utilized to treat different diseases. ${ }^{1-5}$ There are some major reasons for the increased use of herbal drugs: 1) modern medicine is unable to efficiently cure all the human pathologies, 2) there are increasing interests and attention over the assurance and safety of synthetic drugs, and 3) many natural products are being shown to produce better results than synthetic drugs without adverse effects. ${ }^{6}$ However, due to poor oral bioavailability, the clinical application of numerous active compounds of plants is under debate. ${ }^{7,8}$ The weak absorption rate of such constituents may be a result of low lipid solubility, the existence of multi rings polyphenols in their structures, and high molecular weight. ${ }^{9,10}$ Different solutions have been suggested to face such obstacles, ${ }^{11}$ including preparing emulsions, ${ }^{12}$ liposomes, ${ }^{13}$ and nano-formulation, ${ }^{14}$ the adjustment of molecular structure, ${ }^{15}$ and administration of prodrugs. ${ }^{16}$ Between all approaches, phyto-phospholipid complexes (named phytosomes) are appeared to be a great method to boost their bioavailability. ${ }^{9}$ 


\section{Graphical Abstract}

\section{PHYTOSOMES}

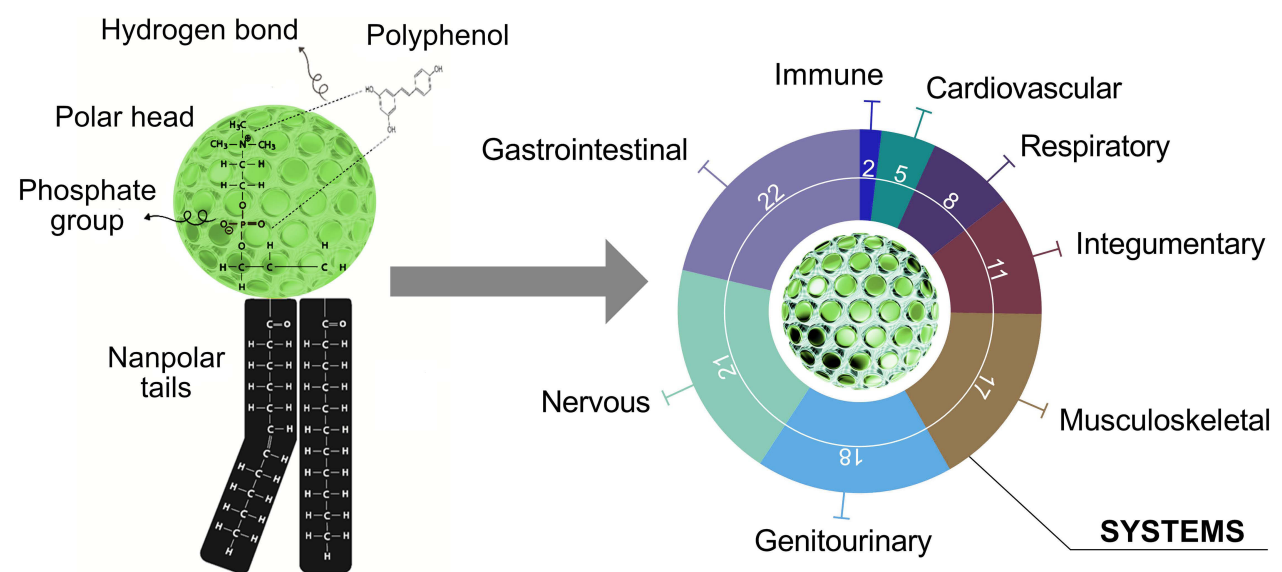

Technology

Biological activities by system

The term "Phyto" refers to the plant, while "some" refers to cell-like. ${ }^{17}$ Phytosomes (or herbosomes) are the vesicular drug delivery system enhancing the absorption and bioavailability of low-soluble drugs. ${ }^{9,17}$ Phytosomes are complex of phospholipids and natural active phytochemicals, bound in their structures, obtained by the reaction between phosphatidylcholine (or any hydrophilic polar head groups) and plant extracts in an aprotic solvent. ${ }^{10,18}$ These formulations exhibit improved pharmacological and pharmacokinetic properties as compared to prevalent preparations. The lipid-soluble phosphatidyl portion completely covers the hydrophilic phytoconstituent-choline complexes. Phytosomes have remarkable benefits such as high drug encapsulation, reveal a better stability profile (chemical bonds are formed among the polar head of the amphiphile molecule and phytoconstituent ${ }^{19}$ ), and have a better bioavailability. ${ }^{20}$ Moreover, a higher absorption rate leads to a lower dosage of active constituents for exerting a biological effect, also for polar phytoconstituents.

There is a variety of possible applications of phytosome that will be discussed in this review.

\section{The Phytochemicals}

Phytochemicals or plant chemicals are comprised of a wide range of naturally occurring bioactive compounds produced by plants. The term bioactive refers to the ability of these compounds to interact with different components of living organisms, thereby exerting their beneficial effects. Phenolics, alkaloids, carbohydrates, lipids, terpenoids, and other nitrogen-containing compounds are the most structurally different major categories of phytochemicals. Moreover, there are several subcategories of phytochemicals based on differences in biogenesis or biosynthetic pathway.

Between all the phytochemicals, only those having an active hydrogen atom (-COOH, - $\mathrm{OH},-\mathrm{NH} 2,-\mathrm{NH}$, etc.), like polyphenols, can be integrated into a phytosome structure. An active hydrogen atom can form a hydrogen bond between the herbal derivatives and the hydrophilic parts of amphiphile molecules. Polyphenols are the major group of phytochemicals extensively found in plant-based foods. Potential health effects of polyphenols were shown in different diseases including cancer, inflammation, neurodegenerative and cardiovascular diseases, type 2 diabetes, and obesity. ${ }^{21}$ Essentially, they are found in conjugated forms composed of sugar residues (one or more) attached to hydroxyl groups; however, the sugar residues may directly attach to an aromatic carbon. ${ }^{22,23}$ Flavonoids and non-flavonoids are two major subgroups of polyphenols (Figure 1). The current review updates the knowledge on the use of polyphenols through phytosomes, paying attention to their structure, preparation, and the biological activities associated with the use of phytochemicals-loaded phytosome.

\section{Phytosome Structure and Preparation Methods}

Bombardelli et al stated for the first time that there is a chemical bond between phospholipids and flavonoid vegetal 


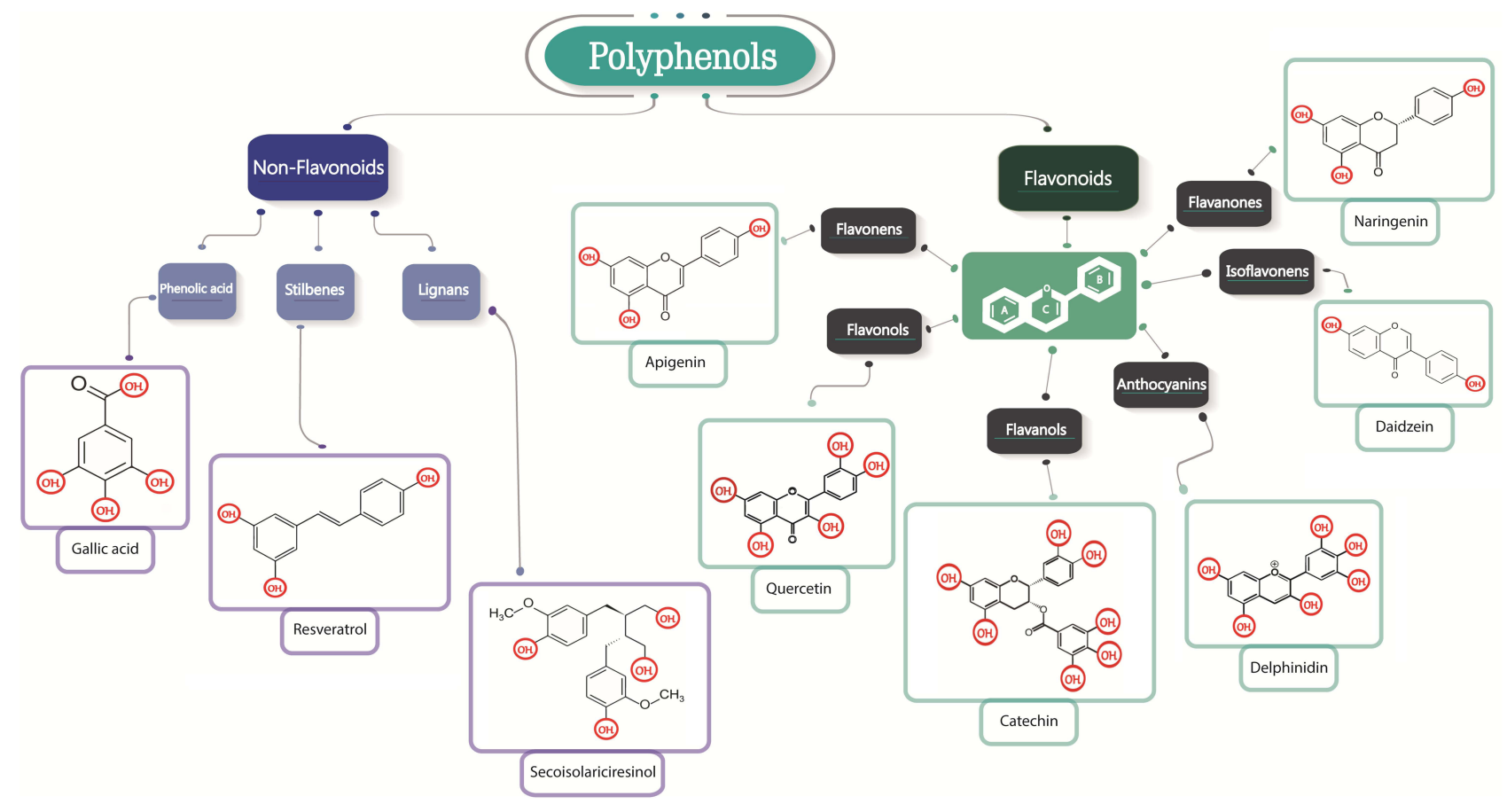

Figure I Polyphenol classifications. Classes of polyphenols and their relationships to each other. One structural example is presented for each class.

derivative molecules. ${ }^{24}$ In 2016, Pu et al examined the molecular docking model for the interaction of 20(S)-protopanaxadiol (PPD) phospholipid complexes. The results indicated that the hydrophobic section of the PPD framework was enclosed by two hydrophobic arms of the phospholipid molecule, and a hydrogen-bond with the phospholipid backbone of the $\mathrm{P}=\mathrm{O}$ section was generated by one of the hydrophilic$\mathrm{OH}$ groups. Many authors have stated that the hydrogen interactions are the main interactions in phytosome vesicles. $^{25}$

Phospholipids have an affinity for polyphenols and form supramolecular adducts that have a definite stoichiometry, which can be obtained from thermal analysis. Semalty et al tested this parameter and found that hydrogen bond formation or hydrophobic interactions were due to the interaction between the two molecules. ${ }^{26}$ The phospholipid-active ingredient is responsible for the creation of a hydrogen connection between the polar head and the active ingredient's polar functionalities. ${ }^{25,27}$ In summary, as presented in Figure 2, the hydroxyl groups of polyphenols can interact effectively with nitrate and phosphate groups of phospholipids.

Several strategies have been proposed for preparing phytosome, such as the rotary evaporator method, anti-solvent precipitation technique, freeze-drying co-solvency, and salting-out technique. The main methodologies for the preparation of the phytosome are shown in Figure 3. Popular and commonly used techniques for producing phospholipid complexes are the evaporator approach and solvent evaporation. The solvent evaporation method for preparing evodiamine phospholipids complex was stated by Liu et al. ${ }^{28}$ In another study, Yu et al prepared the berberine-loaded phytosomes by the method of solvent evaporation and a self-assembly approach. ${ }^{29}$ In the process of solvent evaporation, lipid materials were dissolved in an organic solvent, which was then removed by vacuum rotary evaporation. By the anti-solvent precipitation technique, Singh et al reported the preparation of lawsone-loaded phytosome..$^{30}$ In this process, dichloromethane was refluxed with lawsone and soya lecithin at a temperature not exceeding $60^{\circ} \mathrm{C}$. Then, to get the precipitate stored overnight in vacuum desiccators, $\mathrm{n}$-hexane was added. Karole et al have used the technique of anti-solvent precipitation to prepare phytosomes containing Bombax ceiba extract. $^{31}$ El-Menshawe et al described a soy thermogel based on phytosome made by three different preparation methods (co-solvency, solvent evaporation, and saltingout). ${ }^{32}$ It was observed that the optimal phytosome formulation was the one prepared using the co-solvency technique, obtaining an ideal entrapment efficiency (EE) of $99.89 \%$, a size of $64.44 \mathrm{~nm}$, and a release rate of up to $93 \%$ after 2 hours. Demir et al developed a novel liposomal formulation in an innovative study by encapsulating both Calendula officinalis extract and AuNPs. ${ }^{33}$ Vesicle preparation was 


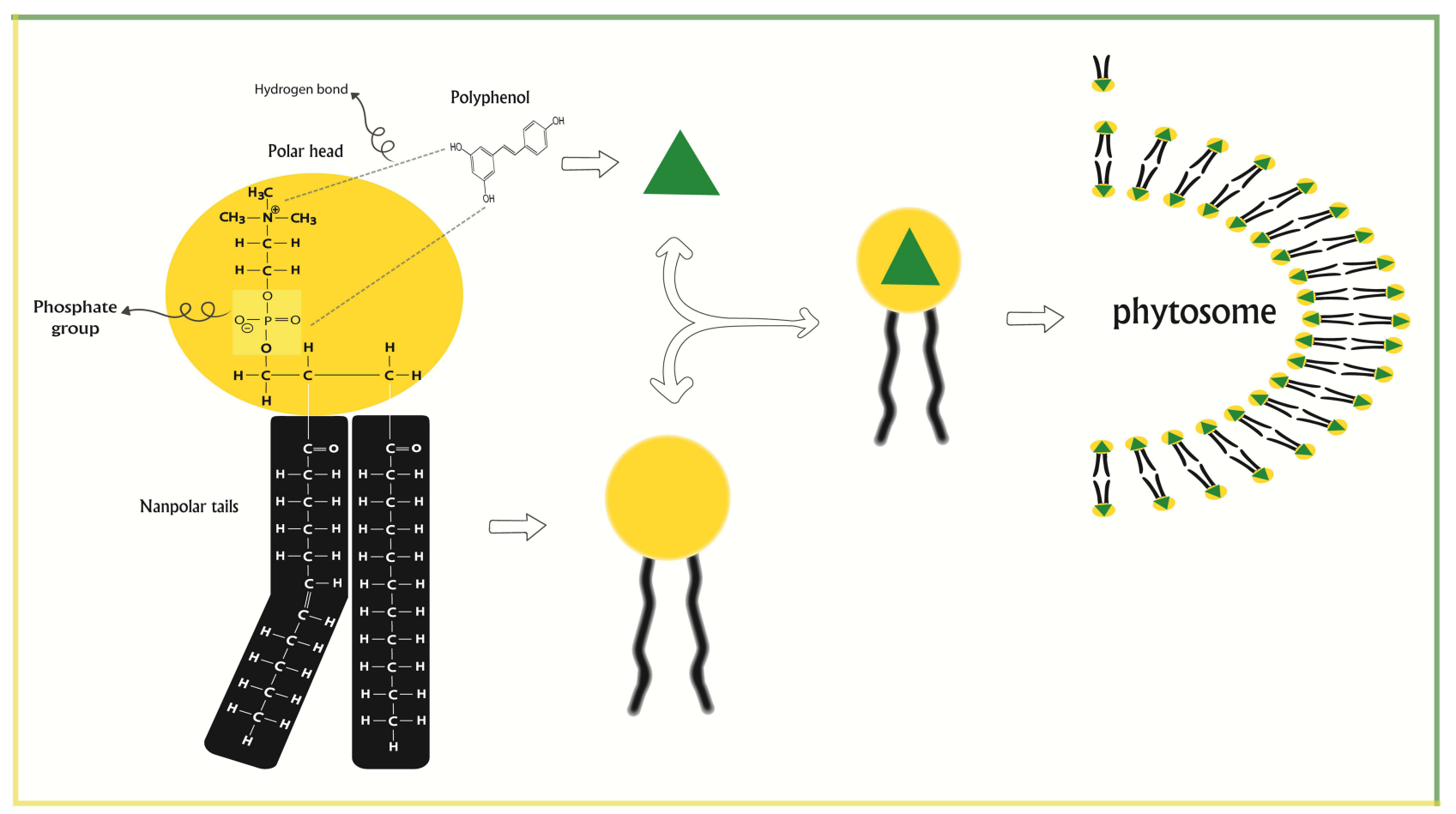

Figure 2 Suggested principle for phytosome formation. Hydrogen bond formation between phytochemical and polar head of phospholipid is depicted as schematic and structural picture. Dashed lines are representative as the hydrogen bonds.
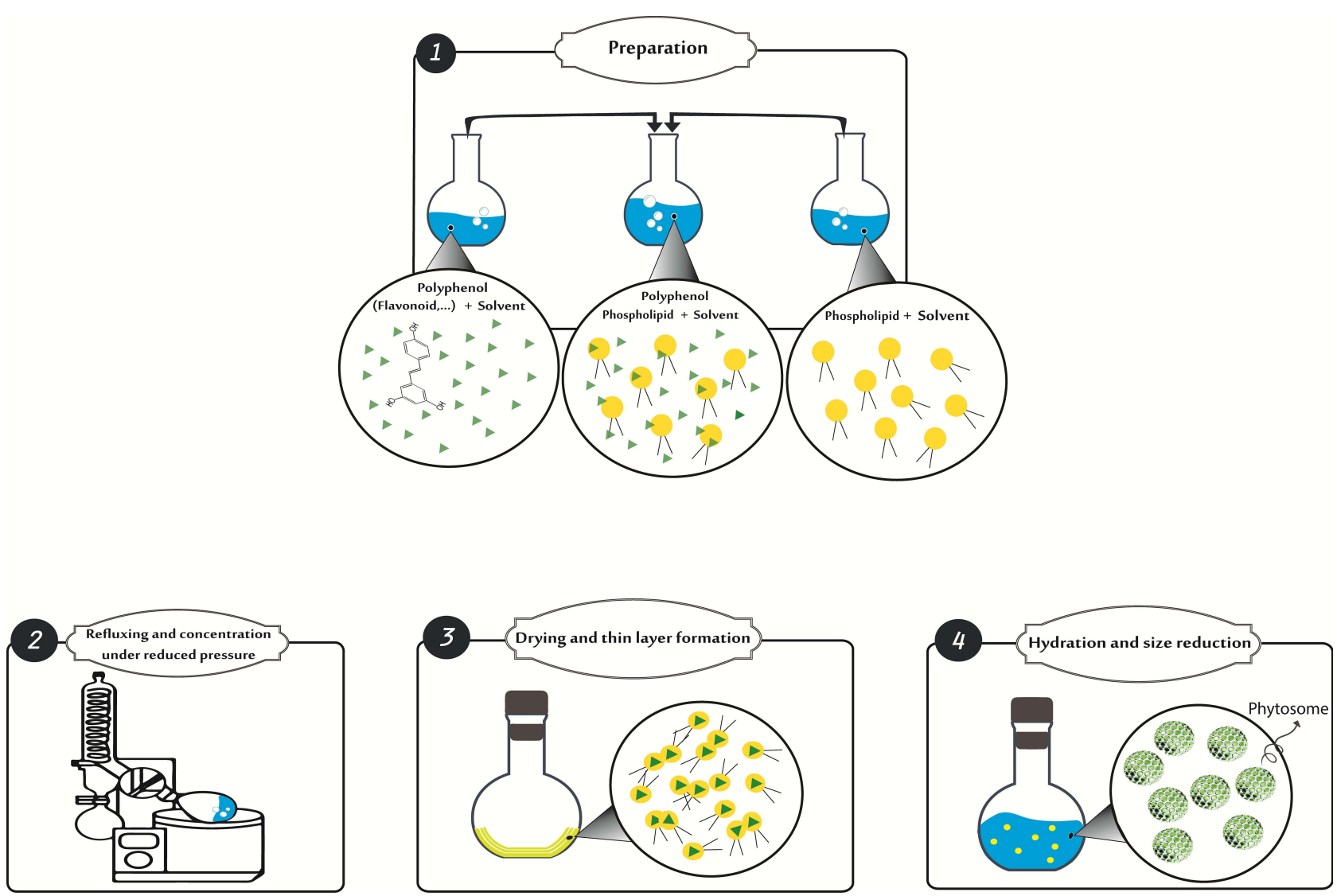

Figure 3 Thin-film hydration as the most common method for phytosome preparation. Steps I to 4 are the procedures of phytosome preparation. 
carried out by the conventional method of thin-film hydration within the extrusion. The findings showed that this method improved the biological activity of AuNP and calendula extract. Other methods have been documented for the preparation of phytosome complexes, such as anhydrous cosolvent lyophilization or lyophilization. ${ }^{34-36}$

Phytosomes are originated from the reaction of a stoichiometric quantity of the phospholipid (phosphatidylcholine) with polyphenolic constituents or standardized extracts (flavonoids, tannins, terpenoids, xanthones) within a non-polar solvent. ${ }^{37}$ Different solvents have been used in various studies as a reaction medium to formulate phyto-phospholipid complexes. In aprotic solvents, no hydrogen atoms exist directly connected to an electronegative atom and have no capability at hydrogen bonding. Traditionally, these solvents like aromatic hydrocarbons, methylene chloride, halogen derivatives, cyclic ethers, and ethyl acetate have been utilized for preparing phyto-phospholipid complexes. However, these are mostly substituted by protic solvents, such as ethanol. ${ }^{38,39}$ In protic solvents, like methanol and ethanol, at least one hydrogen atom is directly connected to an electronegative atom. Thanks to the higher yield of complexes, ethanol is an effective solvent also due to the low presence of residues. Some liposomal drug complexes act in the existence of buffer solution or water, where the interaction of the phytosomes with a solvent occurs with a decreased dielectric constant. ${ }^{40}$ Nevertheless, the use of a single solvent is included in most preparation methods, mixed solvent systems have been used in several studies whereby the phospholipids are dissolved in a different solvent from that of the drug/extract. The mixed solvent systems include dichloromethane and methanol, water and diethyl ether, as well as ethanol and dichloromethane. ${ }^{4-43}$

\section{Vesicular Systems in Phytosome Development}

Targeted delivery and sustained release rate are two relevant factors for phytochemical drug carriers. ${ }^{44}$ Several kinds of nano-systems would be used in various disease imaging or therapies, or as theranostics. ${ }^{45}$ The most used nanocarriers for phytochemicals are the vesicular drug delivery systems, ${ }^{46}$ in which active compounds are encapsulated in a spherical structure. ${ }^{47}$

Various types of vesicular drug delivery systems such as liposome, niosome, transfersome, and ethosome have been developed (Table 1). ${ }^{4-65}$ Figure 4 also depicts a schematic representation of the different vesicle architectures in phytochemical delivery.

\section{The Liposome}

Liposome originated from two Greek words "Lipos signifying fat and Soma meaning body". ${ }^{67}$ Liposomes are phospholipids and cholesterol that made up the spherical shaped vesicles with a diameter of 0.05-5.0 micrometers. They are a very promising carrier for drug delivery in different architectures due to their hydrophobic and lipophilic characters. ${ }^{68-70}$ This drug delivery system attempts to directly target the drug at the desired site of action. ${ }^{71}$ Liposomes are biocompatible, biodegradable, stable, and have a unique property that traps both hydrophilic and lipophilic agents into their compartments and provides a controlled-release effect. ${ }^{72-74}$ Liposomes are used in different pathological conditions, such as cancer, inflammation, eye and skin disease, malaria, and osteosarcomas. ${ }^{75-}$ 80 The liposomes can be designed using various techniques. ${ }^{81,82}$ Overall, most liposome preparatory methods are based on (1) solvation of the lipids in an organic solvent; (2) getting lipid thin film by evaporation; (3) hydration of lipid layer by a hydrophilic solvent; (4) liposome purification (5) and characterize the properties of the final liposome. ${ }^{83-85}$ Also, other synthesis methods can improve the encapsulation of the loaded drug. ${ }^{86-88}$

Besides, phytoconstituent liposomes have been developed to increase the penetration, solubility, and biological impact or to defend against degradation. ${ }^{89,90}$ There are many reports of the use of natural extracts via encapsulation in liposomes to improve their bioactivity or to avoid other side effects. ${ }^{91,92}$ For example, Gautam et al reported CD44 receptor-phyto-liposomes loaded with stigmasterol (STS) for synergistic chemotherapy. The in vitro anticancer activity of HA-DOX-STS-lipo was significantly enhanced in MDA-MB-231, CD44-overexpressing cells relative to MCF-7 cells demonstrating HAmediated targeting effect. HA-DOX-STS-lipo accumulated more and increased antitumor efficacy in the MDA-MB-231 xenograft tumor model expressing high levels of CD44, suggesting the potential of carrier system toward CD44-overexpressing tumors. ${ }^{93}$ Rafiee et al prepared nanoliposomes using a thin hydration process with various amounts of polyphenols of pistachio green hull extract and lecithin and characterized their particle size, PDI, zeta potential, entrapment efficiency (EE), and morphology. Nanoliposomes had the highest EE (52.93\%) composed of $1 \%$ lecithin with $1000 \mathrm{ppm}$ phenolic compounds. The FTIR findings show the formation of hydrogen bonds between both the phospholipid polar zone and 
Table I Most Used Nanovesicle Encapsulated Herbal Formulations

\begin{tabular}{|c|c|c|c|}
\hline Nanovesicle & Phytochemicals & Feature & References \\
\hline \multirow[t]{4}{*}{ Liposome } & $\begin{array}{l}\text { Aphanamixis } \\
\text { polystachya leaf }\end{array}$ & $\begin{array}{l}\text { Great improvement in memory function, locomotive behavior, and dementia-induced } \\
\text { outpatient quality of mice. }\end{array}$ & [63] \\
\hline & Anthocyanins & $\begin{array}{l}\text { Increase physiological stability in vitro for } 14 \text { days and increase the activity of ROS } \\
\text { scavenging and skin absorption. }\end{array}$ & [62] \\
\hline & Curcumin & $\begin{array}{l}\text { Fast permeation rate endothelial cell monolayer crossing blood-brain barrier (BBB) and } \\
\text { good durability toward digestive enzymes. }\end{array}$ & [61] \\
\hline & Eleusine coracana & Effective antibacterial formulations have a great nutritive value. & [60] \\
\hline \multirow[t]{4}{*}{ Niosome } & Carum carvi & $\begin{array}{l}\text { Regulate release and decrease of MCF-7 cell migration, high anti-cancer behavior against } \\
\text { MCF-7 supported by cytometry flow ( } \mathrm{G} 2 / \mathrm{M} \text { arrest). }\end{array}$ & [59] \\
\hline & Lawsone & $\begin{array}{l}\text { Entrapment efficiently of } 70 \% \text {, a sustained release profile, and a significant increase in } \\
\text { antitumor activity. }\end{array}$ & [58] \\
\hline & Fumaria officinalis & $\begin{array}{l}\text { Rapid degradation, stability in Gl conditions simulated, and anti-diabetic and anti- } \\
\text { inflammatory capacity. }\end{array}$ & [57] \\
\hline & Annona squamosa & $\begin{array}{l}\text { Aid with topical drug enhancers to purify the body from harmful impurities and oxidants and } \\
\text { can be applied directly to the skin. }\end{array}$ & [56] \\
\hline \multirow[t]{4}{*}{ Transfersome } & Mulberry leaves & Prolonged delivery system, strong safety, and acne vulgaris care via transdermal route. & [55] \\
\hline & Apigenin & $\begin{array}{l}\text { Drug entrapment of } 84.24 \% \text {, strong stability, enhances the permeability of apigenin in the } \\
\text { long-term release. }\end{array}$ & [53] \\
\hline & $\begin{array}{l}\text { Epigallocatechin-3- } \\
\text { gallate (EGCG) }\end{array}$ & $\begin{array}{l}\text { Increases cell viability, decreases lipid peroxidation, intracellular ROS, MMP expression in } \\
\qquad \mathrm{HaCaT} \text { cells, and increases skin permeation. }\end{array}$ & [52] \\
\hline & Emodin & $\begin{array}{c}\text { High efficiency and stability in encapsulation, reduces body weight, and adipocyte size } \\
\text { through ATGL up-regulation, down-regulation of GOS2 expression in adipose tissue, and } \\
\text { improved insulin sensitivity. }\end{array}$ & [5। \\
\hline \multirow[t]{4}{*}{ Ethosome } & Thymoquinone & $\begin{array}{l}99 \% \text { efficiency for drug trapping. Cytotoxic activity of } 0.95 \mu \mathrm{g} / \mathrm{mL} \text { against MCF-7 cell lines is } \\
\text { improved. }\end{array}$ & [54] \\
\hline & Capsaicin & $\begin{array}{l}\text { Ethosomal hydrogels improve performance and patient compliance with capsaicin } \\
\text { treatment. }\end{array}$ & [50] \\
\hline & Terminalia chebula & $\begin{array}{l}\text { Effective release comparison with extract in the gel. In vitro anti-arthritic activity } \\
\text { demonstrates important anti-arthritic activity as opposed to normal Diclofenac activity }\end{array}$ & [49] \\
\hline & Paeonol & $\begin{array}{l}\text { Paeonol-loaded ethosomes showed improved transdermal absorption and skin retention } \\
\qquad\left(138.58 \mu \mathrm{g} / \mathrm{cm}^{2} \text { and } 52.60 \mu \mathrm{g} / \mathrm{cm}^{2} \text {, respectively) }\right.\end{array}$ & [66] \\
\hline
\end{tabular}

the phenolic compound $\mathrm{OH}$ groups. Also, nanoliposomes obtained a significant shelf life. As a result of this study, the liposome can be used as an effective carrier for the maintenance and enhancement of pistachio extract and bio-functional active agents in food products. ${ }^{94}$ In another study, Shafaei et al evaluated the therapeutic efficacy of sinensetin (SIN), eupatorin (EUP), rosmarinic acid (RA), and 3-hydroxy-5,6,7,4-tetramethoxyflavone (TMF) in Orthosiphon stamineus extract (OS-E) and assessed the formulation of OS-E-derived nanoliposomes (OS-EL) in the plasma of Sprague-Dawley rat after oral and intravenous administration. After intravenous OS-EL administration, all four compounds tended to be poorly distributed and gradually removed from the body as opposed to OSE. On the other hand, in oral administration loaded formulation (OS-EL), the bioavailability of all compounds was greater than OS-E (due to higher solubility of phospholipid encapsulation). These findings indicate that OSEL's greater solubility and bioavailability may be due to liposome encapsulation. ${ }^{95}$ 

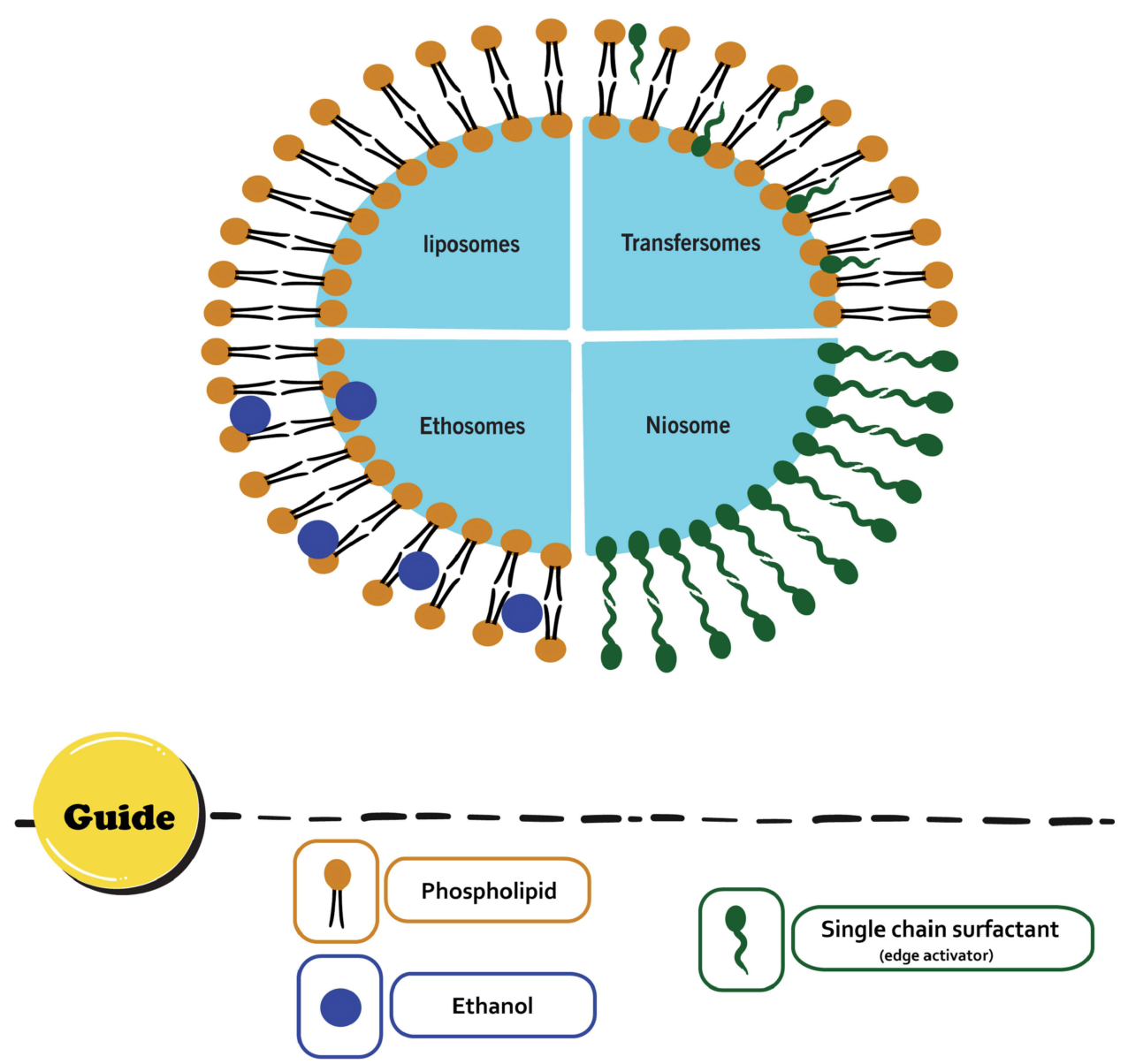

Figure 4 Possible vesicles to form phytosomes. Schematic representation of the different types of vesicles in phytochemical delivery, liposome, transfersome, niosome and ethosome. All these possible vesicles have polar heads.

In a most recent study, Sinisgalli et al evaluated the antioxidant activity of Capsicum annuum pepper extractloaded liposomes. The extracts exhibited no cytotoxicity and reduced the level of ROS in the HepG2 cell line. Based on the RT-PCR assay, the expression of endogenous antioxidants was increased in loaded formulations. ${ }^{96}$ Besides the enhanced ability in phytochemical delivery, liposomes have also some disadvantages. Drugs encapsulated in the liposomes require a high cost of development. Leakage and fusion of encapsulated drugs may occur. Furthermore, the phospholipid liposome may undergo hydrolysis and oxidation, resulting in a shorter half-life.

\section{The Niosome}

Niosomes are nanometric lamellar vesicles that are formed by combining non-ionic surfactant and a helper lipid-like cholesterol. $^{97-99}$ The non-ionic surfactants create a stable bilayer vesicle in hydrophilic systems by using energy (physical agitation and heating). ${ }^{100,101}$ Hydrophobic parts in the bilayer structure are guided aside from the aqueous phase, while the hydrophilic heads stay in contact with the aqueous side. The surfactants used in the preparation of niosomes should be biocompatible, biodegradable, and not immunogenic. ${ }^{102,103}$ Niosomes act like liposomes in vivo and in vitro, extending the circulation of the encapsulated phytochemical, adjusting its organ distribution, and improving bioavailability. The niosomal formulations are more leaky than liposomes with the same cholesterol value. ${ }^{99}$ Previous research has been shown that cholesterol concentration is an important influence factor on vesicle leakage. ${ }^{104}$ As a result, the efficiency of liposomal drug trapping becomes lower than niosomes. ${ }^{105}$ Liposomes are expensive, and their components are unstable for long periods and need special handling and storage. ${ }^{106}$ Niosomes can increase the solubility and sustainability of phytochemicals, considered novel herbal delivery systems. They are designed to target and control the release of natural compounds. ${ }^{57,107-110}$ Our group evaluated the niosome encapsulation of different antioxidant phytochemicals, 
such as lawsone,${ }^{58}$ diosgenin, ${ }^{111}$ D-limonene, ${ }^{111}$ and Carum spp. ${ }^{111}$ In our last study, we designed a natural anti-cancer niosome vesicle based on ergosterol, nonionic surfactants, and Carum carvi extract (Carum). In vitro cytotoxicity, flow cytometry, DNA fragmentation, and cell migration assay of formulations were evaluated. Loaded formulations provided a controlled release compared with free Carum extract. Based on MTT assay and flow cytometry analysis for MCF-7 cancer cell line, Carum encapsulated niosome (Nio/Carum) showed better anti-cancer effects than free Carum extract. Cell cycle analysis showed G2/M arrest in Nio/Carum formulations. Nio/Carum remarkably decreased the migration of MCF7 cells. ${ }^{111}$

Similarly, to improve solubility, stability, and penetration of antioxidant flavonoids (morin, quercetin, myricetin, fisetin, rutin, and breviscapine), Lu et al loaded these phytochemicals into niosome. Results revealed that quercetin showed significant whitening and antioxidant potential and the loaded niosome forms a spherical shape with a size of 97 $\mathrm{nm}, 31.1 \mathrm{mV}$ zeta potential, and $87.3 \%$ drug trapping efficiency. ${ }^{336}$ Rabia et al reported an in vitro assessment of the nanovesicles containing marigold extract and called it phyto-niosome. ${ }^{112}$ Their results showed marigold and its entrapped form in a surfactant-based delivery vesicle have a promising potential for different bio-applications as well as food, its possible use as a component for food additives and dermal cosmetic formulations. Niosomes greatly increased the bioavailability and photostability of quercetin. Quercetinloaded niosomes had a prolonged-release, increased transdermal absorption, and skin absorption 2.95 times stronger than quercetin solution. ${ }^{113}$ Niosomes have some additional advantages over liposomes but also showed some disadvantages. Component of niosome (non-ionic surfactants) is not generally recognized as safe (as phospholipid in liposomes). They are indeed more irritant than liposomes. ${ }^{114}$ Table 1 reports some examples of phytochemical-encapsulated niosomes.

\section{The Transfersome}

Transfersomes are a type of deformable or elastic nanocarriers that were first emerged in the early 1990s. ${ }^{64}$ The regular liposomes do not permeate into the layers of the skin and remain confined to the outer stratum corneum layer (Figure 4). ${ }^{115}$ Therefore, new types of lipid vesicles such as transfersomes have been constructed as an improved type of liposomes. Transfersome is an elastic and ultra-flexible lipid carrier with highly deformable membranes that enhance the transfer of compounds to deeper skin tissues. ${ }^{116}$ The transfersome consists of at least one amphipathic molecule (soy phosphatidylcholine) and a bilayer softening agent for vesicle flexibility (generally a surfactant). When transfersome components are applied to aqueous systems, they selfassembled into a lipid bilayer that finally closes into a lipid vesicle. ${ }^{116}$ Studies of penetration and deformability have shown that transfersomes give deeper penetration of the skin. Transfersome can be used as medication carriers for peptides, small molecules, proteins, and particularly herbal components. ${ }^{117}$ In a recent paper, Wu et al prepared resveratrol (RSV) loaded transfersomes consisting of the liposomal system phosphatidylcholine (PC) and the non-ionic edge stimulators (EA) ${ }^{337}$ Results showed that a $5 \%$ ethanol and 5\% PC/EA (3:1) in distilled water could make the optimum formulation. The size of vesicles was $40 \mathrm{~nm}$, and the $\mathrm{EE} \%$ was $60 \%$. Based on antioxidant activity results, the transfersomes were nearly equivalent to the RSV (free RSV) group. Also, the D1-20(W) formulation showed an improvement of $27 \%$ accumulation for in vitro transdermal delivery analysis. Cell viability analysis revealed that $\mathrm{D} 3-80(\mathrm{~W})$ cytotoxicity was decreased by $34.45 \%$ compared to the free RSV. ${ }^{118}$ Because of their susceptibility to oxidative stress, transfersomes are not chemically stable. The purity of natural phospholipids is also another factor that limits the adoption of transfersomes as standard vehicles for the delivery of drugs. On the other hand, transfersomes can be synthesized on a large scale with simple and easy processes, without the use of pharmaceutically unsuitable additives. ${ }^{64}$ More examples of herbal loaded transfersome are shown in Table 1.

\section{The Ethosome}

Ethosomes are non-invasive carriers that allow medicinal products to enter deep skin layers and systemic circulation.${ }^{119}$ Ethosomes are soft vesicles customized to improve the delivery of active agents, such as drugs and natural products. They are primarily composed of phospholipids (phosphatidylserine, phosphatidylcholine, and phosphatidic acid), high ethanol concentrations, and deionized water. ${ }^{120}$ The high concentration of ethanol makes ethosomes the best choice for skin due to impairment of the skin lipid bilayer. Thus, when ethanol is incorporated into the vesicle membrane, it provides the ability to reach vesicles to the stratum corneum. The lipid membrane in ethosomes is also packaged less firmly than other vesicles due to the presence of ethanol and this ability results in improved drug trafficking capability in stratum corneum lipids. ${ }^{121}$ The ethosomes showed to be appropriate in the biotechnology, pharmaceutical, cosmetic, veterinary, and nutraceutical industries for different purposes. Therefore, these soft vesicles serve as 
new vesicular carriers for improved skin delivery. ${ }^{122}$ The size of ethosomes may be modified from nanometers to micrometers. Ethosomes have been found to be significantly superior in the quantity and depth of drugs delivered through the skin compared to liposomes and many other commercial transdermal and dermal delivery platforms. ${ }^{123}$ A comparative evaluation of phytosome, liposome, niosome, ethosome, and transfersome in nano-delivery systems is summarized in Table 2.

Many authors have shown the advantages of ethosomes as topical vehicles of phytochemicals. Sasindran et al examined the cytotoxicity of combined herbal extracts (Zingiber officinale, Croton tiglium, and Phyllanthus niruri) and extracts loaded ethosome for transdermal delivery. Results of the cell-line analysis indicated that ethosomes loaded with extract inhibit testosterone and improve cell viability similarly to the standard drug (minoxidil). Even so, the encapsulated vesicle did not harm the rat skin layer (based on histopathological study). ${ }^{124}$ The drawback of ethosome is the size variation from nanometers to micrometers, due to its poor consistency and evaporation of ethanol, which leaks out from loaded compounds after a while. To manage this deficiency, alcohol can be located with a combination of propylene glycol and trehalose. ${ }^{125}$ Summarized examples of phospholipids and surfactants that are used in liposome, niosome, ethosome, and transferosome preparations are presented in Figure 5. All mentioned vesicular systems could be used in phytosome technology according to their applications.

\section{Phytosome Characterization}

Nanomaterial measurement approaches are a rapidly growing field, involving effective methods for physical and chemical characterization. ${ }^{126}$ Phytosomes have received tremendous attention for phytochemical delivery as a fast-growing class of nanovesicles. Several techniques were employed to characterize phytosomes size, elemental composition, morphology, and a wide range of other physical characteristics. There are physical properties, which can be investigated by more than one technique. Different limitations and strengths affect the choice of the most appropriate method, while a combinational methodology for characterization is often required. ${ }^{127}$ Also, some statistical studies are needed for better application in real world. ${ }^{128,129}$ The main characteristics of phytosomes are (1) size and shape; (2) surface charge; (3) chemical composition; (4) lamellarity and stability; (5) encapsulation efficiency and (6) release behavior. The goal of this chapter is to provide a thorough summary and a systematic overview of all analytical instruments used to characterize phytosomes, including the latest papers.

\section{Average Size and Shape}

The evaluation of size and morphology is a critical phytosome analysis and provides valuable insight into the quality and different forms of a sample. Different techniques such as DLS, ${ }^{130}$ microscopic observation ${ }^{131}$ (TEM, SEM, ${ }^{132}$ optical, ${ }^{133}$ atomic force, ${ }^{134}$ fluorescence, ${ }^{135}$ etc.), and flow ${ }^{136}$ and size-exclusion chromatography ${ }^{137}$ can be used for phytosome size characterization. Electron microscopy is broadly used for phytosome visualization, and Cryo-TEM and Freeze-fracture-TEM are the most used. ${ }^{138}$ Cryo-TEM could show phytosomes directly in the frozen state to prevent phytosomal disruption. ${ }^{139}$ Freeze-fracture-TEM provides the details on liposomal size and morphology without any structural distortion. ${ }^{140}$ Methods of microscopy are generally of high resolution and rapid productivity, but the sample preparation is complicated and time-consuming; also, some problems such as shrinking or shape distortion can be generated in sample preparation. ${ }^{141}$ The measurement of phytosome size distribution and polydispersity gives data on their physical stability, which can be evaluated by DLS. ${ }^{142}$ DLS is easy, precise, accurate, very fast and can therefore be used for regular size distribution measurements of phytosomes. ${ }^{143,144}$ The biggest benefit of DLS is that the assessment could be carried out in the sample's natural environment. ${ }^{145}$ The disadvantage of this approach is that the heterogeneous emulations could result in false data. ${ }^{146}$

\section{Surface Charge}

Zeta potential (complete charge generated by medium) defines the charge of phytosomes in emulsions. Zeta potential may be negative, positive, or neutral depending on the composition of the phytosome. ${ }^{147,148}$ Zeta potential could reflect the stability of phytosomes in a medium; in fact, charged particles repel each other enough to maintain stability. Phytosome emulsion with a zeta potential greater than or less than $30 \mathrm{mV}$ is known to be stable. ${ }^{149}$ The electrostatic properties of phytosomes can be measured using Doppler velocimetry, ${ }^{150}$ zeta sizer, ${ }^{151}$ master size, ${ }^{152}$ microelectrophoresis, ${ }^{153}$ pH-sensitive fluorophores, ${ }^{154}$ high-performance capillary electrophoresis, ${ }^{147}$ and DLS instruments. ${ }^{155}$ Laser Doppler velocimetry is the method for measuring the velocity or linear or vibrational motion of phytosome emulsions using the Doppler Effect in a laser beam. In light-scattering methods, an electrical field 


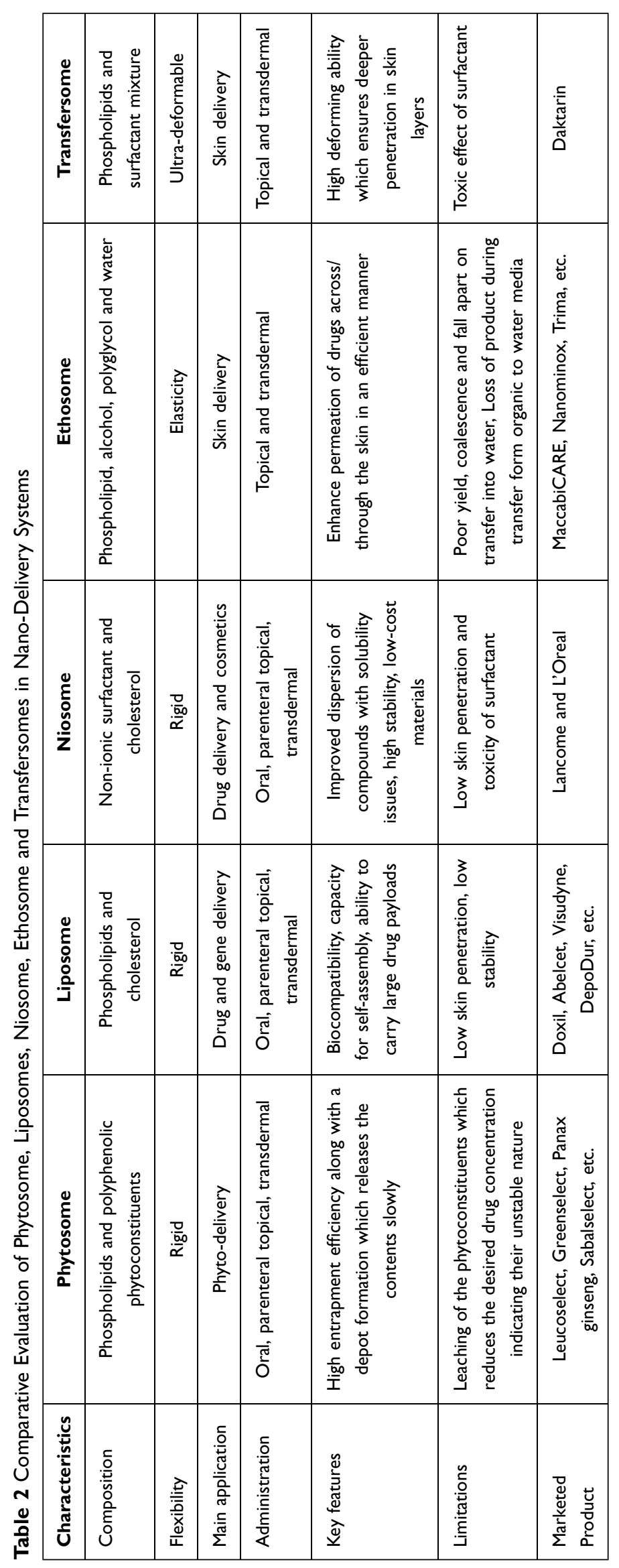




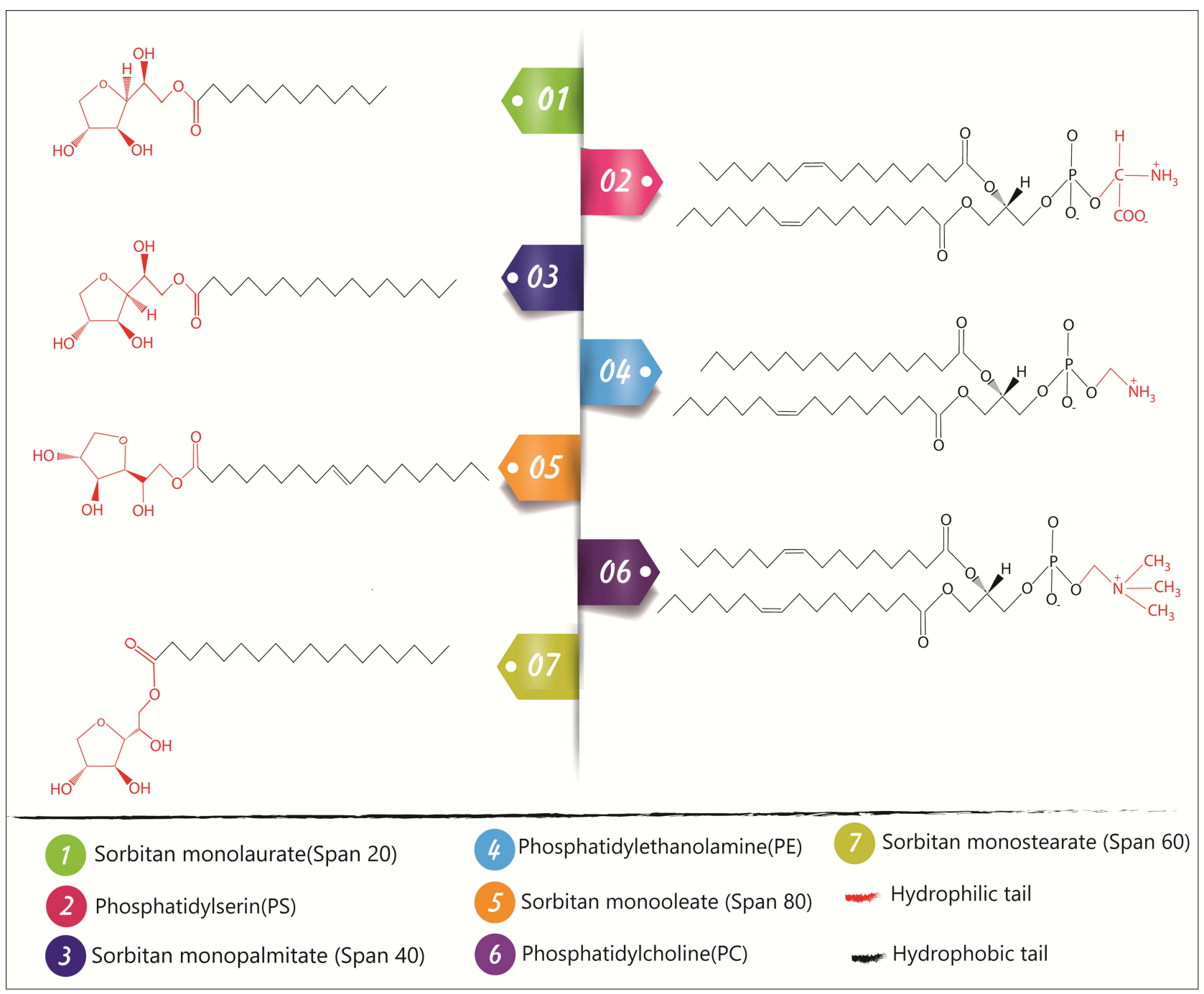

Figure 5 Amphiphile molecules in phytosomes. The most amphiphile molecules used in vesicle preparation in liposome, niosome, ethosome, and transfersome. Red parts are polar and black parts are non-polar.

is applied to the cell that causes phytosome movement within the cell. The results of the size were obtained from these movements of particles.

\section{Chemical Composition}

Assessment of the chemical composition and interaction between vesicle components and phytochemicals is usually studied by NMR, ${ }^{156,157}$ FTIR, ${ }^{158}$ and mass spectrometry. ${ }^{159}$ Besides, phospholipid quantification in phytosomes can be done by reaction with an appropriate reagent, followed by a spectrophotometric quantification. ${ }^{160}$ Due to high signal-tonoise, sensitivity, and selectivity, mass spectrometry is one of the most credible techniques for determining the phytochemical composition of plant extracts and phospholipids. ${ }^{113}$ Many authors have also applied FTIR techniques to determine the interaction between phytochemicals and vesicle components.
For example, de Azambuja Borges et al evaluated the interaction between soy isoflavone genistein and asolectin-loaded liposomes by HATR-FTIR, high-field 31P NMR, and lowfield $1 \mathrm{H}$ NMR methods. The findings showed that isoflavone reduces the phosphate group's degree of hydration and mobility. ${ }^{161}$ In another study, Mazumder et al confirmed that DSC and FTIR can prove the formation of the sinigrin-phytosome complex. ${ }^{35}$ Chen et al also prepared curcumin-liposomes, and TGA and FTIR showed a successful presence of SA and PSA in liposomal lipid bilayers and covalent bonding between SA carboxyl group and WGA amine group. ${ }^{61}$

\section{Lamellarity and Stability}

The word "lamellarity" represents the number of phytosomal lipid bilayers. ${ }^{162}$ The most used methods for the determination of lamellarity are electron microscopy methods, 31P nuclear 
magnetic resonance, and small-angle X-ray scattering. 31P NMR is one of the most precise and simple methods for determining the lamellarity. The weakness of this approach is that it is sensitive to experimental conditions, such as the concentration of the reagent, vesicle type, and concentration of the buffer. Other recently applied visualization methods are negative staining electron microscopy, freeze-fracture, and cryo-microscopy. In order to evaluate the architecture of the vesicle membrane, Nele et al recently merged cryogenic transmission electron microscopy and small-angle neutron dispersion and offered insights into the impact of the formulation method and lipid composition on the development of liposomes with a defined membrane structure. ${ }^{163}$

Phytosomal stability is another important factor in the successful design of a successful carrier. Studies of stability are performed to explore the phytochemical changes of phytosomes during storage and general circulation. Stability can be assessed over several months by determining mean vesicle size, zeta potential, size distribution, and trap efficiency. Cheng et al assessed the thermal and photochemical stability of rhamnolipids (RL) modified curcumin liposomes and results showed improved stability of the loaded liposomes at different $\mathrm{pH}$, ionic, and heat conditions. ${ }^{118}$

\section{Encapsulation Efficiency and Release Behavior}

Encapsulation efficiency (EE percent) describes the amount of phytochemical that is embedded in the phytosome. EE percent can be described as equation 1:

$$
E E \%=\frac{I P-E P}{I P} \times 100
$$

where EE\% is the efficiency of encapsulation, EP is encapsulated phytochemical and IP is the initial content of phytochemicals.

The process of encapsulation efficiency determination begins with the removal of free unencapsulated phytochemicals from the phytosome emulsion by the Sephadex gel column, ultracentrifugation, or dialysis method (defined cut-off) for several hours against buffer solution. Step 2 in EE estimation is the ruination of the phytosome bilayer (with Triton X-100, acetonitrile, methanol, and ethanol) and the quantification of the released active agent by different methods, such as enzymatic assays, gel electrophoresis, fluorescence spectroscopy, and field flow fractionation chromatographic methods, such as HPLC, UPLC, or LC-MS.

Drug release behavior of vesicle carriers has been the subject of extensive research over the past few years, since the release profile obtained in vitro may provide an indicator of the efficiency of the carrier in vivo. ${ }^{164}$ Membrane diffusion strategies (dialysis, micro-dialysis, fractional dialysis, and reverse dialysis), sample and separate strategy, in situ process, and continuous flow are traditional approaches that are most widely used to determine the release rate of active agents. ${ }^{165-170}$ Phytochemical release can be spectrophotometrically determined. Table 3 shows a summary of the experimental techniques that can be used for the characterization of the phytosomes.

Table 3 Overview of the Analytical Methods Used for the Characterization of Phytosomes Featured in This Review

\begin{tabular}{|c|c|}
\hline Parameter & Techniques \\
\hline Size, and shape & $\begin{array}{l}\text { DLS, SEM, TEM, Optical microscopy, Fluorescence microscopy, AFM, Field flow fractionation, Nanoparticle } \\
\text { tracking analysis, Scanning ion occlusion sensing, Flow Cytometry, Size-exclusion chromatography, Centrifugal } \\
\text { sedimentation, and DSC. }\end{array}$ \\
\hline Surface charge & DLS, free-flow electrophoresis, and laser Doppler velocimetry. \\
\hline Chemical composition & FTIR, hI NMR, GC-MS, LC-MS, DSC, TGA, and Thin-layer chromatography. \\
\hline Lamellarity and stability & $\begin{array}{c}31^{P} \text { nuclear magnetic resonance, Small-angle } X \text {-ray scattering, electron microscopy methods, DSC, TGA, DLS, } \\
\text { and UV-Vis. }\end{array}$ \\
\hline $\begin{array}{l}\text { Encapsulation Efficiency and } \\
\text { release behavior }\end{array}$ & $\begin{array}{l}\text { Mini-column centrifugation, HPLC, UPLC, UV-Vis, dialysis, enzymatic assays, gel electrophoresis, field flow } \\
\text { fractionation, sample-and-separate approach, the in-situ method, and the continuous flow. }\end{array}$ \\
\hline Optimization & Design of Experiment (DoE) with Box-Behnken design \\
\hline
\end{tabular}

Abbreviations: DLS, dynamic light scattering; SEM, scanning electron microscope; TEM, transmission electron microscopy; AFM, atomic force microscope; DSC, differential scanning calorimetry; FTIR, Fourier-transform infrared spectroscopy; NMR, nuclear magnetic resonance; GC-MS, gas chromatography-mass spectrometry; LCMS, liquid chromatography-mass spectrometry; TGA, thermal gravimetric analysis; HPLC, high-performance liquid chromatography; UPLC, ultra-performance liquid chromatography. 


\section{Biological Activities of Phytosomes}

The biological activities related to phytosomes are heterogeneous and have been evaluated in more than 100 studies. To simplify the analysis of the results, papers were divided based on the body district involved. Accordingly, the phytosome effects on the following categories have been investigated: cardiovascular, central and peripheral nervous, gastrointestinal, genitourinary, immune, integumentary, musculoskeletal, and respiratory systems. Finally, the last paragraph was devoted to the effects of phytosomes in metabolic syndromes. Figure 6 reports the number of papers related to phytosome and their biological activities, divided according to the system under study, whereas Figure 7 collects the number of studies on phytosome based on the main natural constituent.

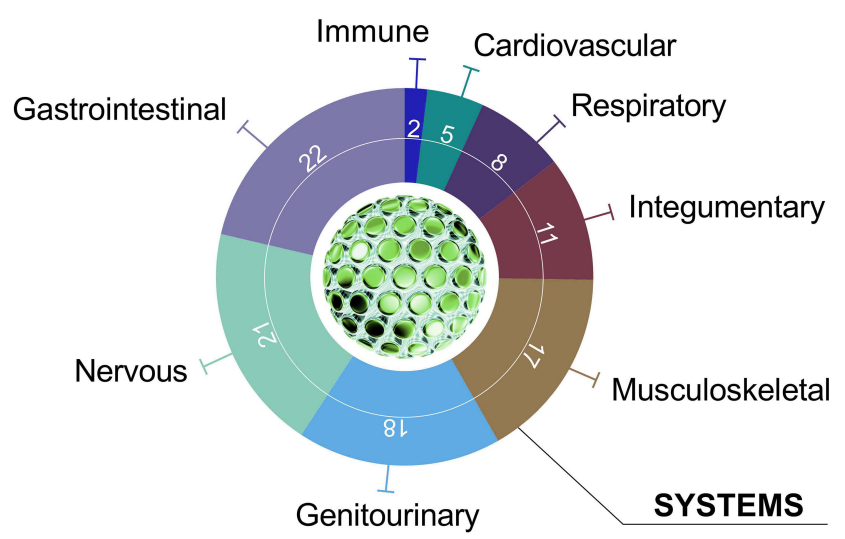

Figure 6 Biological activities of phytosomes by system. The graph shows the number of papers related to phytosomes and their biological activities, divided according to the system under study. The gastrointestinal, nervous, genitourinary, and musculoskeletal systems together account for almost the $75 \%$ of the published works. Systems involved in metabolic syndrome were not considered.

\section{Phytosomes and Cardiovascular Protection}

The isoproterenol (ISO)-induced cardiotoxicity model has been used to evaluate the protective effects of Ginkgo biloba phytosomes in rats. The results showed that Ginkgo biloba phytosome $(200 \mathrm{mg} / \mathrm{kg})$ alleviated ISOinduced myocardial necrosis considerably, as confirmed by histopathological studies. Moreover, the myocardial necrosis diminished and the endogenous antioxidants were increased, thus overall making evident the cardioprotective effect. ${ }^{171}$ The same researchers explored the possible protection by cardiovascular injuries of a combined treatment of Ginkgo biloba phytosome $(100 \mathrm{mg} / \mathrm{kg})$ and Ocimum sanctum extract (OS) (50 and $75 \mathrm{mg} / \mathrm{kg}$ ) in isoproterenol (ISO) $(85 \mathrm{mg} / \mathrm{kg})$-induced myocardial necrosis in rats. The treatment inhibited the increase of serum marker enzymes and the lipid peroxidation marker malondialdehyde (MDA), both induced by ISO. However, none of the combined treatments possessed better cardioprotective or antioxidant activity than the single treatment with Ginkgo biloba phytosome or OS. ${ }^{172}$

Tisato et al investigated the anti-inflammatory effect of Ginkgo biloba phytosome and $\alpha$-Lipoic acid on cytokines and chemokines released by vein endothelial cells (VEC) isolated from patients at different stages of CVD. The antiinflammatory effects of both Ginkgo biloba derivatives and $\alpha$-Lipoic acid were confirmed by the reduction of cell adhesion molecules ICAM-1 and VCAM-1. Ginkgo biloba phytosome diminished the basal release of PDGF and the TNF- $\alpha$-induced PDGF, CXCL10, and RANTES levels. Based on the data collected, $\alpha$-Lipoic acid exhibited a wider and more potent inhibitory activity on the release of cytokines/chemokines concerning Ginkgo biloba phytosome. This study recognized that $\alpha$-Lipoic acid markedly

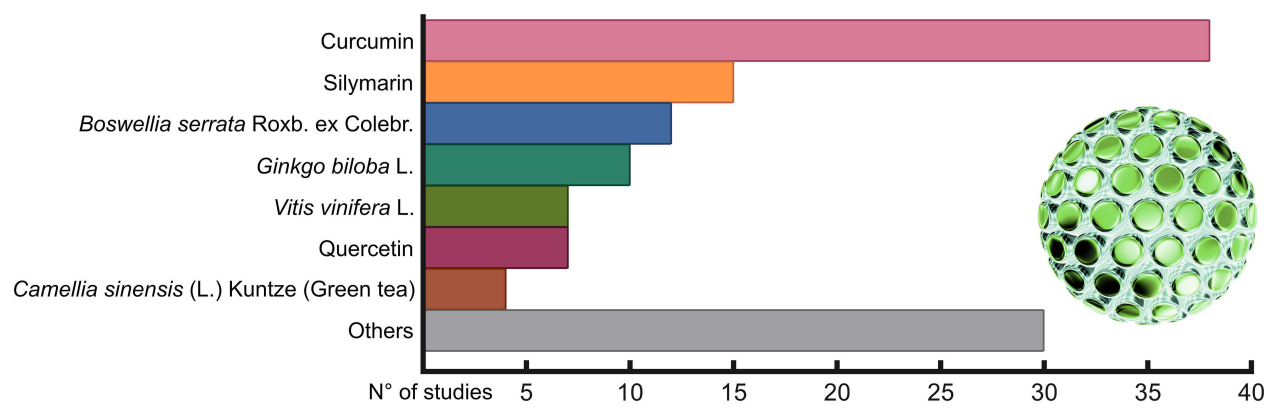

Figure 7 Main natural products in phytosomes. The graph collects the number of studies on phytosomes based on the main natural constituent. The columns group botanical or active principle with 3 or more publications, while constituents with 2 or less studies have been collected in "Others". The data show a higher prevalence of phytosomes loaded with pure compounds rather than natural extracts, especially curcumin. All the references corresponding to the individual studies considered are reported along the manuscript. 
counteracted TNF- $\alpha$-induced NF- $\mathrm{kB}$ and p38/MAPK activation, whereas Ginkgo biloba mostly acted on Akt. ${ }^{173}$

A commercial formulation was examined in a large sample of CVD patients enrolled in 54 Italian centers. The supplement contains phytosome of polyphenolic extract from Vitis vinifera L. seeds, extract from Melilotus officinalis (L.) Pall, and bromelain $100 \mathrm{mg}$. A total of 648 patients were enrolled and received 1 tablet/ day and/or standard compression stockings for 90 days. In all groups, it was reported a notable reduction in the malleolus circumference, both at the left and the right limb. A comparable pattern was observed for the severity of the disease and symptomatology. ${ }^{174}$

Muir et al have investigated the clinical efficacy of Ginkgo biloba phytosome, in the treatment of Raynaud's phenomenon (RP). A painful condition characterized by episodic digital ischemia. A total of 22 patients with RP and without other associated conditions were enrolled. A number of 11 patients were randomized to receive Ginkgo biloba extract (120 mg three times a day for a final amount of $360 \mathrm{mg} /$ day), while 11 patients received matching placebo. The number of RP episodes per week before treatment with Ginkgo biloba phytosome $(13.2 \pm 16.5)$ was reduced by $56 \%$, whereas the placebo reduced the number by only $27 \%(\mathrm{p}<0.00001)$. There were no significant dissimilarities in hemorheology among the two groups. ${ }^{175}$

\section{Evidence on the Role of Phytosomes in the Nervous System}

The Phytosomes in Cognitive Impairment and Neuronal Damage

Several papers report the bioavailability of phytosome concerning the corresponding unformulated products in animal models, focusing on the tissue distribution of the active ingredients. Husch et al found a greater amount of Boswellia acids from Boswellia serrata (ie, KBA, AKBA, $\beta B A)$ following the administration of Boswellia-loaded phytosome. ${ }^{176}$ Another study investigated phytosome formulation loaded with Annona muricata water extract intending to ameliorate its permeability across the bloodbrain barrier (BBB), thus improving the antidepressantlike activity due to inhibition of monoamine oxidase $B$ (MAO-B). Through an in vitro transwell model of BBB, phytosome formulation registered the best performance as a radical scavenger and MAO inhibitor, thus representing a useful model to improve the antidepressant-like activity of the extract. ${ }^{177} \mathrm{La}$ Grange et al investigated the ability of silymarin phytosome to protect fetal rat brain by ethanol administration. Silymarin is a complex of flavonolignans from Silybum marianum Gaertn., namely milk thistle. The activity of antioxidant enzymes, which include gammaglutamyl transpeptidase, was generally higher in the group treated with the phytosome formulation. ${ }^{178}$

Two different studies have been carried on by Naik et al on the biological activities of a Ginkgo biloba phytosome formulation in Wistar rats; in the first study, oral administration at 50 or $100 \mathrm{mg} / \mathrm{kg}$, reduced pentobarbitone-induced sleeping time, decreased the chlorpromazine effects, and induced spontaneous motility in rodents. Moreover, the formulation exhibited antidepressant effects in the amnesia induced by scopolamine, showing general improvement in the behavioral tests. ${ }^{179}$ The second study evaluated the antioxidant activity in the rat brain after acute (7 days) or subchronic treatment (14 days). Brain areas including the cerebellum, striatum, cerebral cortex, and hippocampus were isolated, and the activity of the antioxidant enzymes, GPx, SOD, CAT, and GR, was tested, finding phytosomes-induced increased activities in the brain areas analyzed. ${ }^{180}$

Ullah et al studied the ability of a curcumin phytosome to decrease glial activation in GFAPIL6 mice, an animal model of chronic glial activation. Formulation administered at three doses $(218,438$, and $874 \mathrm{ppm})$ for four weeks caused a decrease of neuroinflammation and number of activated microglia in the hippocampus $(-26.2 \%)$ and the cerebellum $(-48 \%){ }^{181}$

Recently, our group demonstrated that Centella asiatica phytosome administered to adult male rats for ten days at 20 and $100 \mathrm{mg} / \mathrm{kg}$ (calculated as triterpene equivalents) induced BDNF increase in the prefrontal cortex, and the higher dose generally counteracted cognitive impairment. In the NOR test, the increase in the preference index was accompanied by increased levels of the Bdnf expression. In addition, there were no side effects observed during the treatment. ${ }^{182}$ In another paper, we demonstrated that phytosome loaded with Centella asiatica and Curcuma longa extracts, administered chronically to rats (50 or $250 \mathrm{mg} / \mathrm{kg}$ for ten days), affected local protein synthesis through the modulation of BDNF-mTOR-S6 pathway. Our findings supported the use of this preparation in subjects with memory and cognitive impairment. ${ }^{101}$

\section{The Phytosomes in Neurodegenerative Diseases}

Neurodegenerative brain dysfunction is responsible for the development of dementia in aged people. Bahadur S. 
investigated the nanoparticle system to improve the drug delivery or active compounds with poor availability to the brain. ${ }^{183}$ Langasco et al studied the brain delivery of the isoflavone genistein testing various nanotechnological approaches; oxidative stress in PC12 cells (neuron cell line) was diminished by treatment with phytosomes, and the effect was better than the unformulated genistein. ${ }^{184}$ Among phytochemicals, curcumin phytosome was found to increase curcumin bioavailability in the hippocampus and frontal lobe following repeated oral administration of the formulation for five days $(134 \mathrm{mg} / \mathrm{kg} / \mathrm{die}$ as curcuminoids equivalent) in rats. In the frontal lobe, curcumin appeared 30 minutes after treatment, peaked at 1 hour, and tended towards normalization after 3 hours, demonstrating that curcumin phytosome can reach the brain in rats. ${ }^{185}$ Since curcumin possesses anti-amyloid and antiinflammatory activities, which are mostly used against neurodegenerative diseases including Alzheimer's disease, this finding may be useful for future studies aimed at better design drug delivery. ${ }^{186}$

\section{The Phytosomes in Cerebral Ischemia}

Two studies from the same group investigated the potential positive effects of natural compounds in the middle cerebral artery occlusion model in rats. Rutin, a glycoside of the flavonoid quercetin, has been loaded in a phospholipid structure and tested for its bioavailability in an animal model of cerebral ischemia. LC-MS/MS analysis revealed that rutin, administered at $100 \mathrm{mg} / \mathrm{kg}$ to Sprague Dawley rats, reached the brain at concentrations ranging from 20 to $50 \mathrm{ng} / \mathrm{g}$. Rutin-loaded formulation highly ameliorated functional outcomes in an animal model of stroke. ${ }^{187}$ In the second study, a phytosomal complex containing the ethanolic extract of Ashwagandha (Withania somnifera) roots was administered orally $(85 \mathrm{mg} / \mathrm{kg})$ to rats 1 hour before ischemia and six hours post-reperfusion. Treatment provoked a strong reduction of cerebral infarction (82.7\%) and afforded better protection on all neurological deficit parameters. $^{188}$

\section{Effect of Phytosomes in Neuropathy}

Di Pajardi et al studied the clinical potential of oral treatment (3 months, $\mathrm{n}=180$ ) of, curcumin phytosome (500 $\mathrm{mg}$ ), $\alpha$-lipoic acid (300 mg), and vitamins of the B group in subjects with carpal tunnel syndrome awaiting surgical treatment. Patients receiving supplementation for three months twice/day both before and after surgery showed a decrease of night symptoms at 40 days after surgery and were less likely to reach a positive Phalen's test at 3 months post-surgery. ${ }^{189}$ In neuropathic patients, a similar formulation based on curcumin phytosome and piperine and/or $\alpha$-lipoic acid reduced pain $(-66 \%)$ in all the combinations, after 8 weeks. The supplementation decreased by $40 \%$ the use of conventional therapy (ie, dexibuprofen), whereas lipoic acid alone did not show statistically significant results. ${ }^{190}$

\section{The Phytosomes in Migraine}

In two studies of the same research group, the efficacy of Ginkgo biloba terpenes phytosome $(60 \mathrm{mg})$, vitamin B2 (8.7 $\mathrm{mg})$, and coenzyme Q10 (11 mg) as ingredients, administered twice daily, was investigated in fifty subjects suffering from migraine with aura. Positive effects in reducing migraine with aura, both frequency and duration, were already clear within a four-month treatment. These effects were probably due to the presence of ginkgolide B, the most abundant terpene identified in the Ginkgo biloba leaf extract. ${ }^{191}$ Ginkgolide B was found to modulate/ reduce the glutamate neurotransmission in the CNS, which plays a pivotal role in the onset of migraine. ${ }^{192}$ The efficacy of the same formulation in the acute stage of migraine with aura was tested in an open study; during the first symptoms of aura, patients orally consumed two capsules of Ginkgo biloba terpenes phytosome, with no restriction on analgesic intake during the pain phase. About $60 \%$ of patients enrolled in the study experienced a reduction of neurological symptoms after treatment; moreover, the pain phase was completely abolished in almost $20 \%$ of patients. ${ }^{193}$

Balzano et al investigated the beneficial effects of a mixture of magnesium, vitamins (riboflavin, niacin, vitamin D), L-tryptophan, and the Boswellia serrata extractloaded phytosome, in patients with transient tension migraine and migraine without aura. The authors considered pain modulation (NRS scale), monthly attack number, and analgesic intake. Amitriptyline was used as a reference compound. The authors found an improvement in all the outcomes, with greater compliance and no side effects for patients who consumed the phytosome formulation. ${ }^{194}$

\section{The Phytosomes in Nervous System Cancer}

Glioblastomas are among the most aggressive malignancies affecting the central nervous system. To search for novel strategies to cope with the disease, Mukherjee et al studied the ability of the intranasal delivery of curcumin phytosome $(500 \mathrm{mg}$, corresponding to $96 \mathrm{mg}$ 
curcuminoids) to cause remission of glioblastoma in the brain of GL261 (glioblastoma cells)-implanted mice. Tumor remission was observed in $50 \%$ of mice; similar effects were achieved also using intraperitoneal infusion. Therefore, the authors suggest that curcumin-loaded phytosome could affect the viability of glioblastoma cells and also induce repolarization of microglia cells to the tumoricidal M1 state. ${ }^{195}$ Similar results were obtained by the same group studying the effects of curcumin phytosome in natural killer cells and macrophages in GL261 (glioblastoma cells)-implanted mice. The treatment also induced suppression of proteins STAT3 and ARG1, and IL-10 induction of STAT1; suppression of inducible nitric oxide synthase and caspase 3 activation in the glioblastoma cells were also observed. ${ }^{196,197}$

The same curcumin phytosome was investigated in an animal model (D425MED) of medulloblastoma, the most common pediatric central nervous system cancer. The results reveal negligible effects of formulation using either oral or intraperitoneal administration; however, no information on the dose used was reported. ${ }^{198}$

Di Pierro et al studied the efficacy of a Boswellia extract as a phytosome in cerebral edema induced by radio-chemotherapy in patients with glioblastoma. Patients $(n=20)$ received temozolomide and $4500 \mathrm{mg}$ /die of formulation for a maximum of 34 weeks. The stage of the disease was evaluated at different times ranging from 4 to 34 weeks post-surgery, together with steroid consumption. Two subjects showed a significant decrease in brain edema, thus leading to better surgical resection. The authors conclude that supplementation with this type of phytosome may elicit positive effects in reducing cerebral edema induced by radiochemotherapy, and the brain edema reduction may decrease dexamethasone intake, thus minimizing steroid-induced side effects during conventional pharmacological treatment. ${ }^{199}$

\section{The Phytosomes in the Gastrointestinal System}

The Phytosomes and Gut Microbiota

A recent study compared the influence of the two different curcumin-based products, unformulated curcuminoids, and lecithin-curcuminoid formulation, on human colonic metabolism. Both extracts were subjected to fermentation using an in vitro fecal model mass spectrometry was used for curcuminoid quantification and assessment of possible curcuminoid degradation and detection of the main metabolites in the human fecal fermentation. The results showed that the fermentation of lecithin-formulated curcuminoids caused a more pronounced occurrence of curcuminoid catabolites. ${ }^{200}$

\section{The Phytosomes and Pancreatic Cancer}

The potential synergistic effects of gemcitabine and the curcumin phytosome in advanced pancreatic cancer were evaluated in a prospective Phase II trial. A total of 44 patients affected by locally advanced or metastatic pancreatic cancer were enrolled and received $2000 \mathrm{mg} / \mathrm{die}$ daily (4 capsules, each of $500 \mathrm{mg}$ ) in addition to gemcitabine $\left(10 \mathrm{mg} / \mathrm{m}^{2} / \mathrm{min}\right.$, infusion over $100 \mathrm{~min}$ on days 1,8 , 15 every 28 days). The response rate was the primary endpoint of this study; progression-free survival, overall survival, quality of life, and tolerability were the secondary endpoints. The results of the study suggest that curcumin phytosome can be used as a complementary treatment associated with gemcitabine in the therapy of pancreatic cancer. $^{201-203}$

\section{The Phytosomes Against Bowel Inflammation}

An open-label, observational, registry study estimated the effects of a lecithin-based delivery form of standardized Boswellia serrata extract in patients with minimally symptomatic ulcerative colitis in the remission phase. The 43 patients freely decided to receive 1 tablet of $250 \mathrm{mg} /$ day or no supplementation for 4 weeks. Diffuse intestinal pain, bowel movements and cramps, watery stools, blood in stools, anemia, malaise, rectal involvement, and the number of white blood cells were attenuated in the supplementation group. The need for other drugs and medical examinations was also reduced. ${ }^{204}$

Two clinical studies evaluated the efficacy and safety of Boswellia serrata extract phytosome in irritable bowel syndrome (IBS). In the first, 71 healthy subjects with idiopathic IBS were assigned in three groups and received hyoscine butyl bromide, papaverine hydrochloride + Atropa belladonna extract, both administered when needed, or 1 tablet of phytosome (250 mg/day) for 4 weeks. IBS symptoms showed improvements in all groups, but only in the phytosome consumption group a substantial decrease in the need for medical attention and a lower occurrence of side effects, mainly stypsis, was detected. $^{205}$ The second perspective, a controlled, randomized study evaluated the long-term efficacy and the safety of phytosome for the prevention of symptoms in healthy subjects with mild IBS. The same management strategies of the previous study were applied to 71 
subjects. At the follow-up (6 months), compared to the groups receiving the standard treatment, the phytosome group exhibited a lower mean score value for nearly all self-assessed IBS symptoms and a considerably lower need for medicines and consultations or medical evaluation/admissions. ${ }^{206}$

\section{Efficacy of the Phytosomes in Bowel Cancer}

The beneficial effects of oral silibinin and silybin-phytosome against human colorectal HT29 xenograft growth were compared in vivo in athymic nude mice. A dosage of $100 \mathrm{mg} / \mathrm{kg}$ of the silybin-phytosome exhibited an efficacy close to silibinin $200 \mathrm{mg} / \mathrm{kg}$ in reducing tumor weight and volume. $^{207}$

Efficacy of the combination of oxaliplatin and curcumin phytosome was investigated in vitro, in oxaliplatinresistant cells, and in vivo, in colorectal tumor-bearing mice. This combination, compared with oxaliplatin alone and control, improved the antiproliferative capacity of oxaliplatin in vitro. A positive effect was observed also in the HCT116 nude mouse xenograft model, with a decrease of tumor volume, a decrease of pharmacodynamic markers $\mathrm{Ki}-67$ and Notch-1, and an increase of cleaved caspase- $3 .^{208}$ Another study investigated the efficacy of phytosomal curcumin or in association with 5fluorouracil (5-FU) in vitro or in vivo model of colon tumor with the presence of colitis. In CT26 cells, curcumin inhibited cell growth in a concentration-dependent fashion $(0-1000 \mu \mathrm{g} / \mathrm{mL})$ and notably improved the expression of E-cadherin. A combination of curcumin ( $25 \mathrm{mg} / \mathrm{kg} /$ day $)+$ 5 -FU (35 mg/kg/weekly) diminished the tumor-number and tumor-size in mice for curcumin or 5-FU alone. ${ }^{209}$ The same combination of phytosomal curcumin and 5-FU was used in a xenograft mouse model of colorectal cancer. The study showed tumor growth reduction, an increase in the antitumor effect of 5-FU, and anti-angiogenic effects across modulation of VEGF and VEGFR2. ${ }^{210}$

\section{Hepatoprotective Effects of the Phytosomes}

La Grange et al investigated the efficacy of silymarinphytosome in the protection of the fetus from maternal ethanol ingestion in rats. It was compared to the activity of oral with subcutaneously injected phytosome, with doses ranging from 400 to $800 \mathrm{mg} / \mathrm{kg}$. All doses suppressed gamma-glutamyl transpeptidase (GGTP) activity induced by ethanol in brain and liver tissue, in both the fetuses and the dams. The highest dose of phytosome administered orally appeared optimal in reducing maternal brain and fetal GGTP activity. According to the authors, there may be a protective activity of the formulation of ethanol toxicity, as well as direct inhibition of GGTP without protective activity. ${ }^{178}$

The hepatoprotective effects of Ginkgo biloba phytosome on carbon tetrachloride $\left(\mathrm{CCl}_{4}\right)$-induced hepatotoxicity were investigated in rats. Ginkgo biloba phytosome was administered for 10 days in two doses, $25 \mathrm{mg} / \mathrm{kg}$ and $50 \mathrm{mg} / \mathrm{kg}$ i.p., and silymarin (200 mg/kg P.O.) was used as the standard reference. Phytosome decreased enzyme levels of glutamic oxaloacetic transaminase (GOT), glutamic-pyruvic transaminase (GPT), and alkaline phosphatase (ALP) in serum; levels of SOD, CAT, GPx, GR, albumin, and total proteins were significantly increased, and the GSH levels were found close to control levels. On some parameters, the effect of the higher dose of Ginkgo biloba phytosome was comparable with silymarin. ${ }^{211,212}$ The same group investigated the hepatoprotective effects of phytosome on rimpfacin-induced hepatotoxicity in rats. Also in this study, Ginkgo biloba phytosome was administered at $25 \mathrm{mg} / \mathrm{kg}$ and $50 \mathrm{mg} / \mathrm{kg}$, showing hepatoprotective effects by reducing the levels of serum marker enzymes and lipid peroxidation; treatment increased the levels of SOD, GSH, GPx, GR, CAT, albumin, and total protein in a dose-dependent manner. ${ }^{213}$

A Phase III, double-blind, placebo-controlled, randomized clinical trial evaluated the beneficial activities of silybin combined with vitamin $\mathrm{E}$ and phosphatidylcholine on liver function in patients with non-alcoholic fatty liver disease (NAFLD). Several 180 patients with NAFLD (36 with $\mathrm{HCV}$ chronic infection) were enrolled to receive orally active treatment $(n=91)$ (silybin $94 \mathrm{mg}$, phosphatidylcholine $194 \mathrm{mg}$, vitamin E acetate $50 \% 89.28 \mathrm{mg}$, twice daily) or placebo $(n=88)$ for 12 months. In patients receiving the active treatment, improvements in insulin resistance, transaminases and $\gamma$-glutamyltransferase $(\gamma \mathrm{GT})$ levels and several aspects of liver histology were observed. In patients $\mathrm{HCV}$-positive, the active treatment improved markers of fibrogenesis. ${ }^{214}$

Ali et al examined the effects of silybin phytosome (400 mg/kg), curcumin (400 mg/kg), or $\alpha$-R-lipoic acid (200 mg/kg), all given orally, in a model of thioacetamideinduced liver cirrhosis in rats. All supplements significantly decreased serum levels of GPT, GOT, LDH, and $\gamma \mathrm{GT}$; only serum ALP levels were not decreased by silybin phytosome. Collagen deposition, matrix metalloproteinase (MMP)-2 activity (MMP-2), TGF-b1 level, and HSP-47 gene expressions were also reduced. Moreover, all 
supplements improved the oxidative stress status through the increase of liver GSH and the reduction of MDA levels. $^{215}$

Another study compared hepatoprotective activities of silymarin phytosomes and milk thistle extract (both given orally as $200 \mathrm{mg} / \mathrm{kg} /$ day silybin equivalent for 10 days) in $\mathrm{CCl}_{4}$-induced hepatotoxicity in rats. Silymarin phytosome increased SOD and decreased GPT levels more efficiently than milk thistle extract $(\mathrm{p}<0.05)$. No significant difference between the two treatments regarding other biochemical parameters was observed. ${ }^{216}$

The bioavailability of a standardized pomegranate extract (30\% w/w punicalagin - SPE) and soy phospholipids was compared with unformulated SPE in rats treated with $\mathrm{CCl}_{4}$. Pharmacokinetic studies showed that the formulation of pomegranate extract and soy phospholipids (500 mg/kg equivalent SPE) led to the serum concentration of punicalagin higher than SPE $\left(C_{\max } 466.3 \mathrm{ng} / \mathrm{mL}\right.$ and $192.5 \mathrm{ng} / \mathrm{mL}$ respectively). Antioxidant activity was evaluated at two doses (100 and $200 \mathrm{mg} / \mathrm{kg}$ ) as well. Compared with SPE, pomegranate extract and soy phospholipid combination significantly preserved the concentrations of the liver enzymes SOD, glutathione system, CAT. ${ }^{217}$

In vivo Boswellia serrata extract phytosome significantly decreased the serum levels of the pro-inflammatory cytokines TNF- $\alpha$ and IL- 6 and increased the levels of the anti-inflammatory cytokine IL-10 in lipopolysaccharideinduced systemic inflammation in mice. Phytosome showed antioxidant capacities through a significant attenuation of lipid peroxides and increased levels of GSH, glutathione disulfide, and total glutathione concentrations. Moreover, treatment was able to restore CYP transformation and consequently re-establish the biotransformation capacity in the liver. ${ }^{218}$

The hepatoprotective activity of a phytosome formulated with the combination of dry ethanolic extracts from Piper longum fruits and Abutilon indicum leaves was compared with dry ethanolic extracts from each plant alone and with LIV 52, an Ayurvedic formulation indicated for liver disorders. Phytosome (100 mg/kg), dry ethanolic extracts $(100,200,400 \mathrm{mg} / \mathrm{kg})$, and LIV 52 (1 $\mathrm{mL} / \mathrm{kg}$ ) were administrated orally to rats with liver damage induced by $\mathrm{CCl}_{4}$. Phytosome reduced liver damage markers (GPT, GOT, ALP, and bilirubin) to a greater extent than dry ethanolic extracts and in a similar manner to LIV $52 .^{219}$

Hepatoprotective effects of curcumin phytosome were investigated in a model of aluminum chloride $\left(\mathrm{AlCl}_{3}\right)$ induced hepatotoxicity in rats. Compared with the untreated $\mathrm{AlCl}_{3}$ group, treatment with phytosome (200 $\mathrm{mg} / \mathrm{kg} /$ day for 21 days) notably normalized the hepatic markers increased by $\mathrm{AlCl}_{3}$ (GOT, GPT, ALP, LDH, and bilirubin). ${ }^{220}$

The chemopreventive effect of curcumin phytosome was evaluated and compared with unformulated curcumin on hepatitis B virus related-hepatocellular carcinoma by using a transgenic mouse model. Phytosome showed greater efficacy in reducing hepatocellular carcinoma growth, reduction of total tumor volume, and anti-inflammatory activity than unformulated curcumin. ${ }^{221}$

\section{The Phytosomes Effect in the Genitourinary System}

This section describes the biological activities, which affect the genitourinary tract, including the breast, as a gland linked to the reproductive system.

\section{The Phytosomes and Breast Cancer}

In the first study, twelve early breast cancer patients were treated for 4 weeks with a commercial lecithin formulation containing catechins from green tea, at a daily dose of 300 $\mathrm{mg}$ (corresponding to $44.9 \mathrm{mg}$ of epigallocatechin-3-gallate or EGCG) before surgery. The research showed the ability of the active principles to reach human breast tissue; concentrations up to $8 \mathrm{ng} / \mathrm{g}$ of EGCG were found in all the tumor tissues tested. The evaluation of Ki-67, as a biomarker of proliferation, demonstrated a significant inverse correlation with EGCG plasma levels for each patient. $^{222}$

The same research group evaluated the activity of a complex of silybin-phosphatidylcholine, in another group of 12 breast cancer patients, $2.8 \mathrm{~g}$ per day for 28 days. The concentration of silybin reached up to $177 \mathrm{ng} / \mathrm{g}$ in breast tumor tissues, but non-changes in $\mathrm{Ki}-67$ was noted, as well for insulin-like growth factor 1 (IGF-I) and nitric oxide blood levels. ${ }^{223}$ In vitro, silybin-phosphatidylcholine treatments obtained a concentration- and time-dependent decrease in viability of SKBR3, a cell line of human breast adenocarcinoma, confirming a superior membrane transmission (more than 1.5 times) and inhibitory effect on growth (more than 2 times) compared to pure silybin. Both silybin and silybin-phosphatidylcholine downregulated Human Epidermal Growth Factor Receptor 2 (HER2) expression, but the complex gave better results in longer treatment times $(72 \mathrm{~h}){ }^{224}$ A study prepared and evaluated the effect of phytosomes containing luteolin in 
MDA-MB 231 breast tumor cells. Phytosomes increased the activity of doxorubicin in inhibiting the growth of cancer cells, compared to the pure compound. Besides, the related phytosomes were more active than luteolin in inhibiting the gene expression of nuclear factor erythroid 2-related factor 2 ( Nrf2), lowering the antioxidant defense of cancer cells. ${ }^{225}$

Similarly, quercetin phytosomes also increased the efficiency of doxorubicin on the growth of MCF-7 human breast cancer cells. Despite no significant effects were observed on Nrf2 gene expression, quercetin phytosomes decreased the expression of two Nrf2-activated genes, $\mathrm{NAD}(\mathrm{P}) \mathrm{H}$ dehydrogenase (quinone) $1(35 \%)$ and multidrug resistance-associated protein 1 (43\%), more efficiently than pure quercetin. $^{226,227}$

MCF-7 cells treated with a commercial phytosomal-curcumin, showed a dose-response inhibition of proliferation and invasion, linked to higher levels of E-cadherin and MMP-9. Moreover, phytosomal-curcumin enhanced the biological activity of fluorouracil in inhibiting tumor growth of a xenograft mouse model (female BALB/c), by positively regulating MDA levels, catalase, total thiol concentration, and SOD in breast cancer tissue. However, the phytosome alone, without fluorouracil, reduced growth to a lesser extent, without modulating the individual parameters. ${ }^{228,229}$

Phytosomal-curcumin was tested in female BALB/c mice with metastatic breast tumor (4T1). Mice were fed with the phytosomal-curcumin for 14 days with $10 \mathrm{mg}$ once every 3 days. While the treatment alone had minor effects on the primary tumors, it significantly decreased the number of metastases in the lung at a dose of $10 \mathrm{mg} /$ mouse. Although this study lacks comparative data on pure curcumin, the animals treated with cryoablation and phytosome did not improve their survival rate with respect to the animals with saline, or just cryoablation or phytosomal-curcumin alone. ${ }^{230}$

Finally, two studies by the same research group evaluated phytosome bilayer-enveloped casein micelles or phosphatidylcholine-casein micelles, containing Monascus yellow pigments (Monascus purpureus) and resveratrol, by comparing also folate conjugated and PEGylated phytosome modifications. All forms of phytosomes induced higher toxicity in MCF-7 cells comparing to the cotreatment of free resveratrol and Monascus yellow pigments. Tumor-bearing BALB/c mice received through injection the pure compounds/mixtures or phytosomes, corresponding to $5 \mathrm{mg} / \mathrm{kg}$ per day of resveratrol, for consecutive 21 days. At $250 \mu \mathrm{g} / \mathrm{mL}$, the percentage of hemolysis induced by phytosomes was lower than $5 \%$. Phytosomes were superior in tumor regression concerning coadministration of free resveratrol and Monascus yellow pigments. Treatments with phytosomes better-reduced aromatase, NF- $\kappa \mathrm{B}, \mathrm{VEGF}$, and CD1 levels, and increased caspase-3 level and necrosis. ${ }^{231,232}$

\section{The Phytosomes Role in Prostate Diseases}

Three studies evaluated the effects of silibinin-loaded phytosome, in the field of prostate cancer. In the first in vivo study, TRAMP male mice, characterized by a palpable prostate tumor, were exposed to $0.5 \%$ or $1 \% \mathrm{w} / \mathrm{w}$ of a phytosome diet. After 11 weeks, the diet dose-dependently decreased the weight of the prostate together with tumors (up to $60 \%$ ), suppressing metastasis formation by reducing fibroblast growth factor (bFGF), VEGF, MMP-2, and MMP-3. Silibinin led to higher levels of E-cadherin in parallel with a reduction of vimentin and also snail-1 in tumors. ${ }^{233}$ Two clinical studies evaluated the effects on humans. The first pharmacokinetic Phase I study involved 13 subjects with prostate cancer. Phytosome was increased from a $2.5 \mathrm{~g}$ to a 20 g orally daily dose, but a persistent grade 2 hyperbilirubinemia was registered at 15 and $20 \mathrm{~g}$. Silibinin, rapidly conjugated, was released into the urine, pointing out a short plasma half-life, in a range of 1.79-4.99 h. None of the patients under study achieved a 50\% reduction in PSA, but several patients experienced a prolonged stable disease. ${ }^{234}$

The second study from the same research group administered $13 \mathrm{~g}$ of silibinin phytosome daily to 6 prostate cancer patients, for 14-31 days before radical prostatectomy. The plasma silibinin levels were relatively low (1.2 $\mu \mathrm{M})$ at the end of the treatment. Only three patients out of six showed silibinin values reaching from 14.9 to 496.6 $\mathrm{pmol} / \mathrm{g}$ in prostatic tissues. IGF-I, IGFBP-3, or PSA levels were not significantly changed. ${ }^{235}$

The latest research investigated the application of curcumin phytosome formulation in patients with benign prostatic hyperplasia. The phytosome was administered as two tablets per day $(2 \times 500 \mathrm{mg}$ per day, equivalent to $200 \mathrm{mg}$ of daily curcumin) to 33 subjects (range: 55-65 years) in association with the best standard management. All symptoms including urination frequency, intermittency, urgency, straining, and nocturia improved with curcumin administration compared to standard management, except for stream weakness. ${ }^{236}$

\section{The Phytosomes in Female Reproductive System Conditions}

A clinical study evaluated the effect of curcumin phytosome in 6 patients with endometrial cancer. Patients 
received the supplement for 2 weeks with $2 \mathrm{~g}(4 \times 500 \mathrm{mg}$ per day) without simultaneous oncological treatments. Supplementation lowered MHC expression on leukocytes, the number of monocytes, and ICOS protein levels on CD8 $+\mathrm{T}$ cells. No other significant changes were observed in inflammatory markers, such as number of different immune cell types, activation of $\mathrm{T}$ cell, and the protein levels of cyclooxygenase-2 (COX-2). ${ }^{237-239}$

A second study evaluated the effect of a quercetin phytosome (10 or $50 \mathrm{mg} / \mathrm{kg}$, per os) in 48 rats subjected to ovariectomy. Treatment with phytosome induced a significant increase of calcium, inorganic phosphorus, and glutathione in serum, compared to the corresponding doses of free quercetin. Compared to quercetin, the phytosome significantly lowered serum alkaline phosphatase, TNF- $\alpha$, acid phosphatase, MDA, and glucose level and also positively modified the lipid profile. ${ }^{131}$ Furthermore, a study evaluated an icariincontaining phytosome in OVCAR-3 ovarian cancer cells. The phytosomes showed higher cytotoxicity versus ovarian cancer cells compared to pure icariin $(6.31$ vs $13.1 \mu \mathrm{M})$ and in particular, the number of cells in the G2-M phase, the caspase-3 content, and intracellular ROS were enhanced following incubation with phytosomes. ${ }^{240}$

\section{The Phytosomes in Urinary Tract Dysfunctions}

Two clinical trials evaluated the biological effects of phytosomes in the urinary tract. In the first research, cranberry was studied in 13 healthy volunteers to evaluate the Candida albicans antiadhesive properties of urine after cranberry extract phytosome or the corresponding standardized extract consumption. The subjects consumed 2 capsules of cranberry phytosome or cranberry extract per day, for a week and urines were analyzed at different times. The fractions retrieved after $12 \mathrm{~h}$ of extract or phytosomal form treatment significantly and similarly inhibited the adhesion of $C$. albicans, but phytosome contained only $33 \%$ of the cranberry extract (phytosome: $12 \mathrm{mg}$ proanthocyanidins/capsule; extract: $36 \mathrm{mg}$ proanthocyanidins/ capsule). ${ }^{241}$

The second study explored the effect of curcumin in asymptomatic patients suffering from temporary kidney dysfunction. Patients consumed 3 capsules/day for 4 weeks, containing curcumin phytosome (300 mg of curcumin). The subjects treated with curcumin phytosomes had significantly higher improvement in micro- and macroalbuminuria and oxidative stress levels than those on standard management. The number of patients experiencing fatigue was significantly reduced by curcumin phytosome, and compliance and tolerability were good. ${ }^{242}$

\section{The Phytosomes as Modulators of the Immune System}

A couple of studies evaluated the effects of phytosome on parameters related to immune function. Silymarin loaded on liposome/phytosome (lecithin: cholesterol ratio 6:1) showed improved prevention of ROS release compared to unformulated silymarin in RAW 264.7, a murine macrophage cell line. In vivo study performed for seven days in Wistar rats $(50 \mathrm{mg} / \mathrm{kg})$ exerted protection against liver toxicity and inflammation induced by paracetamol. ${ }^{243}$ Another study evaluated the immunomodulatory effects of the phytosomal formulation of grape seed extract, that is particularly rich in epigallocatechin 3-O-gallate. Onemonth administration of grape seed phytosome $(300 \mathrm{mg} /$ die) to elderly patients influenced the immune response, as shown by serum cytokine assessment. In particular, the treatment increased both IL-2 and INF $\gamma$ production, thus suggesting a possible role in the Th1/Th2 rebalance in atopic frail elderly or the enhancement of antiviral response. $^{244}$

\section{The Phytosomes Effect in Integumentary System}

The formulations evaluated at the skin level are more disparate and can be collected in three main areas: skin inflammatory conditions, wound healing, and skin cancer.

\section{The Phytosomes in Skin Inflammatory Conditions}

Two clinical studies showed the effect of phytosomes in the field of skin inflammation. A first blind trial with 30 volunteers investigated the topical effect of a quercetin phytosome, in comparison to a formulation containing $1 \%$ dexchlorpheniramine, in different types of skin insults. Quercetin phospholipids $1 \%$ and dexchlorpheniramine $1 \%$ obtained similar results by significantly reducing UV-induced erythema $(-10.05 \%$ vs $-14.05 \%$, respectively) and in histamine prick test $(-13.25 \%$ vs $-12.23 \%$, respectively). When erythema was induced by sodium lauryl sulfate (SLS) or glycolic acid (GA) only quercetin phospholipids $1 \%$ induced a significant increase in hydration, but both the formulations reduced erythema. ${ }^{245}$ In a Phase III randomized, single-dose, and double-blind placebo clinical trial, 49 patients with chronic psoriasis were treated orally for 12 weeks with phytosome ( 2 g per day) or placebo, while topically applying once daily methylprednisolone aceponate $0.1 \%$ ointment on psoriasis plaques. Curcumin 
phytosome obtained a better effect on PASI compared to placebo. No significant reduction of IL-17 serum levels was observed between the groups, but IL-22 serum levels were lower in the curcumin treated group $(-11.8 \mathrm{pg} / \mathrm{mL}){ }^{246}$ Another study evaluated the effects of curcumin phytosomes in carrageenan-treated mice. Indomethacin, curcumin, or nano-phytosome of curcumin at $15 \mathrm{mg} / \mathrm{kg}$ were administered orally to animals for one week. The nano-phytosome treatment was more antioxidant than curcumin $(\mathrm{P}<0.05)$ in the case of SOD, CAT, GPx, and GR and had a higher latency time compared to curcumin in hot plate and tail-pinch tests. ${ }^{247}$

Three studies evaluated the topical effects of three different phytosomes in carrageenan-induced edema in Wistar rats. The Lawsone-containing phytosome complex (Lawsonia inermis L.) had a higher anti-inflammatory effect than plant extract gel at $4 \mathrm{~h}(\mathrm{P}<0.001) .{ }^{30}$ Escin $\beta$-sitosterol (ES) phytosome 5\% hydrogel showed significantly improved efficacy in antihyperalgesic activity compared to escin and ibuprofen 5\% gel. $^{248}$ A resveratrol phospholipid complex, topically applied with patches, reduced the swelling to $6.1 \%$ after $24 \mathrm{~h}$, a value significantly lower than control $(38.4 \%)$ and diclofenac sodium gel groups $(23.2 \%)(\mathrm{P}<0.05)$. Resveratrol phospholipid complex containing patches resulted in non-irritant effects in albino rabbits, with a skin irritation score (erythema and edema) of less than $1 .^{249}$ Silymarin in nanostructured lipid carriers (NLC) complex was topically applied in rats subjected to UVB irradiation $\left(0.115-0.23 \mathrm{~J} / \mathrm{cm}^{2}\right)$. SilymarinNLC gel application decreased the epidermal thickness and wrinkle score in UV exposed animals. ${ }^{250}$

\section{The Phytosomes Effect in Wound Healing}

A combination of Ginkgo biloba, $\alpha$-lipoic acid, and grape seed phytosome associated with advanced medications, was beneficial in the treatment of chronic diabetic ulcers in subjects with diabetic foot ulcers. ${ }^{251}$ Phytosomes containing Moringa oleifera aqueous leaf extract were found to be non-toxic in NHDF cells till $3.0 \mathrm{mg} / \mathrm{mL}$. The formulation at $1 \mathrm{mg} / \mathrm{mL}$ provided the shortest gap closure time $(94.8 \%$ at $24 \mathrm{~h})$ compared to the extract at the same concentration. Conversely, higher doses (1.25 and 1.50 $\mathrm{mg} / \mathrm{mL}$ ) did not reach statistically significant results, as well for lower doses. ${ }^{252}$ A second in vitro study of NHDF cells evaluated a combination of gold nanoparticle (AuNP) and Calendula officinalis in phytosomal systems. The formulations reduced the interruptions of cell monolayer by about $42.2 \%$ for Calendula phytosomes and $58.7 \%$ for AuNP-Calendula phytosomes $(\mathrm{p}<0.01)$. The combination did not show toxic effects up to $400 \mu \mathrm{g}$ / $\mathrm{mL}{ }^{33}$ A complex of sinigrin-phytosome displayed beneficial effects on wound healing with respect to sinigrin alone, in HaCaT cells. After $42 \mathrm{~h}$, the phytosome at 0.14 $\mathrm{mg} / \mathrm{mL}$ completely solved the wound, whereas pure sinigrin reached only $71 \%$, with negligible cytotoxicity towards cells. ${ }^{35}$

\section{Evidence of the Phytosomes Efficacy in Skin Cancer} Only two studies evaluated the potential effectiveness of phytosomes in fighting skin cancers. The first study showed a cytotoxic effect of the aforementioned sinigrinphytosome complex in A-375 melanoma cells. At 0.14 $\mathrm{mg} / \mathrm{mL}$, the complex inhibited by almost $74 \%$ the cell viability, more than $46 \%$ displayed by free sinigrin, but only minimal toxicity was observed in non-tumoral HaCaT cells. ${ }^{35}$ The second study considered the effect of silymarin in nanostructured lipid carriers (NLC) in vitro. Silymarin-NLC showed a higher inhibition $\left(\mathrm{IC}_{50}: 21 \mu \mathrm{g} /\right.$ $\mathrm{mL}$ ) in cell viability of the human melanoma cell line (SKMEL-2) in comparison to a non-specified phytosome commercial formulation $\left(\mathrm{IC}_{50}: 26 \mu \mathrm{g} / \mathrm{mL}\right) .^{250}$

\section{The Phytosomes Effect in Musculoskeletal System}

Pharmacological treatment of musculoskeletal dysfunctions is mostly based on non-steroidal anti-inflammatory drugs (NSAIDs) or analgesics; unfortunately, the therapy is often accompanied by several side effects. Among 16 studies regarding natural product-loaded phytosomes for treatment of musculoskeletal disorders, $62.5 \%$ were related to turmeric (Curcuma longa) extracts or curcumin, and $31.2 \%$ related to Indian Frankincense (Boswellia serrata) extracts.

One pilot study investigated the treatment of patients with osteopenia. Subjects with low bone density and no symptoms were treated for 24 weeks with the curcuminbased supplementation curcumin phytosome. The bone density of the heel, small finger, and upper jaw was assessed at 4, 12, and 24 weeks. A general improvement in bone density was observed in the group treated with 1 tablet/day containing $1000 \mathrm{mg}$ of curcumin phytosome, whereas no significant changes were observed in the control group. ${ }^{253}$ The same formulation, tested at the same dose either or not combined with other nutritional supplements and exercise, showed positive results in elderly subjects ( $>65$ years) characterized by loss of strength, contributing to improving strength and physical performance. ${ }^{254}$ 
The efficacy of curcumin phytosome ( $1 \mathrm{~g}$ every 12 hours for 5 and 10 days) was tested on rugby players with different osteo-muscular pain conditions due to physical overload or traumatic injuries. The group taking curcumin phytosome $(\mathrm{n}=25)$ was compared with the group treated with conventional analgesic drugs $(\mathrm{n}=25)$. Pain and functio laesa were evaluated at different time points. ${ }^{255}$ The analgesic effect of curcumin phytosome (2 $\mathrm{g}$, corresponding to $400 \mathrm{mg}$ curcumin) was demonstrated in patients with different chronic inflammatory diseases. ${ }^{256}$

Drobnic et al performed additional studies showing reduction of delayed onset muscle soreness following administration of phytosomal form of curcumin (1 g twice daily, for 4 days). ${ }^{257}$ These studies suggest that curcumin-loaded phytosome could represent a useful remedy to counteract pain and osteo-muscular dysfunctions after intense physical activity. Other interesting studies in humans include the beneficial effects of mentioned phytosome $(1 \mathrm{~g} / \mathrm{die})$ taken alone for 8 months ${ }^{258}$ or curcumin phytosome $(0.5 \mathrm{~g} / \mathrm{die})$ in combination with glucosamine $(0.5 \mathrm{~g} / \mathrm{die})$ for 4 months $^{259}$ in patients with osteoarthritis. Administration of curcumin phytosome for 100 days (two 50-day cycle) at the dose $1000 \mathrm{mg} / \mathrm{die}$ for the first 30 days or $500 \mathrm{mg}$ plus $300 \mathrm{mg} \alpha$-lipoic acid for the following 30 days of each cycle in patients with radiculopathy caused by spondyloarthritis or discopathy showed a reduction of pain rating. ${ }^{260}$ The efficacy of a curcumin-phosphatidylcholine complex in children with uveitis associated with juvenile idiopathic arthritis, plus the conventional pharmacological treatment with immunosuppressive drugs, was assessed as well. The therapy in association with curcumin phytosome improved mild chronic anterior chamber flare and reduced inflammatory processes. $^{261}$

The in vivo study by Farinacci et al demonstrated that curcumin-loaded phytosome possesses anti-inflammatory effects in mares and foals with chronic osteoarthritis or osteochondrosis through the downregulation of COX-2, $\mathrm{TNF} \alpha$, IL-1 $\beta$, and interleukin 1 receptor antagonist (IL1RN) in leukocytes, although the effect was found statistically significant for the last two parameters. ${ }^{262}$ Recently, the EFSA Panel on Dietetic Products, Nutrition, and Allergies (NDA) formulated an opinion on the beneficial effects of curcumin and the functioning of joints. Based on the data collected, the Panel concluded that the relationship between treatment with curcumin and efficacy in maintaining joint function cannot be claimed. ${ }^{263}$
Moreover, another phytosomal formulation containing only Boswellia serrata extract (BSE), named Boswellia phytosome, was clinically evaluated for the treatment of osteo-muscular pain in rugby players. The group took the supplement (500 mg/day of BSE) as co-adjuvant to standard therapy, whereas the control group followed only the standard therapy. Supplementation consisted of a single administration of $500 \mathrm{mg} /$ day of Boswellia phytosome (2 tablets of $250 \mathrm{mg}$ ) for 5 days, followed by 23 days administration of $250 \mathrm{mg} /$ day (1 tablet). Results by Visual Analog Scale for Pain (VAS Pain) and reduction of inflammatory biomarkers suggested that supplementation represents an effective therapy for the management of inflammation and pain, in addition to the conventional treatment. ${ }^{264}$ Boswellia phytosome $(250 \mathrm{mg} / \mathrm{die})$ showed efficacy in reducing ankle sprains of mild severity (grade II) due to sports trauma in healthy subjects; parameters were evaluated after 3 and 7 days of treatment. ${ }^{265}$ Boswellia phytosome efficacy in the treatment of musculoskeletal disorders has been recently reviewed. ${ }^{266}$

Another phytosomal formulation with Boswellia (200 $\mathrm{mg}$ ), the rhizome of Curcuma longa (100 mg), the resin of Commiphora wightii $(100 \mathrm{mg})$, and Valeriana officinalis extract $(25 \mathrm{mg}$ ) were tested in 24 patients with osteoarthritis for 4 weeks. The main outcomes were the control of symptoms and functional capacity. The formulation showed promising effects in the management of osteoarthritis. $^{267}$

A recent work investigated the effect of a phytosome (350 mg) loaded with Zingiber officinale $(37.5 \mathrm{mg}$ ) and Acmella oleracea $(7.5 \mathrm{mg})$ extracts against pain and inflammation in patients with moderate knee osteoarthritis. The study lasted 30 days. The formulation showed positive effects on physical activity and improvement of inflammatory biomarkers with no side effects. ${ }^{268}$ Non-loaded liposomes have been studied for their ability to improve osteoblast adiposity and mineralization. Several liposomal formulations were synthesized using phosphatidylcholine, cholesterol and derivatives, and glycerol-phosphoethanolamine, and the effect on osteoblast differentiation and inflammatory condition was assessed. The study showed that neutral lipids induced less adiposity and maintain higher osteoblast mineralization than cationic lipids. In 7F2 mouse osteoblasts, phosphatidylcholine inhibited inflammation suppressing gene expression of COX-2 and MMP-3 induced by IL-1 $\beta$, suggesting that this lipid is particularly relevant in the preparation of phytosomes against symptoms of bone diseases. ${ }^{269}$ 


\section{The Phytosomes Role in the Respiratory System Diseases \\ The Phytosomes in Asthma and Bronchitis}

A pilot study evaluated the effects of quercetin phytosome in addition to standard management (SM) in healthy subjects with mild-moderate asthmatic attacks and rhinitis. Subjects took 1 or 2 QFit tabs/day in association with $\mathrm{SM}$ or only this (control group). After 30 days quercetin phytosome + SM showed superior results compared with the control group, preventing and reducing daily and night symptoms, maintaining higher peak expiratory flow, and decreasing its variability, with a good safety profile. ${ }^{270}$

In a multicenter study, 32 asthmatic subjects were enrolled and received a combination of corticosteroids and beta-agonists, the standard management for patients with mild or severe persistent asthma. The subjects were randomized to receive Boswellia serrata phytosome $500 \mathrm{mg}$ /day or no additional treatment for 4 weeks. Patients in phytosome group needed a lower number of inhalations compared to patients who receive only the standard therapy. The treatment with phytosome was well accepted, only mild-moderate adverse events such as insomnia and nausea were registered. ${ }^{271}$

$\mathrm{Yu}$ et al designed and developed a novel phytosome to promote pulmonary bioavailability of naringenin. One of the main lipids occurring in pulmonary surfactant, dipalmitoylphosphatidylcholine (DPPC), was efficiently used to deliver naringenin. The pharmacodynamic of naringenin-loaded DPPC phytosomes for dry powder inhalation (NPDPIs - 10 $\mathrm{mg} / \mathrm{rat}$, containing about $3 \mathrm{mg}$ naringenin) was studied in rats with acute lung injury, and the relevant mechanisms of action were explored. These phytosomes have demonstrated protection against lung injury in rats when directly administered into the lungs. The data showed that NPDPIs alleviated pulmonary edemas with less fluid exudation and significantly down-regulated expression of cytokines, including COX-2 and ICAM-1. Moreover, naringenin and DPPC suppressed oxidative stress by upregulation of SOD activity in rats and the application of NPDPIs improved this effect. ${ }^{272}$

Singh et al have evaluated in vitro and in vivo a gingerol phytosome complexed with chitosan for treatment of respiratory disease. The sustained release of gingerol from the phytosome was demonstrated in vitro, as well as antioxidant and anti-inflammatory activities. Antimicrobial activity against the respiratory infective bacterial organisms was concentration dependent. The phytosome complex showed an important sustained-release profile and supported a better oral absorption of gingerol in a pharmacokinetic study in vivo. The pharmacodynamic parameters showed an effective prolonged antibacterial and considerable anti-inflammatory activity against bacteria responsible for respiratory infections, in both Grampositive and Gram-negative. ${ }^{273}$

\section{The Phytosomes Role in Lung Cancer}

Curcumin formulated with phosphatidylcholine was evaluated as an antitumor agent in mammary gland tumor cell line (ENU1564) which were injected into the mammary fat of athymic nude mice. The effect of the phytosome was compared with free curcumin. Both substances did not affect tumor volume, but curcumin phytosome significantly decreased lung metastasis and the expression of MMP-9, a protein associated with progression and tumor invasion, including breast cancer. ${ }^{274}$ Mao et al evaluated the biological activities of oral administration of grape seed phytosome in subjects participating in a lung cancer chemoprevention trial. Effects of phytosome on prostacyclin and 15-HETE eicosanoid pathways in human lung premalignant and malignant cells were determined. Results of this study support phytosome group as a chemo-preventive and anti-neoplastic agent against lung cancer. ${ }^{275}$ In another study, oral administration of grape seed phytosome to athymic nude mice (200, 300, and $400 \mathrm{mg} / \mathrm{kg} /$ day for the group, containing GSE 56, 84, $112 \mathrm{mg} /$ $\mathrm{kg} /$ day, respectively) down-regulated the oncomiRs miR-19a/ $\mathrm{b}$ and miR-17-92 cluster host gene (MIR17HG) expressions. This was correlated with the in vitro grape seed phytosome activity in lung neoplastic cells, observed in the same study. ${ }^{276}$ The maximum grape seed phytosome dose was well tolerated; at the end of treatment in bronchial biopsies was observed a significant decrease of $\mathrm{Ki}-67$ labeling index ( $-55 \%)$, as well as a substantial reduction of bronchial histopathology grading, and significant downregulation of the expressions of miR-19a, miR-19b, and miR-106b in serum. ${ }^{277}$

\section{The Phytosomes Efficacy in Metabolic Syndrome}

Metabolic syndrome (MS) is characterized by the presence of different metabolic dysfunctions including insulin resistance, type-2 diabetes, and obesity; the pathological condition is characterized by low-grade chronic inflammatory activity. ${ }^{278}$ In a randomized, double-blind, crossover study, Vigna et al investigated the efficacy of grape seed phytosome on lowdensity lipoprotein (LDL) oxidation in heavy smokers. Enrolled subjects were treated for 4 weeks with 2 capsules twice a day, each containing $75 \mathrm{mg}$ of a grape procyanidin extract, or the same amount of lactose used as placebo, and soy 
phosphatidylcholine (phytosome). Subjects experienced negligible modifications of total cholesterol, triglycerides, and high-density lipoprotein-cholesterol (HDL-C) or LDL during treatment. However, thiobarbituric acid reactive substances (TBARS) amount was decreased, thus making this formulation particularly interesting in diseases characterized by stress oxidative. ${ }^{279}$

Mazzolani et al found that curcumin phytosomal formulation, administered as tablets (500 mg twice daily, representing a daily intake of $200 \mathrm{mg}$ curcuminoids), showed improvement in visual acuity and optical coherence tomography retinal thickness in 11 patients with macular edema caused by diabetes. After 3 months of therapy, $84 \%$ showed improvement in visual activity and $16 \%$ stabilization, whereas no patients showed a reduction. Moreover, $92 \%$ of eyes considered in the open-label study showed a reduction of macular edema, and $8 \%$ stabilization, with no cases of increased pathology severity. ${ }^{280}$

The same curcumin formulation was administered with conventional therapy for 4 weeks at diabetic patients with microangiopathy and retinopathy. At the end of the treatment, patients showed a general improvement in microangiopathy. The amelioration of the veno-arteriolar response and the reduction of peripheral edema, which are indices of better microcirculation, were observed. At the retinal level, Steigerwalt and Snellen's scales showed improvement of retinal edema and visual acuity, respectively. ${ }^{281}$ In another study by Di Pierro et al, 44 participants received 30 days of treatment with the curcumin-based product $(800 \mathrm{mg} /$ die curcumin and 8 $\mathrm{mg} /$ die piperine complexed with $20 \%$ sunflower phospholipid) or just phosphatidylserine (400 mg/die). Treatment with curcumin-induced weight loss and ameliorated percentage reduction of fat and BMI, suggesting that curcumin-based formulations may positively improve weight loss in overweight patients. ${ }^{282}$ Recently, the same formulation $(800 \mathrm{mg}$ phytosomal curcumin containing $200 \mathrm{mg}$ curcumin, $480 \mathrm{mg}$ phosphatidylcholine, $120 \mathrm{mg}$ phosphatidylserine, and $8 \mathrm{mg}$ piperine), administered as two tablets/day, was assessed in 80 overweight subjects with fasting plasma glucose. The curcumin group showed a significant improvement in fasting plasma insulin and waist circumference. ${ }^{283}$

Several studies considered the effects of flavonoidscontaining phytosomes on MS parameters. The phytosome formulation of green tea catechins showed improved blood lipid profile, blood pressure, and weight loss in subjects with borderline MS factors after a 24-week intervention study. ${ }^{284}$ In another study, green tea phytosome $(150 \mathrm{mg} /$ dose) and $15 \mathrm{mg} /$ dose piperine were administered to obese women for three months to counteract weight regain after weight loss. Results of the study indicated that patients supplemented with the formulation maintained the bodyweight reduction previously achieved than those receiving placebo. ${ }^{285}$ These latest results confirm previous observations by Di Pierro et al in which the formulation, combined with low-calorie diet intake, increased weight loss, and reduced significantly BMI. ${ }^{286}$

Formulations including pure flavonoids quercetin or chrysin have been exploited at different levels on parameters related to MS. In particular, quercetin-loaded phytosome was orally administered at ovariectomized rats at 10 and $50 \mathrm{mg} / \mathrm{kg}$ for 4 weeks. Treatment decreased MDA and glucose levels, and improved lipid profile, with inhibition of pro-inflammatory mediators, such as TNF $\alpha .{ }^{131}$ Although these studies have not yet been confirmed in humans, another study showed that quercetin-loaded phytosome formulation administered with antidiabetics including metformin does not show significant drug interaction. ${ }^{287}$ Moreover, better solubility and oral absorption by healthy volunteers were assessed with the quercetin phytosome formulation concerning the unformulated flavonoid. ${ }^{288}$

The dihydroxyflavone chrysin has been studied unformulated or complexed in different formulations including phytosomes. Complexation of chrysin with phospholipids was shown to improve solubility and promote glucose uptake in $\mathrm{C} 2 \mathrm{C} 12$ cells, with nano-formulation CSP-1:3 (chrysin-loaded phytosome prepared with soy phosphatidylcholine at the molar ratio of 1:3) being able to stimulate peroxisome proliferator-activated receptor- $\gamma(\operatorname{PPAR} \gamma)$ and glucose transporter type 4 (GLUT4) genes. The same study demonstrated that phytosome preparation may critically influence bioavailability and consequently biological activity. ${ }^{289}$ Phytosome formulation containing silymarin improved bioavailability of flavonolignans ameliorating dyslipidemia associated with MS in hyper-triglyceridemic rats. After 4 weeks of treatment, $1 \%$ silymarin phytosome lowered plasma triglycerides and total cholesterol, while increased HDL cholesterol levels. ${ }^{290}$ The same group demonstrated that the pure compound silybin seems to be the main component responsible for the observed effects, since it was able to increase HDL and decrease glucose and insulin levels. ${ }^{291}$ In a randomized double-blind, placebo-controlled study, Mollace et al investigated the effects of a phytosome loaded with a standardized extract from bergamot (Citrus x bergamia), rich in naringin, in 60 patients with type 2 diabetes mellitus and hyperlipidemia. The authors described a significant reduction of fasting 
plasma glucose, triglycerides, and LDL cholesterol associated with increased HDL cholesterol levels. Better absorption was observed for phytosome than the corresponding unformulated bergamot extract. ${ }^{292}$

Other studies using phytosomes loaded with phytochemicals or plant extracts include improvement of the hypoglycemic effect of the alkaloid berberine ${ }^{29}$ and antidiabetic effects of a phytosome loaded with Momordica dioica, Momordica balsamina, and Citrullus colocynthis. ${ }^{293}$ Moreover, phytosome containing extracts from mulberry (Morus alba) and ginger (Zingiber officinale), administered orally to male Wistar rats (50-100-200 mg/kg for 21 days), showed antiinflammatory effects in adipose tissue; the formulation was able to decrease oxidative stress mediators and HDAC3, as well as increase PPAR $\gamma$ in the adipose tissue. ${ }^{294}$ Non-loaded phytosomal formulations were also studied for their beneficial effects against obesity; soy phytosomal thermogel was found to possess anti-obesity activity in albino rats, whereas slight effects were observed on lipid profile. ${ }^{32}$ Table 4 summarizes plant extracts and the relative range of doses used in clinical studies in different pathological conditions.

\section{Recent Patented Technologies on the Phytosomes}

The leading dealer of nutraceutical ingredients developed a patented process for Phytosomes in 2011. Several scientists from academic and industries have found out innovative processes and developed phytosome formulations. The different summarized patents on phytosomes and their related innovative technologies are presented in Table 5 .

\section{Marketed Phytosomal Products and Challenges to Commercialization}

Phytosomes are considered as efficient nanocarrier delivery systems. ${ }^{310}$ However, there is a long way from product development to a successful commercialization. Despite all advantages, a few final phytosomal products have been introduced into the markets. ${ }^{311}$ After designing an effective formulation, proofing of safety is a primary barrier for the entrance of phytosomes into the market. Phytosomes have biologically neutral structures, so their introduction into the human body is acceptable without any concern about their safety or immunological

Table 4 Plant Extracts and the Relative Range of Doses Used in Clinical Studies in Different Pathological Conditions

\begin{tabular}{|c|c|c|c|}
\hline Plant Species & Dose (mg/Day) & Application & References \\
\hline Boswellia serrata & $\begin{array}{l}200-4500 \\
250-500 \\
250-500 \\
500\end{array}$ & $\begin{array}{l}\text { Central and peripheral nervous system } \\
\text { Gastrointestinal system } \\
\text { Musculoskeletal system } \\
\text { Respiratory system }\end{array}$ & $\begin{array}{l}{[194,199]} \\
{[204-206]} \\
{[264,265]} \\
{[27 I]}\end{array}$ \\
\hline Camellia sinensis & $\begin{array}{l}150-300 \\
300\end{array}$ & $\begin{array}{l}\text { Metabolic syndrome } \\
\text { Genitourinary system }\end{array}$ & $\begin{array}{l}{[284,285]} \\
{[222]}\end{array}$ \\
\hline Citrus $\mathrm{x}$ bergamia & $500-1000$ & Metabolic syndrome & [292] \\
\hline Curcuma longa & $\begin{array}{c}2000 \\
900-2000 \\
2000 \\
500-2000 \\
800-1000 \\
800-1000\end{array}$ & $\begin{array}{l}\text { Gastrointestinal system } \\
\text { Genitourinary system } \\
\text { Integumentary system } \\
\text { Musculoskeletal system } \\
\text { Metabolic syndrome } \\
\text { Central and peripheral nervous system }\end{array}$ & $\begin{array}{l}{[20 I-203]} \\
{[236,237,242]} \\
{[246]} \\
{[253-257,259-26 I]} \\
{[280-283]} \\
{[189,190]}\end{array}$ \\
\hline Ginkgo biloba & $\begin{array}{l}360 \\
120\end{array}$ & $\begin{array}{l}\text { Cardiovascular system } \\
\text { Central and peripheral nervous system }\end{array}$ & $\begin{array}{l}{[175]} \\
{[191,193]}\end{array}$ \\
\hline Silybum marianum & $\begin{array}{c}2500-20,000 \\
188 \\
2800\end{array}$ & $\begin{array}{l}\text { Genitourinary system } \\
\text { Hepatoprotective effects } \\
\text { Genitourinary system }\end{array}$ & $\begin{array}{l}{[234,235]} \\
{[214]} \\
{[223]}\end{array}$ \\
\hline Vaccinium macrocarpon & 24 & Genitourinary system & [24I] \\
\hline Vitis vinifera & $\begin{array}{l}300-1200 \\
150 \\
300\end{array}$ & $\begin{array}{l}\text { Respiratory system } \\
\text { Metabolic syndrome } \\
\text { Immune system }\end{array}$ & $\begin{array}{l}{[275]} \\
{[279]} \\
{[244]}\end{array}$ \\
\hline
\end{tabular}


Table 5 Phytosomes Related Patents on the Developed Technologies

\begin{tabular}{|c|c|c|c|c|}
\hline Sr. No & Title & Novelty/Innovation & $\begin{array}{l}\text { Patent } \\
\text { No. (Year } \\
\text { of Grant) }\end{array}$ & References \\
\hline I & $\begin{array}{l}\text { Phospholipid complex of curcumin having } \\
\text { improved bioavailability }\end{array}$ & $\begin{array}{l}\text { Phospholipid complexes of curcumin provide a } \\
\text { higher systemic level of parent agent than } \\
\text { uncomplexed curcumin. }\end{array}$ & $\begin{array}{l}\text { WO2009/ } \\
\text { I0I55I } \\
(2009)\end{array}$ & [295] \\
\hline 2 & $\begin{array}{l}\text { Phospholipid complexes of olive fruits or leaves } \\
\text { extract having improved bioavailability }\end{array}$ & $\begin{array}{l}\text { Olive fruits/leaves extracts bioavailability enhanced } \\
\text { using phospholipids complexes }\end{array}$ & $\begin{array}{l}\text { EPI844785 } \\
\quad(2007)\end{array}$ & [296] \\
\hline 3 & $\begin{array}{l}\text { Compositions comprising Ginkgo biloba derivatives } \\
\text { for the treatment of asthmatic and allergic } \\
\text { conditions }\end{array}$ & $\begin{array}{c}\text { Compositions of the fraction gained from Ginkgo } \\
\text { biloba for the treatment of asthma and allergic } \\
\text { conditions }\end{array}$ & $\begin{array}{l}E P I 813280 \\
(2007)\end{array}$ & [297] \\
\hline 4 & $\begin{array}{l}\text { Treatment of skin, and wound repair, with thymosin } \\
\qquad \beta-4\end{array}$ & $\begin{array}{l}\text { The formulation developed containing Thymosin } \\
\qquad \beta 4 \text { for wound healing }\end{array}$ & $\begin{array}{l}\text { US/2007/ } \\
0015698 \\
(2007)\end{array}$ & [298] \\
\hline 5 & Oral compositions for the treatment of cellulite & $\begin{array}{l}\text { Oral and cosmetic pharmaceutical Formulation } \\
\text { containing Centella asiatica triterpenes, extracts of } \\
\text { Vitis vinifera, and Ginkgo biloba flavonoids in the free } \\
\text { or complexed form with phospholipids }\end{array}$ & $\begin{array}{l}\text { US769|422 } \\
\qquad(2007)\end{array}$ & [299] \\
\hline 6 & $\begin{array}{l}\text { Fatty acid monoesters of sorbityl furfural and } \\
\text { compositions for cosmetic and dermatological use }\end{array}$ & $\begin{array}{l}\text { The selected fatty acid monoesters of sorbityl } \\
\text { furfural are lipophilic agents for specific anti } \\
\text { hydroxyl radical activity }\end{array}$ & $\begin{array}{l}\text { EPI690862 } \\
(2006)\end{array}$ & [300] \\
\hline 7 & $\begin{array}{l}\text { Cosmetic and dermatological composition for the } \\
\text { treatment of aging or photodamaged skin }\end{array}$ & $\begin{array}{l}\text { The topical cosmetic or dermatological } \\
\text { preparation containing at least one collagen } \\
\text { synthesis-stimulating agent for anti-wrinkle } \\
\text { treatment }\end{array}$ & $\begin{array}{l}\text { EPI64004I } \\
(2006)\end{array}$ & [30I] \\
\hline 8 & Soluble isoflavone composition & $\begin{array}{l}\text { Isoflavone compositions enhanced the solubility, } \\
\text { texture characteristics, taste, and color of the } \\
\text { formulation }\end{array}$ & $\begin{array}{c}\text { WO/2004/ } \\
045541 \\
(2005)\end{array}$ & [302] \\
\hline 9 & $\begin{array}{l}\text { An anti-oxidant preparation based on plant } \\
\text { extracts for the treatment of circulation and } \\
\text { adiposity problems }\end{array}$ & $\begin{array}{l}\text { The formulation developed having the plant } \\
\text { extracts possessing the anti-oxidant activity for the } \\
\text { treatment of phlebitis, hemorrhoid, } \\
\text { arteriosclerosis, varicose vein, and elevated blood } \\
\text { pressure }\end{array}$ & $\begin{array}{l}\mathrm{EPI} 2 \mid 4084 \\
\quad(2004)\end{array}$ & [303] \\
\hline 10 & $\begin{array}{l}\text { Phospholipid complexes prepared from extracts } \\
\text { of Vitis vinifera as anti-atherosclerotic agents }\end{array}$ & $\begin{array}{l}\text { Vitis vinifera extract phospholipid complexes for the } \\
\text { prevention and treatment of atherosclerosis. }\end{array}$ & $\begin{array}{l}\text { US62972I8 } \\
\qquad(2001)\end{array}$ & [304] \\
\hline 11 & $\begin{array}{l}\text { Bilobalide phospholipid complexes, their } \\
\text { applications, and formulations containing them }\end{array}$ & $\begin{array}{l}\text { Complexes with synthetic or natural phospholipids } \\
\text { and bilobalide (a sesquiterpene found in the Ginkgo } \\
\text { biloba leaves) are revealed, as well as their } \\
\text { formulation and application in inflammatory } \\
\text { conditions and for the treatment of neuritic } \\
\text { processes. This compound exhibited higher } \\
\text { bioavailability than free bilobalide, hence it is } \\
\text { applicable for parenteral and topical administration. }\end{array}$ & $\begin{array}{l}\text { EP } 0441279 \\
\quad(1991)\end{array}$ & [305] \\
\hline
\end{tabular}


Table 5 (Continued).

\begin{tabular}{|c|c|c|c|c|}
\hline Sr. No & Title & Novelty/Innovation & $\begin{array}{l}\text { Patent } \\
\text { No. (Year } \\
\text { of Grant) }\end{array}$ & References \\
\hline 12 & $\begin{array}{l}\text { Complexes of neolignane derivatives with } \\
\text { phospholipids, the use thereof, and } \\
\text { pharmaceutical and cosmetic formulations } \\
\text { containing them }\end{array}$ & $\begin{array}{l}\text { Complexes of lipophilic extracts of Krameria or } \\
\text { Eupomatia plant genus and some neolignanes } \\
\text { isolated from the same extracts showed } \\
\text { antibacterial, antimycotic, and antiradical activities. } \\
\text { So it is a new active principle for the preparation of } \\
\text { cosmetics and medicaments, as well as a good } \\
\text { preservative in cosmetic preparations. }\end{array}$ & $\begin{array}{c}\text { EP } 0464297 \\
(1990)\end{array}$ & [306] \\
\hline 13 & $\begin{array}{l}\text { Complexes of saponins with phospholipids and } \\
\text { pharmaceutical and cosmetic compositions } \\
\text { containing them }\end{array}$ & $\begin{array}{l}\text { The better bioavailability of saponins complexes } \\
\text { with natural phospholipids suitable for cosmetic, } \\
\text { pharmaceutical, and dermatological utilities }\end{array}$ & $\begin{array}{c}\text { EP } 02837 \mid 3 \\
(1988)\end{array}$ & [307] \\
\hline 14 & $\begin{array}{l}\text { Complexes of flavanolignans with phospholipids, } \\
\text { preparation thereof, and associated } \\
\text { pharmaceutical compositions }\end{array}$ & $\begin{array}{l}\text { This innovation consists of preparation lipophilic } \\
\text { complexes of silidianin, silybin, and silicrist by non- } \\
\text { conventional methods. Compared to individual } \\
\text { flavanolignans, the resulted complex showed high } \\
\text { gastrointestinal uptake followed by higher plasma } \\
\text { levels. Because of this improved pharmacokinetic } \\
\text { activity, the compound is applicable in the } \\
\text { management of acute and chronic liver diseases. }\end{array}$ & $\begin{array}{c}\text { EP } 0209038 \\
(1988)\end{array}$ & [308] \\
\hline 15 & $\begin{array}{l}\text { Complex compounds of bioflavonoids with } \\
\text { phospholipids, their preparation and use, and } \\
\text { pharmaceutical and cosmetic compositions } \\
\text { containing them }\end{array}$ & $\begin{array}{l}\text { High lipophilia, improved bioavailability, and } \\
\text { therapeutic properties obtained with complex } \\
\text { compounds of flavonoids with phospholipids in } \\
\text { comparison to free flavonoids. }\end{array}$ & $\begin{array}{c}\text { EP } 0275005 \\
(1983)\end{array}$ & [309] \\
\hline
\end{tabular}

reactions. $^{312}$ However, regarding their nano size, some parameters such as bioaccumulation, biocompatibility, metabolism, and excretion should be determined before their marketing. ${ }^{313}$ Sou et al have successfully prepared a curcumin phytosome for intravenous application in rats, showed high accumulation in bone marrow and spleen tissues. $^{314}$ Another factor should be considered is the ability of phytosomes to merge with biological membranes and passively target normal cells. Hence, their actual biological effects should be determined in well-designed animal models as well as in clinical trial. ${ }^{312}$ In this regard, different studies showed the biological safety of phytosomes. $^{315}$ Further to this, after designing a phytosome, pharmacokinetic and pharmacodynamic parameters should be assessed in animals and humans to prove their superiority rather than pure phyto-constituents. Finding the best dosage form to increase the absorption and efficacy of final product is another step in the way of marketing. ${ }^{316}$ The other challenge is the production of phytosomes in a large scale. However, during scaling up, the characteristics of the product should be kept. This is related to the practicality of laboratory protocol for in the industrial setup. ${ }^{313}$ Although the manufacturing processes of many types of phytosomes are often simple, in regard to $\mathrm{pH}$ sensitive phytosomes, their low physicochemical stability makes their industrial production a challenge. ${ }^{312}$ Phytosomes like other pharmaceutical products also should have reproducibility and should be checked for their quality during time. ${ }^{313}$ Popularity is another factor in a successful commercialization of a product. Taken together, biocompatibility, low-priced and safety of natural products has grown preference of people for this type of therapies in the recent years. Moreover, commercialization of phytosomes is a rapid process due to simple manufacturing process and ease of promotion of phytosomal technology to industrial scale. ${ }^{317}$ The enhanced bioavailability of polar phytoconstituents, advantages, and biological activities of phytosome formulations was explored by several pharmaceutical industries. The marketed phytosomes, their active constituents, the name of the industries, and specific indications are mentioned in Table 6. 


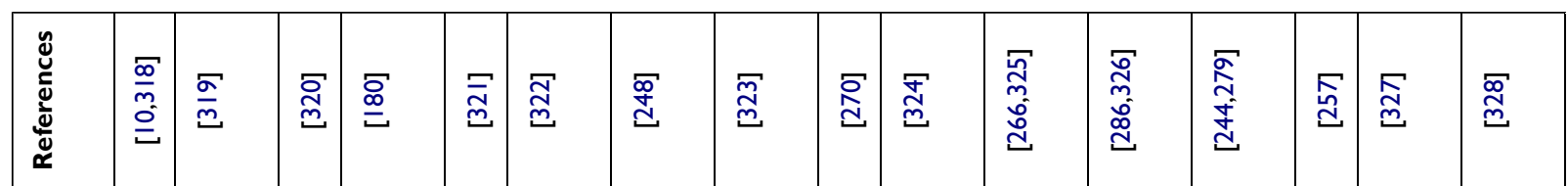

\begin{tabular}{|c|c|c|c|c|c|c|c|c|c|c|c|c|c|c|c|c|}
\hline 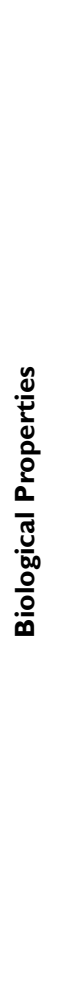 & 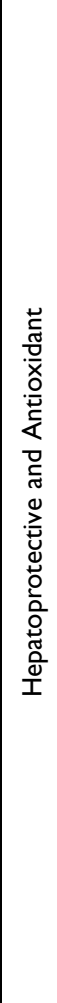 & 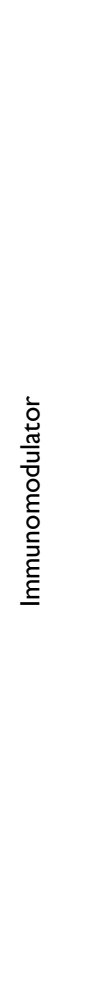 & 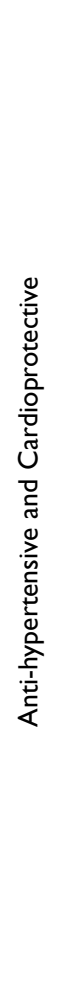 & 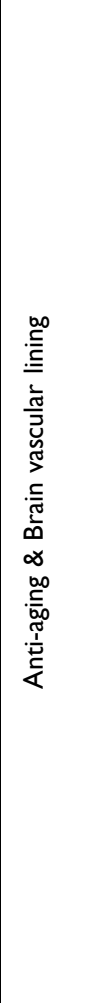 & 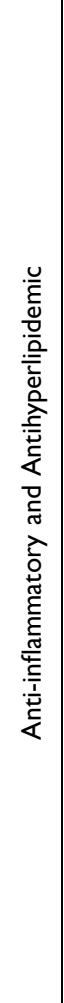 & 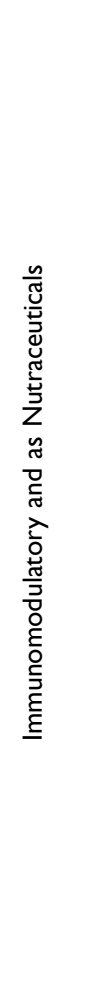 & 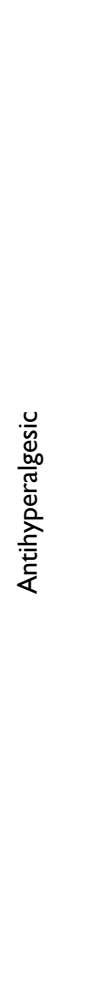 & 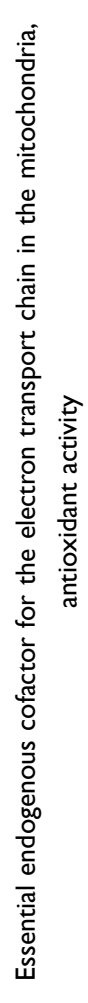 & 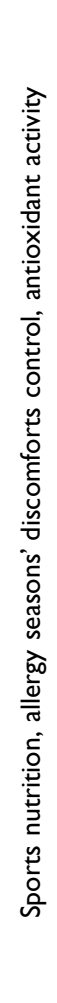 & 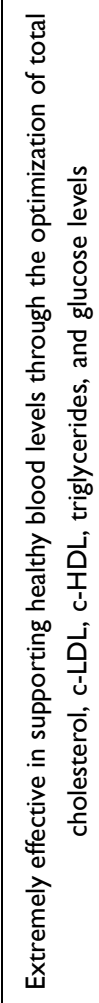 & 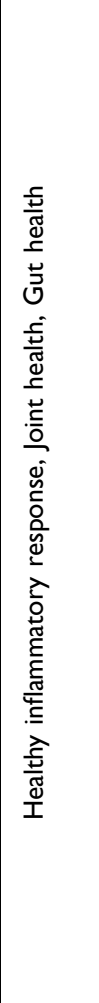 & 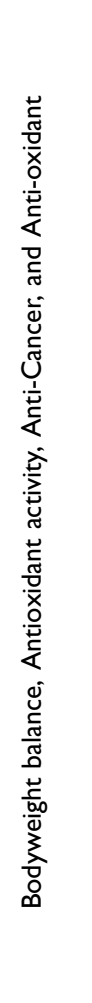 & 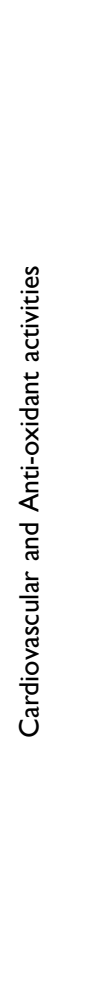 & 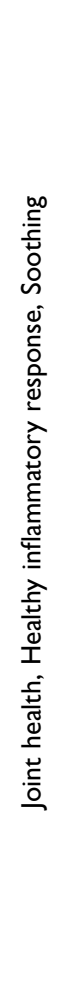 & 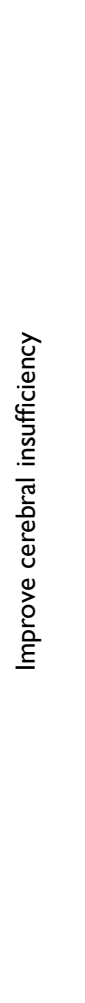 & 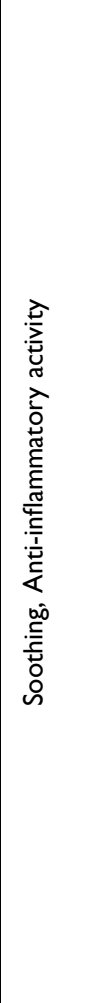 \\
\hline 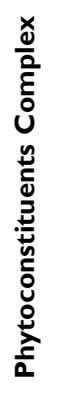 & 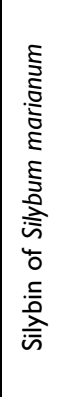 & 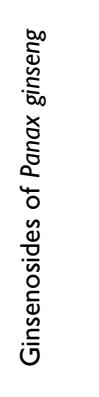 & 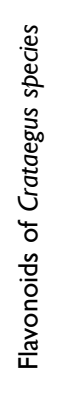 & 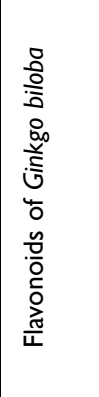 & 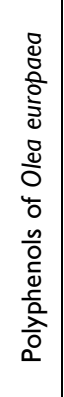 & 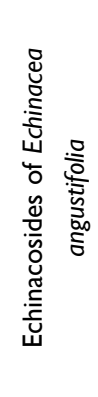 & 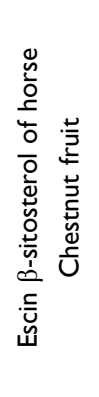 & $\begin{array}{l}\text { 응 } \\
\text { ن }\end{array}$ & 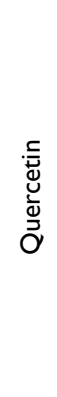 & 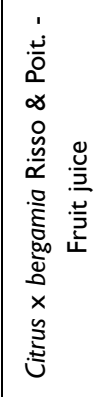 & 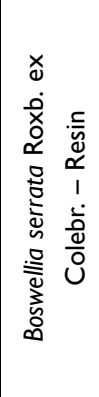 & 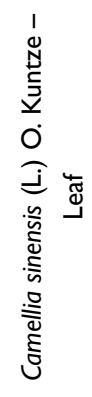 & 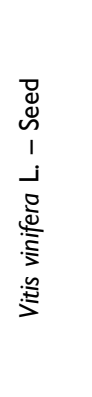 & 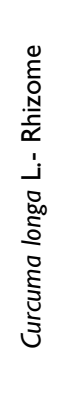 & 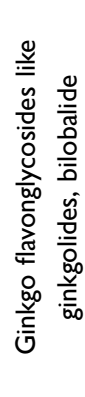 & 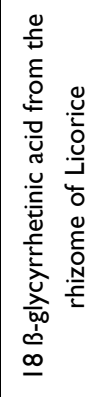 \\
\hline 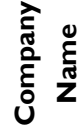 & 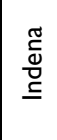 & 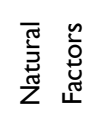 & $\begin{array}{l}\text { 苞 } \\
\underline{\underline{\underline{v}}}\end{array}$ & 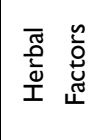 & 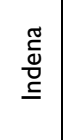 & $\begin{array}{l}\stackrel{\tilde{g}}{\tilde{g}} \\
\underline{\underline{\tilde{g}}}\end{array}$ & 1 & $\begin{array}{l}\tilde{\tilde{v}} \\
\underline{\underline{v}} \\
\underline{\underline{v}}\end{array}$ & 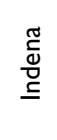 & 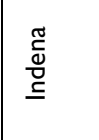 & 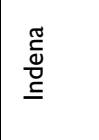 & 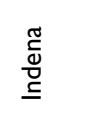 & 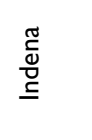 & 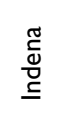 & $\begin{array}{l}\text { w } \\
\underline{\underline{\tilde{v}}} \\
\underline{\underline{v}}\end{array}$ & 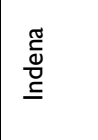 \\
\hline 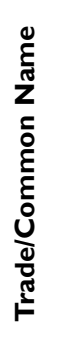 & 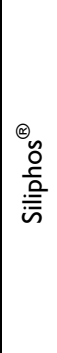 & 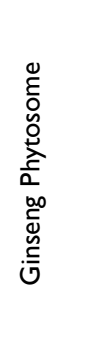 & 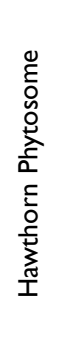 & 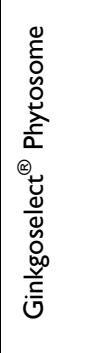 & 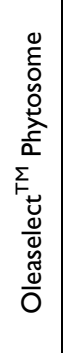 & 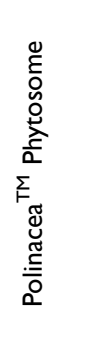 & 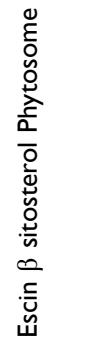 & 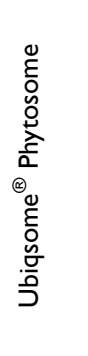 & 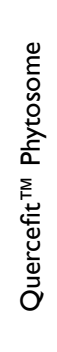 & 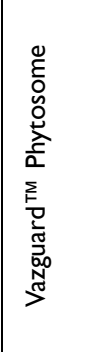 & 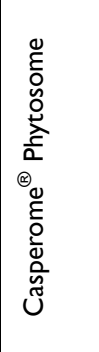 & 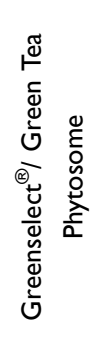 & 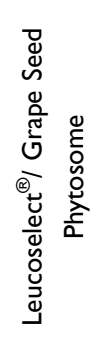 & 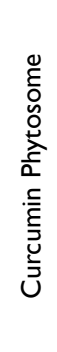 & 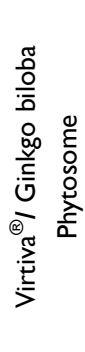 & 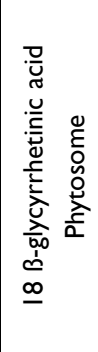 \\
\hline $\begin{array}{l}\dot{z} \\
\dot{n}\end{array}$ & - & $N$ & $m$ & $\sigma$ & in & 0 & r & $\infty$ & $\sigma$ & 으 & $=$ & $\simeq$ & $\underline{m}$ & \pm & $\underline{\underline{ }}$ & $\underline{\varrho}$ \\
\hline
\end{tabular}




\begin{tabular}{|c|c|c|c|c|c|c|c|c|c|c|c|c|c|}
\hline స్ల్ర & $\begin{array}{l}\overline{\tilde{m}} \\
\text {. }\end{array}$ & $\stackrel{\text { F }}{\Xi}$ & 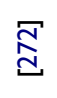 & $\overline{\widetilde{\Xi}}$ & $\overline{\bar{m}}$ & $\underset{\widetilde{m}}{\widetilde{n}}$ & $\underset{\infty}{\stackrel{\Xi}{U}}$ & 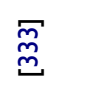 & ळ్ & 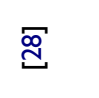 & 胥 & $\underset{\widetilde{d}}{\bar{c}}$ & $\stackrel{\sqrt[p]{0}}{\stackrel{D}{0}}$ \\
\hline 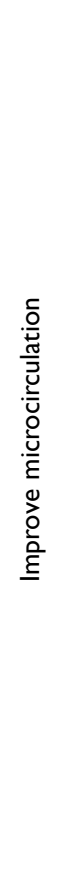 & 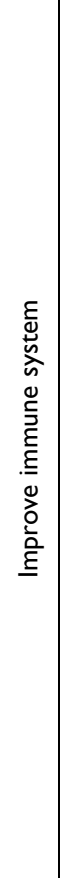 & 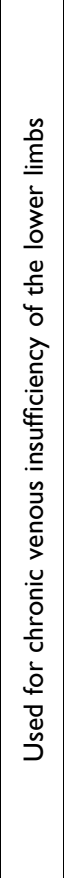 & 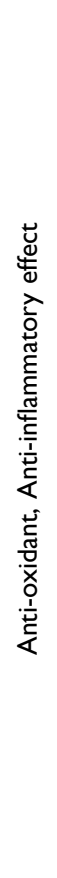 & 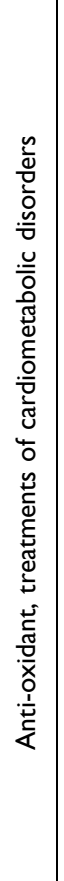 & 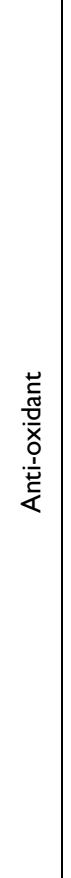 & 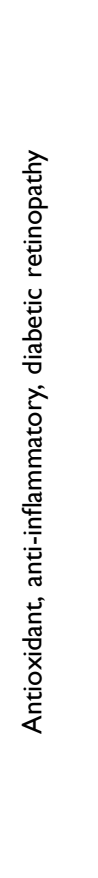 & 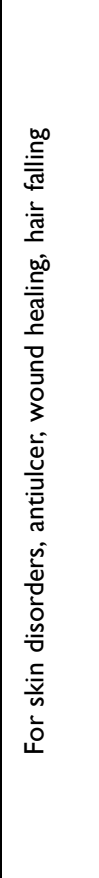 & 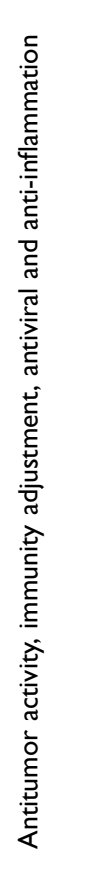 & 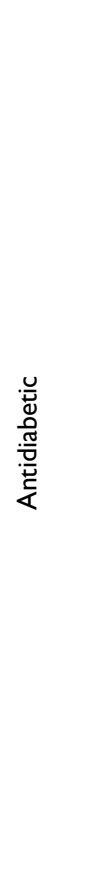 & 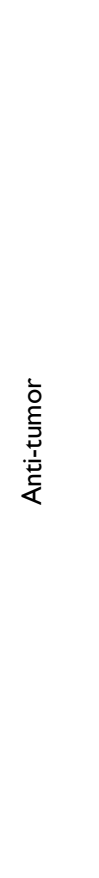 & 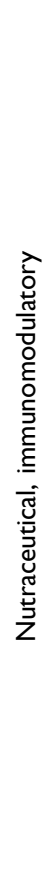 & 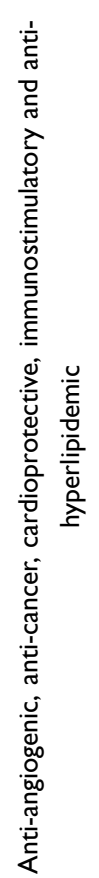 & 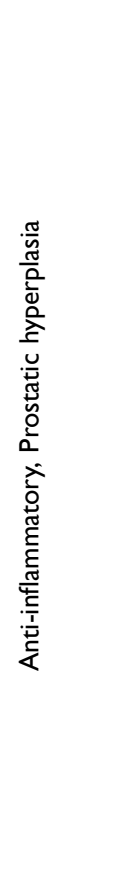 \\
\hline 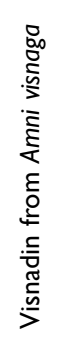 & 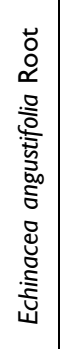 & 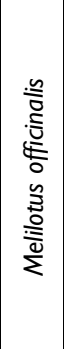 & 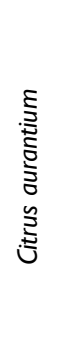 & 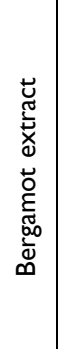 & 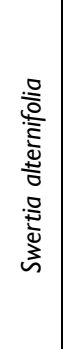 & 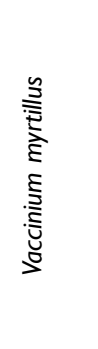 & 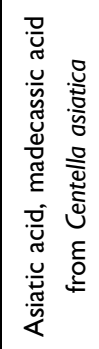 & 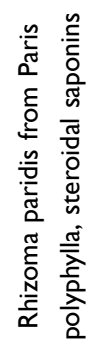 & 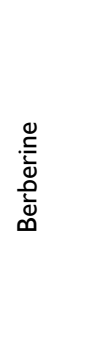 & 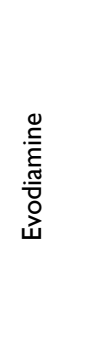 & 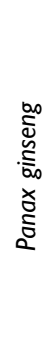 & 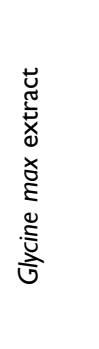 & 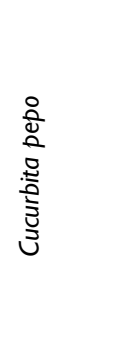 \\
\hline 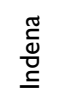 & 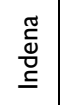 & 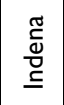 & . & 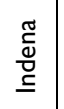 & ' & 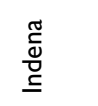 & 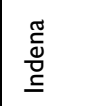 & 1 & 1 & 1 & $\begin{array}{l}\stackrel{\tilde{v}}{\mathbb{v}} \\
\underline{\underline{\underline{v}}}\end{array}$ & 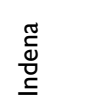 & 1 \\
\hline 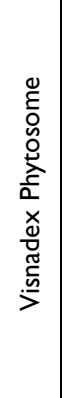 & 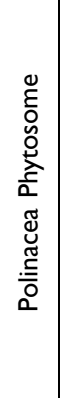 & 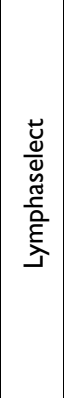 & 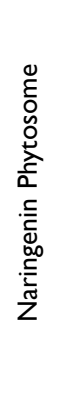 & 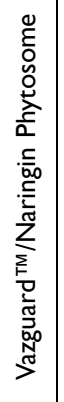 & 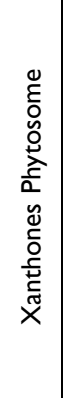 & 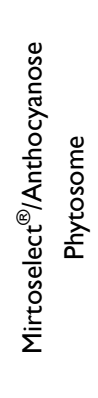 & 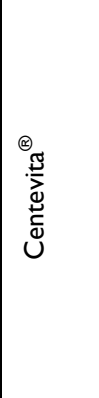 & 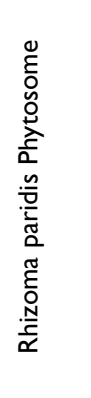 & 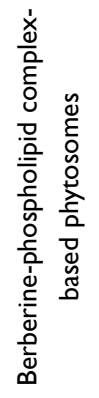 & 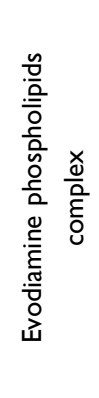 & 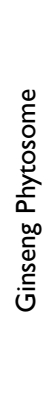 & 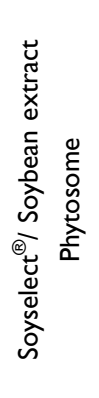 & 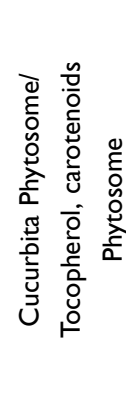 \\
\hline$\Sigma$ & $\underline{\infty}$ & $\underline{\underline{a}}$ & 오 & $\bar{\sim}$ & $\approx$ & $\ddot{\sim}$ & $\stackrel{ \pm}{\sim}$ & $\stackrel{\sim}{\sim}$ & $\stackrel{\sim}{\sim}$ & $\grave{\wedge}$ & $\stackrel{\infty}{\sim}$ & নे & ஓి \\
\hline
\end{tabular}




\section{Conclusion}

With the rise in the number of recently discovered phytochemicals, research will be brought up to date on their medical benefits in a biological environment. However, low solubility and sensitivity to degradation restrict the application of these compounds in food and pharmaceutical products. At this stage, gaining insight into vesicular drug delivery systems could help to improve these characteristics. Vesicles are shown to be very promising delivery systems for various beneficial phytochemicals at a cellular level, because of their remarkable entrapment capacity, biocompatibility, and safety. Among vesicular drug carriers, phytosomes form a complex between phytochemicals and phospholipids, which results in the improvement of absorption and bioavailability of bioactive molecules, together with improved overall compound stability. Liposomes, transfersomes, niosomes, and ethosomes are the most used nanocarriers for phytochemicals, which are characterized by different dimensions, release efficiency, or preferential target (eg, transfersomes and ethosomes for topical application). Similarly, nano-phytosomes are one of the newest lipid-based vesicles with lower dimensions, a development to further boost the transport of plant-based nutraceuticals. Each formulation must be adequately characterized to ensure a high safety profile and meet reproducibility standards, through analysis of physical measures that give information on both dynamics of release and formulation stability.

This review provides an overview of biological activities of phytosomes both for commercial and non-commercial products. The set of collected studies shows a general advantage in the use of these formulations to improve the bioavailability of bioactive phytochemicals, allowing a reduction in dosage, compared to non-formulated compound, or greater biological activity. All the considered human systems are characterized by the presence of at least a clinical study. However, the superiority of the formulation has only rarely been investigated in comparison with its components in clinical trials. Exceptions are studies on the bioavailability of quercetin ${ }^{288}$ and bergamot ${ }^{292}$ and a comparison between the anti-adhesive activity of urine of subjects following oral consumption of cranberry extract;241 in all the cases, the formulations gave higher values. Among the sources of phytochemicals Curcuma longa and Silybum marianum have collected most of the clinical evidence, with positive effects, except for silibinin in the management of prostate cancer, which yielded only marginal results. Overall, clinical studies are currently insufficient to draw conclusions on biological activities of individual preparations, but the overall evidence for these formulations is encouraging and invites the researchers to continue investigations in this field. In the future, clinical studies on standardized products that show superior efficacy compared to non-formulated components or extracts will be fundamental to drive attention to these technologies.

\section{Disclosure}

The authors report no conflicts of interest for this work.

\section{References}

1. Lu M, Qiu Q, Luo X, et al. Phyto-phospholipid complexes (phytosomes): a novel strategy to improve the bioavailability of active constituents. Asian J Pharm Sci. 2019;14(3):265-274. doi:10.1016/j.ajps.2018.05.011

2. Raeiszadeh M, Esmaeili-Tarzi M, Bahrampour-Juybari K, et al. Evaluation the effect of Myrtus communis L. extract on several underlying mechanisms involved in wound healing: an in vitro study. $\quad S$ Afr $j$ Bot. 2018;118:144-150. doi:10.1016/j. sajb.2018.07.006

3. Poursalehi HR, Fekri MS, Far FS, et al. Early and late preventive effect of Nigella sativa on the bleomycin-induced pulmonary fibrosis in rats: an experimental study. Avicenna $J$ Phytomed. 2018;8(3):263.

4. Oloumi MM, Vosough D, Derakhshanfar A, et al. The healing potential of Plantago lanceolata ointment on collagenase-induced tendinitis in burros (Equus asinus). J Equine Vet Sci. 2011;31 (8):470-474. doi:10.1016/j.jevs.2011.03.014

5. Samareh-Fekri M, Poursalehi HR, Mandegary A, et al. The effect of methanol extract of fennel on bleomycin-induced pulmonary fibrosis in rats. J Kerman Univ Medical Sci. 2015;22(5):470-483.

6. Bhise JJ, Bhusnure OG, Jagtap SR, Gholve SB, Wale RR. Phytosomes: a novel drug delivery for herbal extracts. J Drug Deliv Ther. 2019;9(3-s):924-930.

7. Teng $Z$, Yuan $\mathrm{C}$, Zhang $\mathrm{F}$, et al. Intestinal absorption and firstpass metabolism of polyphenol compounds in rat and their transport dynamics in Caco-2 cells. PLoS One. 2012;7(1):e29647. doi:10.1371/journal.pone. 0029647

8. Manach C, Scalbert A, Morand C, Rémésy C, Jiménez L. Polyphenols: food sources and bioavailability. Am J Clin Nutr. 2004;79(5):727-747.

9. Bhattacharya S. Phytosomes: the new technology for enhancement of bioavailability of botanicals and nutraceuticals. Int $J$ Health Res. 2009;2(3):225-232. doi:10.4314/ijhr.v2i3.47905

10. Kidd P, Head K. A review of the bioavailability and clinical efficacy of milk thistle phytosome: a silybin-phosphatidylcholine complex (Siliphos). Altern Med Rev. 2005;10(3):193-203.

11. Ting Y, Jiang Y, Ho C-T, et al. Common delivery systems for enhancing in vivo bioavailability and biological efficacy of nutraceuticals. $J$ Funct Foods. 2014;7:112-128. doi:10.1016/j. jff.2013.12.010

12. Lu W, Kelly AL, Miao S. Emulsion-based encapsulation and delivery systems for polyphenols. Trends Food Sci Technol. 2016;47:1-9. doi:10.1016/j.tifs.2015.10.015

13. Munin A, Edwards-Lévy F. Encapsulation of natural polyphenolic compounds; a review. Pharmaceutics. 2011;3(4):793-829. doi:10.3390/pharmaceutics3040793

14. He J, Luo L, Zeng L. Recent advances in research on preparation technologies and applications of tea polyphenol nanoparticles. Food Sci. 2011;32:317-322. 
15. Lambert JD, Sang S, Hong J, et al. Peracetylation as a means of enhancing in vitro bioactivity and bioavailability of epigallocatechin-3-gallate. Drug Metab Dispos. 2006;34(12):2111-2116. doi:10.1124/dmd.106.011460

16. Mulholland P, Ferry DR, Anderson D, et al. Pre-clinical and clinical study of QC12, a water-soluble, pro-drug of quercetin. Pro-Drug of Quercetin Ann Oncol. 2001;12(2):245-248. doi:10.1023/A:1008372017097

17. Nagar G. Phytosomes: a novel drug delivery for herbal extracts. Int J Pharm Sci Res. 2019. doi:10.13040/IJPSR.0975-8232.4(3).949-59

18. Franco P, Bombardelli E. Complex compounds of bioflavonoids with phospholipids, their preparation and uses and pharmaceutical and cosmetic compositions containing them. US Patent No-EPO. 1998:275005.

19. Dewan N, Dasgupta D, Pandit S, Ahmed P. Review on-herbosomes, A new arena for drug delivery. J Pharmacogn Phytochem. 2016;5(4):104.

20. Jain N, Gupta BP, Thakur N, et al. Phytosome: a novel drug delivery system for herbal medicine. Int J Pharm Sci Drug Res. 2010;2(4):224-228.

21. Cory H, Passarelli S, Szeto J, et al. The role of polyphenols in human health and food systems: a mini-review. Front Nutr. 2018;5:87. doi:10.3389/fnut.2018.00087

22. Kondratyuk TP, Pezzuto JM. Natural product polyphenols of relevance to human health. Pharm Biol. 2004;42(sup1):46-63. doi:10.3109/13880200490893519

23. Tsao R. Chemistry and biochemistry of dietary polyphenols. Nutrients. 2010;2(12):1231-1246. doi:10.3390/nu2121231

24. Bombardelli E, Curri SB, Della Loggia R, et al. Complexes Between Phospholipids and Vegetal Derivatives of Biological Interest. Fitoterpia. 1989;60:1-9.

25. Pu Y, Zhang X, Zhang Q, et al. 20(S)-protopanaxadiol phospholipid complex: process optimization, characterization, in vitro dissolution and molecular docking studies. Molecules. 2016;21 (10):1396. doi:10.3390/molecules21101396

26. Semalty A, Semalty M, Rawat MSM, et al. Supramolecular phospholipids-polyphenolics interactions: the PHYTOSOME ${ }^{\circledR}$ strategy to improve the bioavailability of phytochemicals. Fitoterapia. 2010;81(5):306-314. doi:10.1016/j.fitote.2009.11.001

27. Tripathy S, Patel DK, Barob L, et al. A review on phytosomes, their characterization, advancement \& potential for transdermal application. J Drug Deliv Ther. 2013;3(3):147-152. doi:10.22270/jddt.v3i3.508

28. Liu S, Tan QY, Wang H, Liao H, Zhang JQ. Preparation, characterization and in vitro anti-tumor activities of evodiamine phospholipids complex. Chin Pharm J. 2012;7:11

29. Yu F, Li Y, Chen Q, et al. Monodisperse microparticles loaded with the self-assembled berberine-phospholipid complex-based phytosomes for improving oral bioavailability and enhancing hypoglycemic efficiency. Eur $J$ Pharm Biopharm. 2016;103:136-148. doi:10.1016/j.ejpb.2016.03.019

30. Singh RP, Narke R. Preparation and evaluation of phytosome of lawsone. Int J Pharm Sci Res. 2015;6(12):5217.

31. Karole S, Gupta GKGS. Preparation and evaluation of phytosomes containing ethanolic extract of leaves of bombax ceiba for hepatoprotective activity. Evaluation. 2019;6(2):1.5.

32. El-Menshawe SF, Ali AA, Rabeh MA, Khalil NM. Nanosized soy phytosome-based thermogel as topical anti-obesity formulation: an approach for acceptable level of evidence of an effective novel herbal weight loss product. Int J Nanomedicine. 2018;13:307. doi:10.2147/IJN.S153429

33. Demir B, Barlas FB, Guler E, et al. Gold nanoparticle loaded phytosomal systems: synthesis, characterization and in vitro investigations. RSC Adv. 2014;4(65):34687-34695. doi:10.1039/ C4RA05108D
34. He N, Zhang L, Zhu F, Rui K, Yuan MQ, Qin H. Formulation of self-nanoemulsifying drug delivery systems for insulin-soybean lecithin complex. West China J Pharm Sci. 2010;25(4):396-399.

35. Mazumder A, Dwivedi A, Du Preez JL, et al. In vitro wound healing and cytotoxic effects of sinigrin-phytosome complex. Int J Pharm. 2016;498(1-2):283-293. doi:10.1016/j.ijpharm.2015.12.027

36. Telange DR, Patil AT, Pethe AM, Tatode AA, Anand S, Dave VS. Kaempferol-phospholipid complex: formulation, and evaluation of improved solubility, in vivo bioavailability, and antioxidant potential of kaempferol. J Excip Food Chem. 2016;7(4):1174.

37. Singh A, Saharan VA, Singh M, Bhandari A. Phytosome: drug delivery system for polyphenolic phytoconstituents. Iran J Pharm Res. 2011;7(4):209-219.

38. Khan J, Alexander A, Saraf S, et al. Recent advances and future prospects of phyto-phospholipid complexation technique for improving pharmacokinetic profile of plant actives. J Control Release. 2013;168(1):50-60. doi:10.1016/j.jconrel.2013.02.025

39. Shakeri A, Sahebkar A. Opinion paper: phytosome: a fatty solution for efficient formulation of phytopharmaceuticals. Recent Pat Drug Deliv Formul. 2016;10(1):7-10. doi:10.2174/1872211309666150813152305

40. Patel J, Patel R, Khambholja K, Patel N. An overview of phytosomes as an advanced herbal drug delivery system. Asian $J$ Pharm Sci. 2009;4(6):363-371.

41. Sikarwar MS, Sharma S, Jain AK, et al. Preparation, characterization and evaluation of marsupsin-phospholipid complex. Aaps Pharmscitech. 2008;9(1):129-137. doi:10.1208/s12249-007-9020-x

42. Das MK, Kalita B. Design and evaluation of phyto-phospholipid complexes (phytosomes) of rutin for transdermal application. $J$ Appl Pharm Sci. 2014;4(10):51-57. doi:10.7324/JAPS.2014.401010

43. Keerthi B, Pingali PS, Srinivas P. Formulation and evaluation of capsules of ashwagandha phytosomes. Int J Pharm Sci Rev Res. 2014;29(2):138-142.

44. Baishya R, Boruah JL, Bordoloi MJ, Kumar D, Kalita P. Novel Drug Delivery System in Phytochemicals: Modern Era of Ancient Science, in Herbal Medicine in India. Springer; 2020:175-189.

45. Trohopoulos P, Christensen JB, Torres-cebada T, et al. Nanosystems for therapy and/or diagnosis and/or therapy monitoring and/or theranostics of disease. Google Patents. 2019.

46. Lagoa R, Silva J, Rodrigues JR, et al. Advances in phytochemical delivery systems for improved anticancer activity. Biotechnol Adv. 2020;38:107382. doi:10.1016/j.biotechadv.2019.04.004

47. Supraja B, Mulangi S. An updated review on pharmacosomes, a vesicular drug delivery system. J Drug Deliv Ther. 2019;9(1s):393-402. doi:10.22270/jddt.v9i1-s.2234

48. Ma H, Guo D, Fan Y, et al. Paeonol-loaded ethosomes as transdermal delivery carriers: design, preparation and evaluation. Molecules. 2018;23(7):1756. doi:10.3390/molecules23071756

49. Fatima Grace X, Suganya K, Shanmuganathan S. Development of Terminalia chebula loaded ethosomal gel for transdermal drug delivery. Asian J Pharm Clin Res. 2018;11(12):380-383.

50. Thapa B, Pepic I, Vanic Z, Basnet P, Skalko-Basnet N. Topical delivery system for phytochemicals: capsaicin and capsicum tincture. J Pharm Drug Dev. 2013;1(2):1-7.

51. Lu K, Xie S, Han S, et al. Preparation of a nano emodin transfersome and study on its anti-obesity mechanism in adipose tissue of dietinduced obese rats. J Transl Med. 2014;12(1):72. doi:10.1186/14795876-12-72

52. Avadhani KS, Manikkath J, Tiwari M, et al. Skin delivery of epigallocatechin-3-gallate (EGCG) and hyaluronic acid loaded nano-transfersomes for antioxidant and anti-aging effects in UV radiation induced skin damage. Drug Deliv. 2017;24(1):61-74. doi:10.1080/10717544.2016.1228718

53. Jangdey MS, Gupta A, Saraf S, et al. Development and optimization of apigenin-loaded transfersomal system for skin cancer delivery: in vitro evaluation. Artif Cells, Nanomed Biotechnol. 2017;45(7):1452-1462. doi:10.1080/21691401.2016.1247850 
54. Nasri S, Ebrahimi-Hosseinzadeh B, Rahaie $M$, et al. Thymoquinone-loaded ethosome with breast cancer potential: optimization, in vitro and biological assessment. $J$ Nanostructure Chem. 2020;10(1):19-31. doi:10.1007/s40097019-00325-w

55. Nangare S, Dhananjay B, Mali R, et al. Development of novel freeze-dried mulberry leaves extract-based transfersomal gel. Turk J Pharm Sci. 2019. doi:10.4274/tjps.98624

56. Abd-Elghany AA, Mohamad EA. Ex-vivo transdermal delivery of annona squamosa entrapped in niosomes by electroporation. $J$ Radiat Res Appl Sci. 2020;13(1):164-173. doi:10.1080/ 16878507.2020.1719329

57. Raafat KM, El-Zahaby SA. Niosomes of active fumaria officinalis phytochemicals: antidiabetic, antineuropathic, anti-inflammatory, and possible mechanisms of action. Chin Med. 2020;15 (1):1-22. doi:10.1186/s13020-020-00321-1

58. Barani M, Mirzaei M, Torkzadeh-Mahani M, et al. Lawsoneloaded niosome and its antitumor activity in MCF-7 breast cancer cell line: a nano-herbal treatment for cancer. DARU J Pharm Sci. 2018;26(1):11-17. doi:10.1007/s40199-018-0207-3

59. Barani M, Mirzaei M, Torkzadeh-Mahani M, et al. Evaluation of Carum-loaded niosomes on breast cancer cells: physicochemical properties, in vitro cytotoxicity, flow cytometric, DNA fragmentation and cell migration assay. Sci Rep. 2019;9(1):1-10. doi:10.1038/s41598-019-43755-w

60. Ogbeba J. Phytochemical and antibacterial property of finger millet (Eleusine coracana) on some selected clinical bacteria. Access Microbiol. 2019;1(1A). doi:10.1099/acmi.ac2019. po0037

61. Chen M-H, Chiang B-H. Modification of curcumin-loaded liposome with edible compounds to enhance ability of crossing blood brain barrier. Colloids Surf a Physicochem Eng Asp. 2020;599:124862. doi:10.1016/j.colsurfa.2020.124862

62. Lee C, Na K. Anthocyanin-loaded liposomes prepared by the $\mathrm{pH}-$ gradient loading method to enhance the anthocyanin stability, antioxidation effect and skin permeability. Macromol Res. 2019;28:1-9.

63. Shariare MH, Rahman M, Lubna SR, et al. Liposomal drug delivery of Aphanamixis polystachya leaf extracts and its neurobehavioral activity in mice model. Sci Rep. 2020;10(1):1-16. doi:10.1038/s41598-020-63894-9

64. Rai S, Pandey V, Rai G. Transfersomes as versatile and flexible nano-vesicular carriers in skin cancer therapy: the state of the art. Nano Rev Exp. 2017;8(1):1325708. doi:10.1080/20022727. 2017.1325708

65. Nematollahi MH, Torkzadeh-Mahanai M, Pardakhty A, et al. Ternary complex of plasmid DNA with NLS-Mu-Mu protein and cationic niosome for biocompatible and efficient gene delivery: a comparative study with protamine and lipofectamine. Artif Cells, Nanomed Biotechnol. 2018;46(8):1781-1791.

66. Harandi H, Majd A, Falahati-pour S, et al. Anti-cancer effects of hydro-alcoholic extract of pericarp of pistachio fruits. Asian Pac J Trop Biomed. 2018;8(12):598. doi:10.4103/22211691.248097

67. Chauhan BP. Hybrid Nanomaterials: Synthesis, Characterization, and Applications. John Wiley \& Sons; 2011.

68. Lian T, Ho RJY. Trends and developments in liposome drug delivery systems. J Pharm Sci. 2001;90(6):667-680. doi:10.1 002/jps. 1023

69. Sharma A, Sharma US. Liposomes in drug delivery: progress and limitations. Int J Pharm. 1997;154(2):123-140. doi:10.1016/ S0378-5173(97)00135-X

70. Daraee H, Etemadi A, Kouhi M, et al. Application of liposomes in medicine and drug delivery. Artif Cells, Nanomed Biotechnol. 2016;44(1):381-391. doi:10.3109/21691401.2014.953633
71. Eroğlu İ, Ibrahim M. Liposome-ligand conjugates: a review on the current state of art. J Drug Target. 2020;28(3):225-244. doi:10.1080/1061186X.2019.1648479

72. Li T, Cipolla D, Rades T, et al. Drug nanocrystallisation within liposomes. J Control Release. 2018;288:96-110. doi:10.1016/j. jconrel.2018.09.001

73. Mathiyazhakan M, Wiraja C, Xu C. A concise review of gold nanoparticles-based photo-responsive liposomes for controlled drug delivery. Nanomicro Lett. 2018;10(1):10. doi:10.1007/ s40820-017-0166-0

74. Kaddah S, Khreich N, Kaddah F, et al. Cholesterol modulates the liposome membrane fluidity and permeability for a hydrophilic molecule. Food Chem Toxicol. 2018;113:40-48. doi:10.1016/j. fct.2018.01.017

75. Rudokas M, Najlah M, Alhnan MA, et al. Liposome delivery systems for inhalation: a critical review highlighting formulation issues and anticancer applications. Med Princ Pract. 2016;25 (Suppl. 2):60-72. doi:10.1159/000445116

76. Ohigashi H, Hashimoto D, Takahashi S, et al. Ocular instillation of vitamin A-coupled liposomes containing HSP47 siRNA ameliorates dry eye syndrome in chronic graft-versus-host disease. Biol Blood Marrow Transplant. 2019;25(3):S167. doi:10.1016/j. bbmt.2018.12.469

77. Gabizon AA, Tahover E, Golan T, et al. Pharmacokinetics of mitomycin-c lipidic prodrug entrapped in liposomes and clinical correlations in metastatic colorectal cancer patients. Invest New Drugs. 2020;38:1-10.

78. La-beck NM, Liu X, Shmeeda H, Shudde C, Gabizon AA. Repurposing amino-bisphosphonates by liposome formulation for a new role in cancer treatment. Semin Cancer Biol. 2021;68:175-185. doi:10.1016/j. semcancer.2019.12.001

79. Moles E, Kavallaris M, Fernàndez-Busquets X. Modeling the distribution of diprotic basic drugs in liposomal systems: perspectives on malaria nanotherapy. Front Pharmacol. 2019;10:1064. doi:10.3389/fphar.2019.01064

80. Asleh M, Abu Quider A, Ben-Harosh M, Fruchtman Y, Beck G, Kapelushnik JB. PEGylated liposomal doxorubicin in the treatment of relapsed osteosarcoma. Clin Oncol. 2019;4:1646.

81. Gregoriadis G, Zadi B, Jayasekera PN. Method of forming liposomes. Google Patents. 2017.

82. Zhang H. Thin-film hydration followed by extrusion method for liposome preparation. Methods Mol Biol. 2017;1522:17-22. doi:10.1007/978-1-4939-6591-5 2.

83. Amoabediny G, Haghiralsadat F, Naderinezhad S, et al. Overview of preparation methods of polymeric and lipid-based (niosome, solid lipid, liposome) nanoparticles: a comprehensive review. Int J Polym Mater Polym Biomater. 2018;67(6):383-400. doi:10.1080/00914037.2017.1332623

84. Akhlaghi SP, Ribeiro IR, Boyd BJ, et al. Impact of preparation method and variables on the internal structure, morphology, and presence of liposomes in phytantriol-Pluronic ${ }^{\circledR}$ F127 cubosomes. Colloids Surf B Biointerfaces. 2016;145:845-853. doi:10.1016/j. colsurfb.2016.05.091

85. Maclachlan I, Jeffs L, Palmer LR, Giesbrecht C; Inventors. Liposomal apparatus and manufacturing methods. Google Patents. 2016.

86. Lamichhane N, Udayakumar T, D'Souza W, et al. Liposomes: clinical applications and potential for image-guided drug delivery. Molecules. 2018;23(2):288. doi:10.3390/molecules23020288

87. van der Geest T, Laverman P, Metselaar JM, et al. Radionuclide imaging of liposomal drug delivery. Expert Opin Drug Deliv. 2016;13(9):1231-1242. doi:10.1080/17425247.2016.1205584

88. Sercombe L, Veerati T, Moheimani F, et al. Advances and challenges of liposome assisted drug delivery. Front Pharmacol. 2015;6:286. doi:10.3389/fphar.2015.00286 
89. Karpuz M, Gunay MS, Ozer AY. Liposomes and Phytosomes for Phytoconstituents, in Advances and Avenues in the Development of Novel Carriers for Bioactives and Biological Agents. Elsevier; 2020:525-553.

90. Gnananath K, Nataraj KS, Rao BG. Phospholipid complex technique for superior bioavailability of phytoconstituents. $A d v$ Pharm Bull. 2017;7(1):35. doi:10.15171/apb.2017.005

91. Le NTT, Pham LP, Nguyen DH, et al. Liposome-based nanocarrier system for phytoconstituents. In: Gupta M, Chauhan DN, Sharma V, Chauhan NS, editors. Novel Drug Delivery Systems for Phytoconstituents. 1st edition. Boca Raton: CRC Press; 2019;45-69.

92. Singh AK, Singh A. Phyto-phospholipid complexes: a potential novel carrier system for improving bioavailability of phytoconstituents. Res J Pharm Technol. 2020;13(2):1059-1066. doi:10.5958/0974-360X.2020.00195.X

93. Gautam M, Thapa RK, Gupta B, et al. Phytosterol-loaded CD44 receptor-targeted PEGylated nano-hybrid phyto-liposomes for synergistic chemotherapy. Expert Opin Drug Deliv. 2020;17 (3):423-434. doi:10.1080/17425247.2020.1727442

94. Rafiee Z, Barzegar M, Sahari MA, et al. Nanoliposomal carriers for improvement the bioavailability of high - valued phenolic compounds of pistachio green hull extract. Food Chem. 2017;220:115-122. doi:10.1016/j.foodchem.2016.09.207

95. Shafaei A, Saeed MAA, Aisha AFA, et al. Pharmacokinetics and bioavailability of orthosiphon stamineus ethanolic extract and its-nano liposomes in Sprague-Dawley rats. Int J Pharm Pharm Sci. 2016;9(1):199-206. doi:10.22159/ ijpps.2017v9i1.12407

96. Sinisgalli C, Faraone I, Vassallo A, et al. Phytochemical profile of Capsicum annuum L. cv senise, incorporation into liposomes, and evaluation of cellular antioxidant activity. Antioxidants. 2020;9 (5):428. doi:10.3390/antiox 9050428

97. Matos M, Pando D, Gutiérrez G. Nanoencapsulation of Food Ingredients by Niosomes, in Lipid-Based Nanostructures for Food Encapsulation Purposes. Elsevier; 2019:447-481.

98. Muzzalupo R, Mazzotta E. Do Niosomes Have a Place in the Field of Drug Delivery? Taylor \& Francis; 2019.

99. Bartelds R, Nematollahi MH, Pols T, et al. Niosomes, an alternative for liposomal delivery. PLoS One. 2018;13(4):e0194179. doi:10.1371/journal.pone.0194179

100. Elkordy AA, Chaw CS, Yeo LK. Effects of preparation methods on the characteristics of niosomes. Br J Pharm. 2019;4(1). doi:10.5920/bjpharm.616

101. Sbrini G, Brivio P, Sangiovanni E, et al. Chronic treatment with a phytosomal preparation containing Centella asiatica L. and Curcuma longa $\mathrm{L}$. affects local protein synthesis by modulating the BDNF-mTOR-S6 pathway. Biomedicines. 2020;8(12):544. doi:10.3390/biomedicines8120544

102. Kumar S, Kaur D. Niosome as an innovative drug delivery system. Central Asian J Med Nat Sci. 2020;1(1):1-15.

103. Barani M, Mirzaei M, Torkzadeh-Mahani M, et al. A new formulation of hydrophobin-coated niosome as a drug carrier to cancer cells. Mater Sci Eng C. 2020;113:110975. doi:10.1016/j. msec.2020.110975

104. Nematollahi MH, Pardakhty A, Torkzadeh-Mahanai M, et al. Changes in physical and chemical properties of niosome membrane induced by cholesterol: a promising approach for niosome bilayer intervention. $R S C \quad A d v$. 2017;7(78):49463-49472. doi:10.1039/C7RA07834J

105. Rezvani M, Hesari J, Peighambardoust SH, et al. Potential application of nanovesicles (niosomes and liposomes) for fortification of functional beverages with isoleucine-proline-proline: a comparative study with central composite design approach. Food Chem. 2019;293:368-377. doi:10.1016/j.foodchem.2019.05.015
106. Barde LG, Dighe NS. A review on niosomes: as a vesicular drug delivery system. Stud Indian Place Names. 2020;40 (70):281-288.

107. Hajizadeh MR, Parvaz N, Barani M, et al. Diosgenin-loaded niosome as an effective phytochemical nanocarrier: physicochemical characterization, loading efficiency, and cytotoxicity assay. DARU J Pharm Sci. 2019;27(1):329-339. doi:10.1007/s40199019-00277-0

108. Raeiszadeh M, Pardakhty A, Sharififar F, et al. Development, physicochemical characterization, and antimicrobial evaluation of niosomal myrtle essential oil. Res Pharm Sci. 2018;13 (3):250. doi:10.4103/1735-5362.228955

109. Raeiszadeh M, Pardakhty A, Sharififar F, Mehrabani M. Phytoniosome: a novel drug delivery for myrtle extract. Iran $J$ Pharm Res. 2018;17(3):804.

110. Rameshk M, Sharififar F, Mehrabani M, et al. Proliferation and in vitro wound healing effects of the microniosomes containing Narcissus tazetta L. bulb extract on primary human fibroblasts (HDFs). DARU J Pharm Sci. 2018;26(1):31-42. doi:10.1007/ s40199-018-0211-7

111. Hajizadeh MR, Maleki H, Barani M, et al. In vitro cytotoxicity assay of D-limonene niosomes: an efficient nano-carrier for enhancing solubility of plant-extracted agents. Res Pharm Sci. 2019;14(5):448. doi:10.4103/1735-5362.268206

112. Un RN, Barlas FB, Yavuz M, et al. Phyto-niosomes: in vitro assessment of the novel nanovesicles containing marigold extract. Int J Polym Mater Polym Biomater. 2015;64(17):927-937. doi:10.1080/00914037.2015.1030663

113. Ersoy E, Eroglu Ozkan E, Boga M, et al. Anti-aging potential and anti-tyrosinase activity of three Hypericum species with focus on phytochemical composition by LC-MS/MS. Ind Crops Prod. 2019;141:111735. doi:10.1016/j.indcrop.2019.111735

114. Singh TG, Sharma N. Nanobiomaterials in Cosmetics: Current Status and Future Prospects, in Nanobiomaterials in Galenic Formulations and Cosmetics. Elsevier; 2016:149-174.

115. Ghanbarzadeh S, Arami S. Enhanced transdermal delivery of diclofenac sodium via conventional liposomes, ethosomes, and transfersomes. Biomed Res Int. 2013;2013:1-7. doi:10.1155/ 2013/616810

116. Bhardwaj V, Shukla V, Singh A, Malviya R, Sharma PK. Transfersomes ultra flexible vesicles for transdermal delivery. Int J Pharm Sci Res. 2010;1(3):12-20.

117. Vasanth S, Dubey A, G.s. R, et al. Development and investigation of vitamin C-enriched adapalene-loaded transfersome gel: a collegial approach for the treatment of acne vulgaris. AAPS PharmSciTech. 2020;21(2):61. doi:10.1208/s12249-019-1518-5

118. Cheng C, Wu Z, McClements DJ, et al. Improvement on stability, loading capacity and sustained release of rhamnolipids modified curcumin liposomes. Colloids Surf B Biointerfaces. 2019;183:110460. doi:10.1016/j.colsurfb.2019.110460

119. Paliwal S, Tilak A, Sharma J, et al. Flurbiprofen loaded ethosomes - transdermal delivery of anti-inflammatory effect in rat model. Lipids Health Dis. 2019;18(1):133. doi:10.1186/s12944019-1064-x

120. Natsheh H, Vettorato E, Touitou E. Ethosomes for dermal administration of natural active molecules. Curr Pharm Des. 2019;25 (21):2338-2348. doi:10.2174/1381612825666190716095826

121. Nasr S, Rady M, Gomaa I, et al. Ethosomes and lipid-coated chitosan nanocarriers for skin delivery of a chlorophyll derivative: a potential treatment of squamous cell carcinoma by photodynamic therapy. Int J Pharm. 2019;568:118528. doi:10.1016/j. ijpharm.2019.118528

122. Niu X-Q, Zhang DP, Bian Q, et al. Mechanism investigation of ethosomes transdermal permeation. Int $j$ Pharm $X$. 2019;1:100027. 
123. Fathalla D, Youssef EMK, Soliman GM. Liposomal and ethosomal gels for the topical delivery of anthralin: preparation, comparative evaluation and clinical assessment in psoriatic patients. Pharmaceutics. 2020;12(5):446. doi:10.3390/pharmaceutics12050446

124. Sasindran S, Easwaran M, Shyamala G, Karuppaiah A, Siram K, Veintramuthu S. Phytochemical screening and cytotoxicity evaluation of crude extracts: toxicity comparison of crude extracts and its ethosomal formulations. J Cosmet Dermatol. 2020;19(7):1794-1803.

125. Liu Y, Feng N. Nanocarriers for the delivery of active ingredients and fractions extracted from natural products used in traditional Chinese medicine (TCM). Adv Colloid Interface Sci. 2015;221:60-76. doi:10.1016/j.cis.2015.04.006

126. Azevedo J, Sizilio RH, Brito MB, et al. Physical and chemical characterization insulin-loaded chitosan-TPP nanoparticles. $J$ Therm Anal Calorim. 2011;106(3):685-689. doi:10.1007/ s10973-011-1429-5

127. Manral K, Singh AK, Sah V. Development and characterization of morin loaded phytosomes for its anti-oxidant activity. J Drug Deliv Ther. 2019;9(4):30-36.

128. Safari-Katesari H, Zaroudi S. Analysing the impact of dependency on conditional survival functions using copulas. Stat Transit New Ser. 2021;22(1):217-226. doi:10.21307/stattrans2021-013

129. Safari-Katesari H, Zaroudi S. Count copula regression model using generalized beta distribution of the second kind. Statistics. 2020;21:1-12.

130. Khalil NM. Phytosomes: A Novel Approach for Delivery of Herbal Constituents. J Nutr Diet Probiotics. 2018;1(2):180007.

131. El-Fattah AIA, Fathy MM, Ali ZY, et al. Enhanced therapeutic benefit of quercetin-loaded phytosome nanoparticles in ovariectomized rats. Chem Biol Interact. 2017;271:30-38. doi:10.1016/j. cbi.2017.04.026

132. Perrie Y, Ali H, Kirby DJ, Mohammed AUR, McNeil SE, Vangala A. Environmental scanning electron microscope imaging of vesicle systems. In: D'Souza G, editor. Methods in Molecular Biology. Volume 1522. New York: Human Press; 2017:131-143.

133. Nguyen TA, Tang QD, Doan DC, Dang MC. Micro and nano liposome vesicles containing curcumin for a drug delivery system. Adv Nat Sci: Nanosci Nanotechnol. 2016;7(3):035003.

134. Benne N, Leboux RJT, Glandrup M, et al. Atomic force microscopy measurements of anionic liposomes reveal the effect of liposomal rigidity on antigen-specific regulatory $\mathrm{T}$ cell responses. $J$ Control Release. 2020;318:246-255. doi:10.1016/j.jconrel.2019.12.003

135. Tutkus M, Akhtar P, Chmeliov J, et al. Fluorescence microscopy of single liposomes with incorporated pigment-proteins. Langmuir. 2018;34(47):14410-14418. doi:10.1021/acs. langmuir. 8 b02307

136. Simonsen JB. A liposome-based size calibration method for measuring microvesicles by flow cytometry. J Thromb Haemost. 2016;14(1):186-190. doi:10.1111/jth.13176

137. Lee S-H, Sato Y, Hyodo M, et al. Size-dependency of the surface ligand density of liposomes prepared by post-insertion. Biol Pharm Bull. 2017;40(7):1002-1009. doi:10.1248/bpb.b16-00990

138. Varga Z, Fehér B, Kitka D, et al. Size measurement of extracellular vesicles and synthetic liposomes: the impact of the hydration shell and the protein corona. Colloids Surf B Biointerfaces. 2020;192:111053. doi:10.1016/j.colsurfb.2020.111053

139. Chung J-H, Kim HM. The Nobel Prize in chemistry 2017: highresolution cryo-electron microscopy. Appl Microsc. 2017;47 (4):218-222. doi:10.9729/AM.2017.47.4.218

140. Manna S, Wu Y, Koo B, et al. Significance of Cryo-Scanning Electron Microscopy (Cryo-SEM) in evaluating the morphology of multivesicular liposomes. Microsc Microanal. 2019;25 (S2):1272-1273. doi:10.1017/S1431927619007098
141. Gupta AZ, Mandal MK, Singh B, et al. Liposomes: current approaches for development and evaluation. Int J Drug Deliv Technol. 2017;7(04):269-275. doi:10.25258/ijddt.v7i04.10649

142. Yen TTH, Nhung TH, Hue PTM. Impact of sample concentration on the determination of particle size of nano polymer particles and nano liposomes by dynamic light scattering. $V N U \mathrm{~J} \mathrm{Sci}$. 2019;35(2). doi:10.25073/2588-1132/vnumps.4181

143. Sutariya PG, Pandya A, Lodha A, et al. A simple and rapid creatinine sensing via DLS selectivity, using calix[4]arene thiol functionalized gold nanoparticles. Talanta. 2016;147:590-597. doi:10.1016/j.talanta.2015.10.029

144. Singh P, Bodycomb J, Travers B, et al. Particle size analyses of polydisperse liposome formulations with a novel multispectral advanced nanoparticle tracking technology. Int $J$ Pharm. 2019;566:680-686. doi:10.1016/j.ijpharm.2019.06.013

145. Ternullo S, Gagnat E, Julin K, et al. Liposomes augment biological benefits of curcumin for multitargeted skin therapy. Eur J Pharm Biopharm. 2019;144:154-164. doi:10.1016/j.ejpb.2019.09.016

146. Lewis EN, McCaffrey J, Patil V, Haber $\mathrm{K}$; Inventors. Heterogeneous fluid sample characterization. Google Patents. 2019.

147. Smith MC, Crist RM, Clogston JD, et al. Zeta potential: a case study of cationic, anionic, and neutral liposomes. Anal Bioanal Chem. 2017;409(24):5779-5787. doi:10.1007/s00216-017-0527-z

148. Chibowski E, Szcześ A. Zeta potential and surface charge of DPPC and DOPC liposomes in the presence of PLC enzyme. Adsorption. 2016;22(4-6):755-765. doi:10.1007/s10450-0169767-z

149. Ojha S. In vitro and in vivo neuroprotective study of solid lipid nanoparticles loaded with dimethyl fumarate. Asian J Pharm. 2018;12(01). doi:10.22377/ajp.v12i01.2044

150. Duse L, Pinnapireddy SR, Strehlow B, et al. Low level LED photodynamic therapy using curcumin loaded tetraether liposomes. Eur J Pharm Biopharm. 2018;126:233-241. doi:10.1016/ j.ejpb.2017.10.005

151. Uhl P, Pantze S, Storck P, et al. Oral delivery of vancomycin by tetraether lipid liposomes. Eur J Pharm Sci. 2017;108:111-118. doi:10.1016/j.ejps.2017.07.013

152. Khan MA, Aljarbou AN, Aldebasi YH, et al. Liposomal formulation of glycosphingolipids from Sphingomonas paucimobilis induces antitumour immunity in mice. J Drug Target. 2018;26 (8):709-719. doi:10.1080/1061186X.2018.1424857

153. Kotyńska J, Figaszewski ZA. Binding of trivalent metal ions (Al $3+$, in $3+$, La 3+) with phosphatidylcholine liposomal membranes investigated by microelectrophoresis. Eur Phys J E. 2018;41 (5):70. doi:10.1140/epje/i2018-11679-6

154. Dolder N, von Ballmoos C. Bifunctional DNA duplexes permit efficient incorporation of $\mathrm{pH}$ probes into liposomes. ChemBioChem. 2020;21(15):2219-2224.

155. Yeo EWL. Fabrication and Characterization of Targeting Liposomes for Nanomedicine Applications. Nanyang Technological University; 2018. Available from: https://dr.ntu. edu.sg/handle/10356/73645.

156. Peleg-Shulman T, Gibson D, Cohen R, et al. Characterization of sterically stabilized cisplatin liposomes by nuclear magnetic resonance. Biochim Biophys Acta Biomembr. 2001;1510(1-2):278291. doi:10.1016/S0005-2736(00)00359-X

157. Maurer N, Wong KF, Hope MJ, et al. Anomalous solubility behavior of the antibiotic ciprofloxacin encapsulated in liposomes: a 1H-NMR study. Biochim Biophys Acta Biomembr. 1998;1374(1-2):9-20. doi:10.1016/S0005-2736(98)00125-4

158. Jain P, Soni A, Jain P, Bhawsar J. Phytochemical analysis of Mentha spicata plant extract using UV-VIS, FTIR and GC/MS technique. J Chem Pharm Res. 2016;8(2):1-6. 
159. Al-Tameme HJ, Hadi MY, Hameed IH. Phytochemical analysis of urtica dioica leaves by Fourier-transform infrared spectroscopy and gas chromatography-mass spectrometry. $J$ Pharmacogn Phytotherapy. 2015;7(10):238-252. doi:10.5897/JPP2015.0361

160. Neves B, Duarte S, Domingues P, et al. Advancing target identification of nitrated phospholipids in biological systems by HCD specific fragmentation fingerprinting in orbitrap platforms. Molecules. 2020;25(9):2120. doi:10.3390/molecules 25092120

161. de Azambuja Borges CRL, Silva NO, Rodrigues MR, et al. Dimiristoylphosphatidylcholine/genistein molecular interactions: a physico-chemical approach to anti-glioma drug delivery systems. Chem Phys Lipids. 2019;225:104828. doi:10.1016/j. chemphyslip.2019.104828

162. Gurunathan S, Kang M-H, Qasim M, et al. Nanoparticle-mediated combination therapy: two-in-one approach for cancer. Int $J \mathrm{Mol}$ Sci. 2018;19(10):3264. doi:10.3390/ijms 19103264

163. Nele V, Holme MN, Kauscher U, et al. Effect of formulation method, lipid composition, and PEGylation on vesicle lamellarity: a small-angle neutron scattering study. Langmuir. 2019;35 (18):6064-6074. doi:10.1021/acs.langmuir.8b04256

164. Solomon D, Gupta N, Mulla NS, et al. Role of in vitro release methods in liposomal formulation development: challenges and regulatory perspective. AAPS J. 2017;19(6):1669-1681. doi:10.1208/s12248-017-0142-0

165. Xu X, Khan MA, Burgess DJ. A two-stage reverse dialysis in vitro dissolution testing method for passive targeted liposomes. Int J Pharm. 2012;426(1-2):211-218. doi:10.1016/j. ijpharm.2012.01.030

166. Wallenwein CM, Nova MV, Janas C, et al. A dialysis-based in vitro drug release assay to study dynamics of the drug-protein transfer of temoporfin liposomes. Eur $J$ Pharm Biopharm. 2019;143:44-50. doi:10.1016/j.ejpb.2019.08.010

167. Manna S, Wu Y, Wang Y, et al. Probing the mechanism of bupivacaine drug release from multivesicular liposomes. $J$ Control Release. 2019;294:279-287. doi:10.1016/j. jconrel.2018.12.029

168. Roy D, Das S, Samanta AA. Design and in vitro release kinetics of liposomal formulation of acyclovir. Int J App Pharm. 2019;11 (6):61-65. doi:10.22159/ijap.2019v11i6.34917

169. Zhu H-M, Gu J-H, Xie Y, et al. Hydroxycamptothecin liposomes based on thermal and magnetic dual-responsive system: preparation, in vitro and in vivo antitumor activity, microdialysis-based tumor pharmacokinetics. J Drug Target. 2018;26(4):345-356. doi:10.1080/1061186X.2017.1380654

170. Dimov N, Kastner E, Hussain M, et al. Formation and purification of tailored liposomes for drug delivery using a module-based micro continuous-flow system. Sci Rep. 2017;7(1):1-13. doi:10.1038/s41598-017-11533-1

171. Panda VS, Naik SR. Cardioprotective activity of Ginkgo biloba phytosomes in isoproterenol-induced myocardial necrosis in rats: a biochemical and histoarchitectural evaluation. Exp Toxicol Pathol. 2008;60(4-5):397-404. doi:10.1016/j.etp.2008.03.010

172. Panda VS, Naik SR. Evaluation of cardioprotective activity of Ginkgo biloba and Ocimum sanctum in rodents. Altern Med Rev. 2009;14(2):161-171.

173. Tisato V, Zauli G, Rimondi E, et al. Inhibitory effect of natural anti-inflammatory compounds on cytokines released by chronic venous disease patient-derived endothelial cells. Mediators Inflamm. 2013;2013:423407.

174. Albrigo R, Andreoni C, Anello G, et al. Nédemax ${ }^{\circledR}$ mese (Leucoselect $^{\circledR}$, Lymphaselect ${ }^{\circledR}$, bromelain) in the treatment of chronic venous disease: a multicenter, observational study. Acta Phlebol. 2019;20(1):8-14. doi:10.23736/S1593-232X.19.00437-5

175. Muir AH, Robb R, McLaren M, et al. The use of Ginkgo biloba in raynaud's disease: a double-blind placebo-controlled trial. Vasc Med. 2002;7(4):265-267. doi:10.1191/1358863x02vm455oa
176. Husch J, Bohnet J, Fricker G, et al. Enhanced absorption of boswellic acids by a lecithin delivery form $\left(\right.$ Phytosome $^{\circledR}$ ) of boswellia extract. Fitoterapia. 2013;84:89-98. doi:10.1016/j. fitote. 2012.10.002

177. Mancini S, Nardo L, Gregori M, et al. Functionalized liposomes and phytosomes loading Annona muricata L. aqueous extract: potential nanoshuttles for brain-delivery of phenolic compounds. Phytomedicine. 2018;42:233-244. doi:10.1016/j.phymed.2018.03.053

178. La Grange L, Wang M, Watkins R, et al. Protective effects of the flavonoid mixture, silymarin, on fetal rat brain and liver. $J$ Ethnopharmacol. 1999;65(1):53-61. doi:10.1016/S0378-8741(98) 00144-5

179. Naik SR, Pilgaonkar VW, Panda VS. Neuropharmacological evaluation of Ginkgo biloba phytosomes in rodents. Phytother Res. 2006;20(10):901-905. doi:10.1002/ptr.1973

180. Naik SR, Pilgaonkar VW, Panda VS. Evaluation of antioxidant activity of Ginkgo biloba phytosomes in rat brain. Phytother Res. 2006;20(11):1013-1016. doi:10.1002/ptr.1976

181. Ullah F, Liang H, Niedermayer G, et al. Evaluation of phytosomal curcumin as an anti-inflammatory agent for chronic glial activation in the GFAP-IL6 mouse model. Front Neurosci. 2020;14:170. doi:10.3389/fnins.2020.00170

182. Sbrini G, Brivio P, Fumagalli M, et al. Centella asiatica L. Phytosome improves cognitive performance by promoting bdnf expression in rat prefrontal cortex. Nutrients. 2020;12(2):355. doi:10.3390/nu12020355

183. Bahadur S, Sachan N, Harwansh RK, et al. Nanoparticlized system: promising approach for the management of Alzheimer's disease through intranasal delivery. Curr Pharm Des. 2020;26 (12):1331-1344. doi:10.2174/1381612826666200311131658

184. Langasco R, Fancello S, Rassu G, et al. Increasing protective activity of genistein by loading into transfersomes: a new potential adjuvant in the oxidative stress-related neurodegenerative diseases? Phytomedicine. 2019;52:23-31. doi:10.1016/j.phymed.2018.09.207

185. Dell'Agli M, Sangiovanni E, Risè P, et al. Bioavailability of Curcumin in the Rat Frontal Lobe and Hippocampus After Repeated Administration of MERIVA, in Planta Medica. Copenhagen, Denmark: George Thieme Verlag KG; 2016.

186. Maiti P, Dunbar GL. Use of curcumin, a natural polyphenol for targeting molecular pathways in treating age-related neurodegenerative diseases. Int J Mol Sci. 2018;19(6):1637. doi:10.3390/ ijms 19061637

187. Ahmad H, Arya A, Agrawal S, et al. Rutin phospholipid complexes confer neuro-protection in ischemic-stroke rats. RSC $A d v$. 2016;6(99):96445-96454. doi:10.1039/C6RA17874J

188. Ahmad H, Arya A, Agrawal S, et al. Phospholipid complexation of NMITLI118RT+: way to a prudent therapeutic approach for beneficial outcomes in ischemic stroke in rats. Drug Deliv. 2016;23(9):3606-3618. doi:10.1080/10717544.2016.1212950

189. Pajardi G, Bortot P, Ponti V, et al. Clinical usefulness of oral supplementation with alpha-lipoic acid, curcumin phytosome, and B-group vitamins in patients with carpal tunnel syndrome undergoing surgical treatment. Evid Based Complement Alternat Med. 2014;2014:1-7. doi:10.1155/2014/891310

190. Di Pierro F, Settembre R. Safety and efficacy of an add-on therapy with curcumin phytosome and piperine and/or lipoic acid in subjects with a diagnosis of peripheral neuropathy treated with dexibuprofen [Erratum]. J Pain Res. 2013;6:641. doi:10.2147/JPR.S52226

191. D’Andrea G, Bussone G, Allais G, et al. Efficacy of Ginkgolide B in the prophylaxis of migraine with aura. Neurol Sci. 2009;30 (S1):S121-S124. doi:10.1007/s10072-009-0074-2

192. Williams B, Watanabe CMH, Schultz PG, et al. Age-related effects of Ginkgo biloba extract on synaptic plasticity and excitability. Neurobiol Aging. 2004;25(7):955-962. doi:10.1016/j. neurobiolaging.2003.10.008 
193. Allais G, D'Andrea G, Maggio M, et al. The efficacy of ginkgolide B in the acute treatment of migraine aura: an open preliminary trial. Neurol Sci. 2013;34(S1):S161-S163. doi:10.1007/ s10072-013-1413-x

194. Balzano L, Ciccone B. Preliminary efficacy study in prophylaxes of episodic tension cephala and hemicrania without aura using a combination of magnesium, L-triptofano, Boswellia serrata Casperome (r), niacina, riboflavina and vitamin d compared with amitriptiline. In: Meet Abstracts; 12th European Headache Federation Congress jointly with 32nd National Congress of the Italian Society for the Study of Headaches. Journal of Headache and Pain. 2018;19(Suppl 1):129-130.

195. Mukherjee S, Baidoo J, Fried A, et al. Curcumin changes the polarity of tumor-associated microglia and eliminates glioblastoma. Int $J$ Cancer. 2016;139(12):2838-2849. doi:10.1002/ijc.30398

196. Mukherjee S, Fried A, Hussaini R, et al. Phytosomal curcumin causes natural killer cell-dependent repolarization of glioblastoma (GBM) tumor-associated microglia/macrophages and elimination of GBM and GBM stem cells. $J$ Exp Clin Cancer Res. 2018;37:1-8.

197. Pan D, Xia -X-X, Zhou H, et al. COCO enhances the efficiency of photoreceptor precursor differentiation in early human embryonic stem cell-derived retinal organoids. Stem Cell Res Ther. 2020;11 (1):1-12. doi:10.1186/s13287-020-01883-5

198. Wright A, Benjamin S, Ruggieri R, et al. Meriva and a novel chemically-modified curcumin for the treatment of medulloblastoma. In 4th Biennial Conference on Pediatric Neuro-Oncology Basic and Translational Research, June 15-16, 2017. New York City; 2017:iv45.

199. Di Pierro F, Simonetti G, Petruzzi A, et al. A novel lecithin-based delivery form of Boswellic acids as complementary treatment of radiochemotherapy-induced cerebral edema in patients with glioblastoma multiforme: a longitudinal pilot experience. J Neurosurg Sci. 2019;63(3):286-291. doi:10.23736/S0390-5616.19.04662-9

200. Bresciani L, Favari C, Calani L, et al. The effect of formulation of curcuminoids on their metabolism by human colonic microbiota. Molecules. 2020;25(4):940. doi:10.3390/molecules25040940

201. Pastorelli D, Fabricio ASC, Giovanis P, et al. Phytosome complex of curcumin as complementary therapy of advanced pancreatic cancer improves safety and efficacy of gemcitabine: results of a prospective phase II trial. Pharmacol Res. 2018;132:72-79. doi:10.1016/j.phrs.2018.03.013

202. Solda C, Bardini R, Sperti C, et al. Phase II study of Gemcitabine and Curcumin $\left(\right.$ Meriva $^{\circledR}$ ) as first line treatment for locally advanced or metastatic pancreatic cancer: preliminary results. Ann Oncol. 2015;26:102. doi:10.1093/annonc/mdv344.41

203. Solda C, Sperti C, Romeo B, et al. Use of meriva as complementary therapy of locally advanced or metastatic pancreatic cancer (PC) with gemcitabine (GEM). J Clin Oncol. 2016;34(15_suppl): e15696-e15696. doi:10.1200/JCO.2016.34.15_suppl.e15696

204. Pellegrini L, Milano E, Franceschi F, et al. Managing ulcerative colitis in remission phase: usefulness of Casperome (R), an innovative lecithin-based delivery system of Boswellia serrata extract. Eur Rev Med Pharmacol Sci. 2016;20(12):2695-2700.

205. Belcaro G, Gizzi G, Pellegrini L, et al. Supplementation with a lecithin-based delivery form of Boswellia serrata extract (Casperome (R)) controls symptoms of mild irritable bowel syndrome. Eur Rev Med Pharmacol Sci. 2017;21(9):2249-2254.

206. Riva A, Giacomelli L, Togni S, et al. Oral administration of a lecithin-based delivery form of boswellic acids $\left(\right.$ Casperome $\left.^{\mathbb{B}}\right)$ for the prevention of symptoms of irritable bowel syndrome: a randomized clinical study. Minerva Gastroenterol Dietol. 2019;65 (1):30-35. doi:10.23736/S1121-421X.18.02530-8

207. Singh RP, Gu M, Agarwal R. Silibinin inhibits colorectal cancer growth by inhibiting tumor cell proliferation and angiogenesis. Cancer Res. 2008;68(6):2043-2050. doi:10.1158/0008-5472. CAN-07-6247
208. Howells LM, Sale S, Sriramareddy SN, et al. Curcumin ameliorates oxaliplatin-induced chemoresistance in HCT116 colorectal cancer cells in vitro and in vivo. Int J Cancer. 2011;129(2):476486. doi:10.1002/ijc. 25670

209. Marjaneh RM, Rahmani F, Hassanian SM, et al. Phytosomal curcumin inhibits tumor growth in colitis-associated colorectal cancer. J Cell Physiol. 2018;233(10):6785-6798. doi:10.1002/ jcp. 26538

210. Moradi-Marjaneh R, Hassanian SM, Rahmani F, et al. Phytosomal curcumin elicits anti-tumor properties through suppression of angiogenesis, cell proliferation and induction of oxidative stress in colorectal cancer. Curr Pharm Des. 2019;24 (39):4626-4638. doi:10.2174/1381612825666190110145151

211. Naik SR, Panda VS. Antioxidant and hepatoprotective effects of Ginkgo biloba phytosomes in carbon tetrachloride-induced liver injury in rodents. Liver Int. 2007;27(3):393-399. doi:10.1111/ j.1478-3231.2007.01463.x

212. Zhao N, Deng L, Luo D, et al. One-step fabrication of biomassderived hierarchically porous carbon/ $\mathrm{MnO}$ nanosheets composites for symmetric hybrid supercapacitor. Appl Surf Sci. 2020;526:146696. doi:10.1016/j.apsusc.2020.146696

213. Naik SR, Panda VS. Hepatoprotective effect of Ginkgoselect phytosome ${ }^{\circledR}$ in rifampicin induced liver injury in rats: evidence of antioxidant activity. Fitoterapia. 2008;79(6):439-445. doi:10.1016/j.fitote.2008.02.013

214. Loguercio C, Andreone P, Brisc C, et al. Silybin combined with phosphatidylcholine and vitamin $\mathrm{E}$ in patients with nonalcoholic fatty liver disease: a randomized controlled trial. Free Radic Biol Med. 2012;52(9):1658-1665. doi:10.1016/j.freeradbiomed.2012.02.008

215. Ali SO, Darwish HAE-M, Ismail NAE-F. Modulatory effects of curcumin, silybin-phytosome and alpha-R-lipoic acid against thioacetamide-induced liver cirrhosis in rats. Chem Biol Interact. 2014;216:26-33. doi:10.1016/j.cbi.2014.03.009

216. El-Gazayerly ON, Makhlouf AIA, Soelm AMA, et al. Antioxidant and hepatoprotective effects of silymarin phytosomes compared to milk thistle extract in $\mathrm{CCl} 4$ induced hepatotoxicity in rats. J Microencapsul. 2014;31(1):23-30. doi:10.3109/02652048.2013.805836

217. Vora A, Londhe V, Pandita N. Herbosomes enhance the in vivo antioxidant activity and bioavailability of punicalagins from standardized pomegranate extract. J Funct Foods. 2015;12:540-548. doi:10.1016/j.jff.2014.12.017

218. Loeser K, Seemann S, König S, et al. Protective effect of casperome (R), an orally bioavailable frankincense extract, on lipopolysaccharide-induced systemic inflammation in mice. Front Pharmacol. 2018;9:387.

219. Sharma S, Sahu AN. Development, characterization, and evaluation of hepatoprotective effect of abutilon indicum and piper longum phytosomes. Pharmacognosy Res. 2016;8(1):29-36. doi:10.4103/0974-8490.171102

220. Al-Kahtani M, Abdel-Daim MM, Sayed AA, et al. Curcumin phytosome modulates aluminum-induced hepatotoxicity via regulation of antioxidant, Bcl-2, and caspase-3 in rats. Environ Sci Pollut Res Int. 2020;27(17):21977-21985. doi:10.1007/s11356020-08636-0

221. Teng CF, Yu CH, Chang HY, et al. Chemopreventive effect of phytosomal curcumin on hepatitis B virus-related hepatocellular carcinoma in a transgenic mouse model. Sci Rep. 2019;9:1-3.

222. Lazzeroni M, Guerrieri-Gonzaga A, Gandini S, et al. A Presurgical Study of lecithin formulation of green tea extract in women with early breast cancer. Cancer Prev Res. 2017;10 (6):363-369. doi:10.1158/1940-6207.CAPR-16-0298

223. Lazzeroni M, Guerrieri-Gonzaga A, Gandini S, et al. A Presurgical Study of oral silybin-phosphatidylcholine in patients with early breast cancer. Cancer Prev Res. 2016;9(1):89-95. doi:10.1158/1940-6207.CAPR-15-0123 
224. Mahmoodi N, Motamed N, Paylakhi SH, Mahmoodi NO. Comparing the effect of silybin and silybin advanced (TM) on viability and HER2 expression on the human breast cancer SKBR3 cell line by no serum starvation. Iran J Pharm Res. 2015;14(2):521-530.

225. Sabzichi M, Hamishehkar H, Ramezani F, et al. Luteolin-loaded phytosomes sensitize human breast carcinoma MDA-MB 231 cells to doxorubicin by suppressing Nrf2 mediated signalling. Asian Pac J Cancer Prev. 2014;15(13):5311-5316. doi:10.7314/ APJCP.2014.15.13.5311

226. Minaei A, Sabzichi M, Ramezani F, et al. Co-delivery with nanoquercetin enhances doxorubicin-mediated cytotoxicity against MCF-7 cells. Mol Biol Rep. 2016;43(2):99-105. doi:10.1007/ s11033-016-3942-x

227. Pang X, Gong K, Zhang X, et al. Osteopontin as a multifaceted driver of bone metastasis and drug resistance. Pharmacol Res. 2019;144:235-244. doi:10.1016/j.phrs.2019.04.030

228. Hashemzehi M, Behnam-Rassouli R, Hassanian SM, et al. Phytosomal-curcumin antagonizes cell growth and migration, induced by thrombin through AMP-kinase in breast cancer. $J$ Cell Biochem. 2018;119(7):5996-6007. doi:10.1002/jcb.26796

229. Wu P, Gao W, Su M, et al. Adaptive mechanisms of tumor therapy resistance driven by tumor microenvironment. Front Cell Dev Biol. 2021;9:357.

230. Chandra D, Jahangir A, Cornelis F, et al. Cryoablation and meriva have strong therapeutic effect on triple-negative breast cancer. Oncoimmunology. 2016;5(1):e1049802. doi:10.1080/2162402X. 2015.1049802

231. El-Far SW, Helmy MW, Khattab SN, et al. Folate conjugated vs PEGylated phytosomal casein nanocarriers for codelivery of fungal- and herbal-derived anticancer drugs. Nanomedicine. 2018;13 (12):1463-1480. doi:10.2217/nnm-2018-0006

232. El-Far SW, Helmy MW, Khattab SN, et al. Phytosomal bilayerenveloped casein micelles for codelivery of Monascus yellow pigments and resveratrol to breast cancer. Nanomedicine. 2018;13(5):481-499. doi:10.2217/nnm-2017-0301

233. Singh RP, Raina K, Sharma G, et al. Silibinin inhibits established prostate tumor growth, progression, invasion, and metastasis and suppresses tumor angiogenesis and epithelial-mesenchymal transition in transgenic adenocarcinoma of the mouse prostate model mice. Clin Cancer Res. 2008;14(23):7773-7780. doi:10.1158/ 1078-0432.CCR-08-1309

234. Flaig TW, Gustafson DL, Su L-J, et al. A phase I and pharmacokinetic study of silybin-phytosome in prostate cancer patients. Invest New Drugs. 2006;25(2):139-146. doi:10.1007/s10637-006-9019-2

235. Flaig TW, Glodé M, Gustafson D, et al. A study of high-dose oral silybin-phytosome followed by prostatectomy in patients with localized prostate cancer. Prostate. 2010;70(8):848-855. doi:10.1002/pros.21118

236. Ledda A, Belcaro G, Dugall M, et al. Meriva (R), a lecithinized curcumin delivery system, in the control of benign prostatic hyperplasia: a pilot, product evaluation registry study. Panminerva Med. 2012;54(1):17-22.

237. Tuyaerts S, Rombauts K, Everaert T, et al. A phase 2 study to assess the immunomodulatory capacity of a lecithin-based delivery system of curcumin in endometrial cancer. Front Nutr. 2019;5. doi:10.3389/fnut.2018.00138

238. Wang B, Kong B, Li F, et al. Changes in the thermal stability and structure of protein from porcine longissimus dorsi induced by different thawing methods. Food Chem. 2020;316:126375. doi:10.1016/j.foodchem.2020.126375

239. Wang B, Li F, Pan N, et al. Effect of ice structuring protein on the quality of quick-frozen patties subjected to multiple freeze-thaw cycles. Meat Sci. 2021;172:108335. doi:10.1016/j.meatsci.2020.108335
240. Alhakamy NA, A. Fahmy U, Badr-Eldin SM, et al. Optimized icariin phytosomes exhibit enhanced cytotoxicity and apoptosisinducing activities in ovarian cancer cells. Pharmaceutics. 2020;12(4):346. doi:10.3390/pharmaceutics 12040346

241. Baron G, Altomare A, Regazzoni L, et al. Profiling Vaccinium macrocarpon components and metabolites in human urine and the urine ex-vivo effect on Candida albicans adhesion and biofilmformation. Biochem Pharmacol. 2020;173:113726.

242. Ledda A, Belcaro G, Feragalli B, et al. Temporary kidney dysfunction: supplementation with Meriva (R) in initial, transient kidney micro-macro albuminuria. Panminerva Med. 2019;61 (4):444-448.

243. Ram P, Vivek K, Kumar SP. Nanotechnology in sustainable agriculture: present concerns and future aspects. Afr J Biotechnol. 2014;13 (6):705-713. doi:10.5897/AJBX2013.13554

244. Magrone T, Pugliese V, Fontana S, et al. Human use of leucoselect (R) phytosome (R) with special reference to inflammatory-allergic pathologies in frail elderly patients. Curr Pharm Des. 2014;20 (6):1011-1019. doi:10.2174/138161282006140220144411

245. Maramaldi G, Togni S, Pagin I, et al. Soothing and anti-itch effect of quercetin phytosome in human subjects: a single-blind study. Clinical, Cosmetic and Investigational Dermatology. 2016;9:5562. doi:10.2147/CCID.S98890

246. Antiga E, Bonciolini V, Volpi W, et al. Oral curcumin (Meriva) is effective as an adjuvant treatment and is able to reduce IL-22 serum levels in patients with psoriasis vulgaris. Biomed Res Int. 2015;2015:1-7. doi:10.1155/2015/283634

247. Baradaran S, Hajizadeh Moghaddam A, Khanjani Jelodar S, et al. Protective effects of curcumin and its nano-phytosome on carrageenan-induced inflammation in mice model: behavioral and biochemical responses. J Inflamm Res. 2020;13:45-51. doi:10.2147/ JIR.S232462

248. Djekic L, Čalija B, Micov A, et al. Topical hydrogels with escin $\beta$-sitosterol phytosome and escin: formulation development and in vivo assessment of antihyperalgesic activity. Drug Dev Res. 2019;80(7):921-932. doi:10.1002/ddr.21572

249. Kalita B, Das MK, Sarma M, et al. Sustained anti-inflammatory effect of resveratrol-phospholipid complex embedded polymeric patch. Aaps Pharmscitech. 2017;18(3):629-645. doi:10.1208/ s12249-016-0542-y

250. Singh P, Singh M, Kanoujia J, et al. Process optimization and photostability of silymarin nanostructured lipid carriers: effect on UV-irradiated rat skin and SK-MEL 2 cell line. Drug Deliv Transl Res. 2016;6(5):597-609. doi:10.1007/s13346-016-0317-8

251. Minniti V, Pietris G, Barbullushi Eet al. Usage of Ginkgo biloba and lipoic acid in patients with diabetic ulcers. Acta Vulnologica. 2015;13(3):144-154.

252. Lim AW, Ng PY, Chieng N, Ng SF. Moringa oleifera leaf extractloaded phytophospholipid complex for potential application as wound dressing. J Drug Deliv Sci Technol. 2019;54:101329.

253. Riva A, Togni S, Giacomelli L, et al.Effects of a curcumin-based supplementation in asymptomatic subjects with low bone density: a preliminary 24-week supplement study. Eur Rev Med Pharmacol Sci. 2017;21(7):1684-1689.

254. Franceschi F, Feregalli B, Togni S, et al. A novel phospholipid delivery system of curcumin (Meriva (R)) preserves muscular mass in healthy aging subjects. Eur Rev Med Pharmacol Sci. 2016;20(4):762-766.

255. Di Pierro F, Zacconi P, Bertuccioli A, et al. A naturally-inspired, curcumin-based lecithin formulation (Meriva (R) formulated as the finished product Algocur (R)) alleviates the osteo-muscular pain conditions in rugby players. Eur Rev Med Pharmacol Sci. 2017;21(21):4935-4940. 
256. Di Pierro F, Eleonora AD, Giovanni A, Federico F, Stefano T. Comparative evaluation of the pain-relieving properties of a lecithinized formulation of curcumin (Meriva (R)), nimesulide, and Acetaminophen. J Pain Res. 2013;6:201-205.

257. Drobnic F, Riera J, Appendino G, et al. Reduction of delayed onset muscle soreness by a novel curcumin delivery system $\left(\right.$ Meriva $\left.^{\circledR}\right)$ : a randomised, placebo-controlled trial. $J$ Int Soc Sports Nutr. 2014;11(1). doi:10.1186/1550-2783-11-31

258. Belcaro G, Cesarone MR, Dugall M, et al. Efficacy and safety of meriva (R), a curcumin-phosphatidylcholine complex, during extended administration in osteoarthritis patients. Altern Med Rev. 2010;15(4):337-344.

259. Belcaro G. Meriva (R) plus glucosamine versus condroitin plus glucosamine in patients with knee osteoarthritis: an observational study. Eur Rev Med Pharmacol Sci. 2014;18(24):3959-3963.

260. Maida G. Clinical usefulness of oral supplementation with curcumin phytosome in patients with radiculopathy due to spondyloarthritis or discopathy. Minerva Ortop Traumatol. 2016;67(2): $75-78$.

261. Miserocchi E, Giuffrè C, Cicinelli MV, et al. Oral phospholipidic curcumin in juvenile idiopathic arthritis-associated uveitis. Eur $J$ Ophthalmol. 2020;30(6):1390-1396.

262. Farinacci M, Gaspardo B, Colitti M, et al. Dietary administration of curcumin modifies transcriptional profile of genes involved in inflammatory cascade in horse leukocytes. Ital J Anim Sci. 2009;8 (sup2):84-86. doi:10.4081/ijas.2009.s2.84

263. Turck D, Bresson JL, Burlingame B, et al. Curcumin and normal functioning of joints: evaluation of a health claim pursuant to article 13 (5)of regulation (EC) No 1924/2006. EFSA J. 2017;15 (5): 04774.

264. Franceschi F, Togni S, Belcaro G, et al. A novel lecithin based delivery form of boswellic acids (casperome $(\mathrm{R})$ ) for the management of osteo-muscular pain: a registry study in young rugby players. Eur Rev Med Pharmacol Sci. 2016;20(19):4156-4161.

265. Feragalli B, Ippolito E, Dugall M, et al. Effectiveness of a novel boswellic acids delivery form (Casperome (R)) in the management of grade II ankle sprains due to sport trauma - a registry study. Eur Rev Med Pharmacol Sci. 2017;21(20):4726-4732.

266. Riva A, Allegrini P, Franceschi F, et al. A novel boswellic acids delivery form (casperome (R)) in the management of musculoskeletal disorders: a review. Eur Rev Med Pharmacol Sci. 2017;21 (22):5258-5263.

267. Belcaro G, Dugall M, Luzzi R, et al. Phytoproflex ${ }^{\circledR}$ : supplementary management of osteoarthrosis: a supplement registry. Minerva Med. 2018;109(2):88-94. doi:10.23736/S00264806.17.05460-X

268. Rondanelli M, Riva A, Allegrini P, et al. The use of a new foodgrade lecithin formulation of highly standardized ginger (Zingiber officinale) and acmella oleracea extracts for the treatment of pain and inflammation in a group of subjects with moderate knee osteoarthritis. J Pain Res. 2020;13:761-770. doi:10.2147/JPR. S214488

269. Chang S-F, Yeh -C-C, Chen P-J, et al. The impact of lipid types and liposomal formulations on osteoblast adiposity and mineralization. Molecules. 2018;23(1):95. doi:10.3390/ molecules 23010095

270. Cesarone MR, Belcaro G, Hu S, et al. Supplementary prevention and management of asthma with quercetin phytosome: a pilot registry. Minerva Med. 2019;110(6):524-529.

271. Ferrara T, De Vincentiis G, Di Pierro F. Functional study on Boswellia phytosome as complementary intervention in asthmatic patients. Eur Rev Med Pharmacol Sci. 2015;19(19):3757-3762.

272. Yu Z, Liu X, Chen H, et al. Naringenin-loaded dipalmitoylphosphatidylcholine phytosome dry powders for inhaled treatment of acute lung injury. J Aerosol Med Pulm Drug Deliv. 2020;33 (4):194-204. doi:10.1089/jamp.2019.1569
273. Singh RP, Gangadharappa HV, Mruthunjaya K. Phytosome complexed with chitosan for gingerol delivery in the treatment of respiratory infection: in vitro and in vivo evaluation. Eur $J$ Pharm Sci. 2018;122:214-229. doi:10.1016/j.ejps.2018.06.028

274. Ibrahim A, El-Meligy A, Fetaih H, et al. Effect of curcumin and meriva on the lung metastasis of murine mammary gland adenocarcinoma. In Vivo. 2010;24(4):401-408.

275. Mao JT, Smoake J, Park HK, et al. Grape seed procyanidin extract mediates antineoplastic effects against lung cancer via modulations of prostacyclin and 15-HETE eicosanoid pathways. Cancer Prev Res. 2016;9(12):925-932. doi:10.1158/1940-6207. CAPR-16-0122

276. Mao JT, Xue B, Smoake J, et al. MicroRNA-19a/b mediates grape seed procyanidin extract-induced anti-neoplastic effects against lung cancer. J Nutr Biochem. 2016;34:118-125. doi:10.1016/j. jnutbio.2016.05.003

277. Mao JT, Lu Q-Y, Xue B, et al. A pilot study of a grape seed procyanidin extract for lung cancer chemoprevention. Cancer Prev Res. 2019;12(8):557-565. doi:10.1158/1940-6207.CAPR19-0053

278. Di Lorenzo C, Dell'Agli M, Colombo E, et al. Metabolic syndrome and inflammation: a critical review of in vitro and clinical approaches for benefit assessment of plant food supplements. Evid Based Complement Alternat Med. 2013;2013:782461. doi:10.1155/2013/782461

279. Vigna GB, Costantini F, Aldini G, et al. Effect of a standardized grape seed extract on low-density lipoprotein susceptibility to oxidation in heavy smokers. Metabolism. 2003;52(10):12501257. doi:10.1016/S0026-0495(03)00192-6

280. Mazzolani F, Togni S, Giacomelli L, et al. Oral administration of a curcumin-phospholipid formulation (meriva (R)) for treatment of chronic diabetic macular edema: a pilot study. Eur Rev Med Pharmacol Sci. 2018;22(11):3617-3625.

281. Steigerwalt R, Nebbioso M, Appendino G, et al. Meriva (R), a lecithinized curcumin delivery system, in diabetic microangiopathy and retinopathy. Panminerva Med. 2012;54(4):11-16.

282. Di Pierro F, Bressan A, Ranaldi D, et al. Potential role of bioavailable curcumin in weight loss and omental adipose tissue decrease: preliminary data of a randomized, controlled trial in overweight people with metabolic syndrome. Preliminary study. Eur Rev Med Pharmacol Sci. 2015;19(21):4195-4202.

283. Cicero AFG, Sahebkar A, Fogacci F, et al. Effects of phytosomal curcumin on anthropometric parameters, insulin resistance, cortisolemia and non-alcoholic fatty liver disease indices: a doubleblind, placebo-controlled clinical trial. Eur J Nutr. 2020;59 (2):477-483. doi:10.1007/s00394-019-01916-7

284. Belcaro G, Ledda A, Hu S, et al. Greenselect phytosome for borderline metabolic syndrome. Evid Based Complement Alternat Med. 2013;2013:1-7. doi:10.1155/2013/869061

285. Gilardini L, Pasqualinotto L, Di Pierro F, et al. Effects of greenselect phytosome $(\mathrm{R})$ on weight maintenance after weight loss in obese women: a randomized placebo-controlled study. BMC Complement Altern Med. 2016;16:1-7.

286. Di Pierro F, Menghi AB, Barreca A, Lucarelli M, Calandrelli A. GreenSelect $(\mathrm{R})$ phytosome as an adjunct to a low-calorie diet for treatment of obesity: a clinical trial. Altern Med Rev. 2009;14 (2):154-160.

287. Riva A, Corti A, Belcaro G, et al. Interaction study between antiplatelet agents, anticoagulants, diabetic therapy and a novel delivery form of quercetin. Minerva Cardioangiol. 2019;67 (1):79-83. doi:10.23736/S0026-4725.18.04795-3

288. Riva A, Ronchi M, Petrangolini G, Bosisio S, Allegrini P. Improved oral absorption of quercetin from quercetin phytosome $^{\circledR}$, a new delivery system based on food grade lecithin. Eur J Drug Metab Pharmacokinet. 2019;44(2):169177. doi:10.1007/s13318-018-0517-3 
289. Kim S-M, Jung J-I, Chai C, et al. Characteristics and glucose uptake promoting effect of chrysin-loaded phytosomes prepared with different phospholipid matrices. Nutrients. 2019;11 (10):2549. doi:10.3390/nu11102549

290. Poruba M, Kazdová L, Oliyarnyk O, et al. Improvement bioavailability of silymarin ameliorates severe dyslipidemia associated with metabolic syndrome. Xenobiotica. 2015;45(9):751-756. doi:10.3109/00498254.2015.1010633

291. Poruba M, Matuskova Z, Kazdova L, et al. Positive effects of different drug forms of silybin in the treatment of metabolic syndrome. Physiol Res. 2015;65(Suppl 1):S507-S512. doi:10.33549/physiolres.933235

292. Mollace V, Scicchitano M, Paone S, et al. Hypoglycemic and hypolipemic effects of a new lecithin formulation of bergamot polyphenolic fraction: a Double Blind, Randomized, PlaceboControlled Study. Endocr Metab Immune Disord Drug Targets. 2019;19(2):136-143. doi:10.2174/1871530319666 181203151513

293. Rathee S, Kamboj A. Optimization and development of antidiabetic phytosomes by the Box-Behnken design. J Liposome Res. 2018;28(2):161-172. doi:10.1080/08982104.2017.1311913

294. Palachai N, Wattanathorn J, Muchimapura S, et al. Antimetabolic syndrome effect of phytosome containing the combined extracts of mulberry and ginger in an animal model of metabolic syndrome. Oxid Med Cell Longev. 2019;2019:1-19. doi:10.1155/ 2019/5972575

295. Giori A, Franceschi F. Phospholipid complexes of curcumin having improved bioavailability. Google Patents. 2020.

296. Franceshi F, Giori A. A phospholipid complex of olive fruits or leaves extracts having improved bioavailability. Patent No. EP1844785. 2007.

297. Di Pierro F. Compositions comprising Ginko biloba derivatives for the treatment of asthmatic and allergic conditions. EP1813280. 2007.

298. Kleinman H, Goldstein A, Malinda K, Sosne G; Inventors. Treatment of skin, and wound repair, with thymosin beta 4 . Google Patents. 2007.

299. Bombardelli E. Oral compositions for the treatment of cellulite. Google Patents. 2010.

300. Bertelli V. Fatty acid monoesters of sorbityl furfural and compositions for cosmetic and dermatological use. EP1690862. 2006.

301. Doering T, Traeger A, Waldmann-Laue M. Cosmetic and dermatological composition for the treatment of aging or photodamaged skin. EP1640041. 2006.

302. Khare AB. Soluble isoflavone compositions. Google Patents. 2005.

303. Merizzi G. Anti-oxidant preparation based on plant extracts for the treatment of circulation and adiposity problems. Google Patents. 2004.

304. Morazzoni P, Bombardelli E. Phospholipid complexes prepared from extracts of Vitis vinifera as anti-atherosclerotic agents. Google Patents. 2001.

305. Bombardelli E, Mustich G. Bilobalide Phospholipide Complexes, Their Applications and Formulations Containing Them. Milano, Italy: Indena Spa; 1991.

306. Bombardelli E, Patri G, Pozzi R. Complexes of Neolignane Derivatives with Phospholipids, the Use Thereof and Pharmaceutical and Cosmetic Formulations Containing Them. Milano, Italy: Indena Spa; 1992.

307. Bombardelli E, Patri GF, Pozzi R. Complexes of Saponins with Phospholipids and Pharmaceutical and Cosmetic Compositions Containing Them. Milano, Italy: Indena Spa; 1988.

308. Gabetta B, Bombardelli E, Pifferi G. Complexes of flavanolignans with phospholipids, preparation thereof and associated pharmaceutical compositions. Google Patents. 1988.
309. Bombardelli E, Patri GF. Complex compounds of bioflavonoids with phospholipids, their preparation and use, and pharmaceutical and cosmetic compositions containing them. Google Patents. 1991.

310. Permana AD, Utami RN, Courtenay AJ, et al. Phytosomal nanocarriers as platforms for improved delivery of natural antioxidant and photoprotective compounds in propolis: an approach for enhanced both dissolution behaviour in biorelevant media and skin retention profiles. $J$ Photochem Photobiol $B$. 2020;205:111846. doi:10.1016/j.jphotobiol.2020.111846

311. Vali CS, Khan A, Bharathi MP. Int J Mod Pharm Res. 2021;5 (2):33-41

312. Babazadeh A, Zeinali M, Hamishehkar H. Nano-phytosome: a developing platform for herbal anti-cancer agents in cancer therapy. Curr Drug Targets. 2018;19(2):170-180. doi:10.2174/ 1389450118666170508095250

313. Kaur IP, Kakkar V, Deol PK, et al. Issues and concerns in nanotech product development and its commercialization. $J$ Control Release. 2014;193:51-62. doi:10.1016/j. jconrel.2014.06.005

314. Sou K, Inenaga S, Takeoka S, Tsuchida E. Loading of curcumin into macrophages using lipid-based nanoparticles. Int J Pharm. 2008;352(1-2):287-293. doi:10.1016/j.ijpharm.2007.10.033

315. Kidd PM. Bioavailability and activity of phytosome complexes from botanical polyphenols: the silymarin, curcumin, green tea, and grape seed extracts. Altern Med Rev. 2009;14(3):226-246.

316. Gupta S, Kesarla R, Omri A. Formulation strategies to improve the bioavailability of poorly absorbed drugs with special emphasis on self-emulsifying systems. Int Sch Res Notices. 2013;2013. doi: $10.1155 / 2013 / 848043$

317. Agarwal A, Chakraborty P, Chakraborty DD, et al. Phytosomes: complexation, utilisation and commercial status. J Biol Act Prod Nat. 2012;2(2):65-77. doi:10.1080/22311866.2012.10719111

318. Tedesco D, Tameni M, Steidler S, Galletti S, Di Pierro F. Effect of silymarin and its phospholipid complex against AFM1 excretion in an organic dairy herd. Milchwissenschaft. 2003;58(7-8):416-419.

319. Kiefer DS, Pantuso T. Panax ginseng. Am Fam Physician. 2003;68(8):1539-1542.

320. Suryawanshi JS. Phytosome: an emerging trend in herbal drug treatment. J Med Genet Genomics. 2011;3(6):109-114.

321. Shivanand P, Kinjal P. Phytosomes: technical revolution in phytomedicine. Int J Pharmtech Res. 2010;2(1):627-631.

322. Li F, Yang X, Yang Y, et al. Phospholipid complex as an approach for bioavailability enhancement of echinacoside. Drug Dev Ind Pharm. 2015;41(11):1777-1784. doi:10.3109/03639045.2015.1004183

323. Petrangolini G, Ronchi M, Frattini E, et al. A new food-grade coenzyme q10 formulation improves bioavailability: single and repeated pharmacokinetic studies in healthy volunteers. Curr Drug Deliv. 2019;16(8):759-767. doi:10.2174/ 1567201816666190902123147

324. Riva A, Longo V, Berlanda D, et al. Healthy Protection of Bergamot is Linked to the Modulation of Microbiota. J Appl Microb Res. 2020;3(2):45-51.

325. Togni S, Maramaldi G, Di Pierro F, Biondi M. A cosmeceutical formulation based on boswellic acids for the treatment of erythematous eczema and psoriasis. Clin Cosmet Investig Dermatol. 2014;7:321.

326. Gilardini L, Pasqualinotto L, Di Pierro F, et al. Effects of greenselect phytosome ${ }^{\circledR}$ on weight maintenance after weight loss in obese women: a randomized placebo-controlled study. $B M C$ Complement Altern Med. 2016;16(1):233. doi:10.1186/s12906016-1214-x

327. Di Pierro F, Togni S, Franceschi F, Eghenhofner R, Giacomelli L. Effects of standardized Ginkgo biloba extract complexed with phosphatidylserine $\left(\right.$ Virtiva $\left.^{\circledR}\right)$ on physiological response to prolonged, intense physical activity. Minerva Ortop Traumatol. 2016;67(3):119-123. 
328. Bombardelli E, Curri SB, Della Loggia R, et al. AntiInflammatory Activity of 18-ß-Glycyrrhetinic Acid in Phytosome Form. Fitoterapia. 1989;60:29-37.

329. Alam MA, Al-Jenoobi FI, Al-mohizea AM. Commercially bioavailable proprietary technologies and their marketed products. Drug Discov Today. 2013;18(19-20):936-949. doi:10.1016/j. drudis.2013.05.007

330. Sgorlon S, Colitti M, Asquini E, et al. Administration of botanicals with the diet regulates gene expression in peripheral blood cells of Sarda sheep during ACTH challenge. Domest Anim Endocrinol. 2012;43(3):213-226. doi:10.1016/j.domaniend.2012.03.001

331. Kalita B, Das MK, Sharma AK. Novel phytosome formulations in making herbal extracts more effective. Res J Pharm Technol. 2013;6(11):1295-1301.

332. Artaria C, Pace R, Maramaldi G, Appendino G. Different brands of bilberry extract: a comparison of selected components. Nutr Foods. 2007;6:13-18.

333. Liu Z, Wang J, Gao W, et al. Formulation and in vitro absorption analysis of rhizoma paridis steroidal saponins. Int J Pharm. 2013;441(1-2):680-686. doi:10.1016/j.ijpharm.2012.10.028
334. Chen X-M, Wu XK, Kong DG, Chen S. Preparation and preliminary study of quality evaluation of ginsenosides phospholipid compound. Qilu Pharma Spain. 2011;9:102-114.

335. Huang Z, Brennan CS, Zhao H, et al. Fabrication and assessment of milk phospholipid-complexed antioxidant phytosomes with vitamin C and E: a comparison with liposomes. Food Chem. 2020;324:126837. doi:10.1016/j.foodchem.2020.126837

336. Lu B, Huang Z, Ye J, Xu H, Chen W, Long X. Niosomal Nanocarriers for Enhanced Skin Delivery of Quercetin with Functions of Anti-Tyrosinase and Antioxidant. Molecules. 2019;24(12):2322. doi:10.3390/molecules24122322

337. Wu PS, Li YS, Kuo YC, Tsai SJ, Lin CC. Preparation and Evaluation of Novel Transfersomes Combined with the Natural Antioxidant Resveratrol. Molecules. 2019;24(3):600. doi:10.3390/molecules24030600

\section{Publish your work in this journal}

The International Journal of Nanomedicine is an international, peerreviewed journal focusing on the application of nanotechnology in diagnostics, therapeutics, and drug delivery systems throughout the biomedical field. This journal is indexed on PubMed Central, MedLine, CAS, SciSearch ${ }^{\mathbb{R}}$, Current Contents ${ }^{\mathbb{R}} /$ Clinical Medicine, $^{-}$
Journal Citation Reports/Science Edition, EMBase, Scopus and the Elsevier Bibliographic databases. The manuscript management system is completely online and includes a very quick and fair peer-review system, which is all easy to use. Visit http://www.dovepress.com/ testimonials.php to read real quotes from published authors. 